\title{
MARgarete KLEIN
}

\section{Características clínicas, neuropsicológicas e morfológicas cerebrais de idosos com transtorno de déficit de atenção e hiperatividade (TDAH) - comparação com idosos sem TDAH}

\author{
Dissertação apresentada à Faculdade de Medicina \\ da Universidade de São Paulo, para obtenção do \\ título de Mestre em Ciências \\ Programa de Fisiopatologia Experimental \\ Orientador: Prof. Dr. Mario Rodrigues Louzã Neto
}

(Versão corrigida. Resolução CoPGr 6018, de 03 de outubro de 2011.

A versão original está disponível na Biblioteca FMUSP)

\section{São Paulo}


Dados Internacionais de Catalogação na Publicação (CIP)

Preparada pela Biblioteca da

Faculdade de Medicina da Universidade de São Paulo

Creprodução autorizada pelo autor

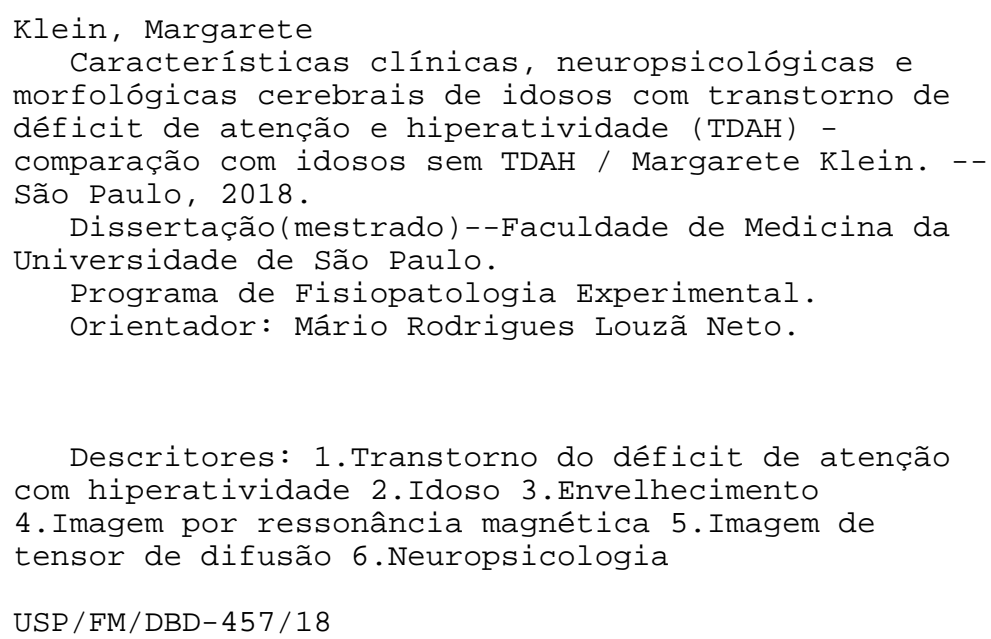

Responsável: Erinalva da Conceição Batista, CRB-8 6755 


\section{Dedicatória}

À minha mãe, razão maior desta pesquisa e

ao meu pai (i.m.) que sempre me incentivou nos estudos. 


\section{Agradecimentos}

Agradeço a Deus acima de tudo, pela oportunidade de me realizar desenvolvendo esta pesquisa.

Ao meu orientador, Prof. Dr. Mario Rodrigues Louzã Neto, pelo acolhimento, pela confiança, pelos ensinamentos, pela paciência e por exigir o melhor de mim.

Às doutoras Tânia Maria Alves e Anny Karinna Pires Mendes Menezes pela atenção e carinho com que trataram todos os pacientes da pesquisa.

Ao Prof. Dr. Geraldo Busatto Filho pela oportunidade de meu primeiro contato com a neuroimagem.

À equipe do LIM 21, em especial ao Dr. Fábio Luís de Souza Duran, pelos ensinamentos técnicos e orientações, à Tássia Nunes, Naomi Antunes da Costa, Paula Squarzoni e Márcia Emiko Morimoto pelas contribuições diretas ou indiretas e em suas respectivas áreas de atuação.

Aos funcionários da RM do Ipq, em especial Leila Lima Barros.

À Faculdade de Medicina da Universidade de São Paulo e ao seu Instituto de Psiquiatria, pela infraestutura física e de pessoal essenciais para o desenvolvimento do projeto.

À Josefina Nacarato e Edna Maria Bethania pelo apoio logístico.

Aos estatísticos do Centro de Apoio a Pesquisa (Ceapesq) do Instituto de Psiquiatria. Sou grata também à estatística Dra. Margarida Maria Hoeppner Zaroni.

Aos pacientes, pela participação na pesquisa e incentivos sobre o estudo. 
Ao Prof. Dr. Florindo Stella e à Psicóloga Maristela da Silva Farci que muito me ensinaram e abriram as primeiras portas que possibilitaram meu envolvimento com o assunto de minha pesquisa.

Ao Prof. Dr. José Maria Ferraz Gusman pelo incentivo e sugestões em vários momentos no decorrer da minha pesquisa.

Aos meus amados irmãos, a todos meus familiares e amigos, pelo apoio constante e pela compreensão dos momentos que me ausentei para me dedicar à pesquisa.

Aos membros da banca da minha qualificação Prof. Dr. Mauro Muszkat, Profa. Dra. Claúdia Kimie Suemoto e Dra. Maria Aparecida Silva pelas valiosas observações e sugestões.

À Fundação de Apoio à Pesquisa do Estado de São Paulo (FAPESP) por parcialmente financiar essa pesquisa. 


\section{NORMALIZAÇÃO ADOTADA}

Esta dissertação está de acordo com as seguintes normas, em vigor no momento desta publicação:

Referências: Adaptado de International Comitee of Medical Journals Editors (Vancouver).

Universidade de São Paulo. Faculdade de Medicina. Divisão de Biblioteca e Documentação. Guia de apresentação de dissertações, teses e monografias. Elaborado por Anneliese Carneiro da Cunha, Maria Julia de A. L. Freddi, Maria F. Crestana, Marinalva de Souza Aragão, Suely Campos Cardoso, Valéria Vilhena. 3a ed. São Paulo: Divisão de Biblioteca e Documentação; 2011.

Abreviaturas dos títulos dos periódicos de acordo com List of Journals Indexed in Index Medicus. 


\title{
Sumário
}

\author{
LISTA DE SIGLAS
}

LISTA DE TABELAS

LISTA DE FIGURAS

RESUMO

ABSTRACT

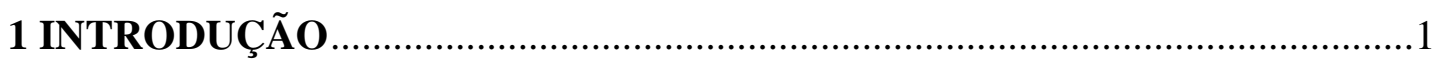

1.1 Transtorno de Déficit de Atenção e Hiperatividade (TDAH) ..........................3

1.1.1 Funções neurocognitivas no TDAH ..............................................

1.1.2 Estruturas cerebrais envolvidas nas disfunções cognitivas no

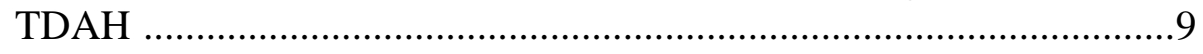

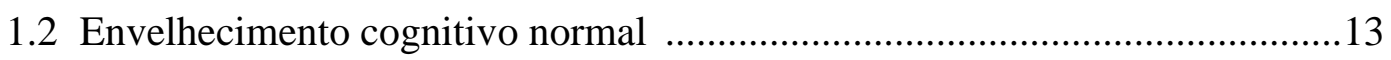

1.2.1 Alterações de estruturas cerebrais no envelhecimento normal ..........16

1.3 Transtorno de Déficit de Atenção e Hiperatividade no Idoso ........................19

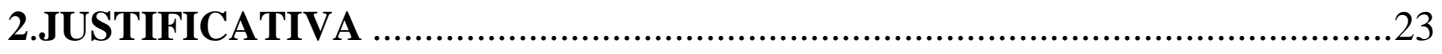

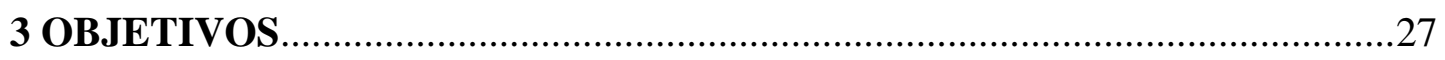

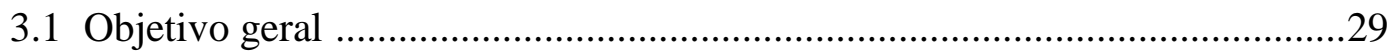

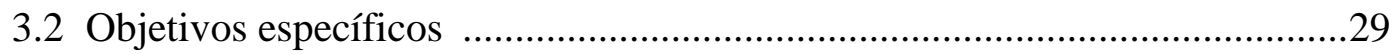

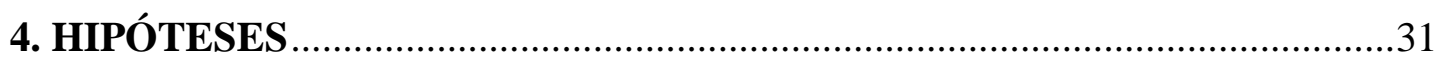

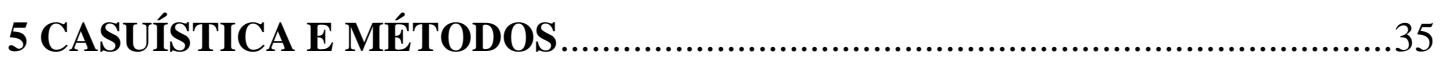

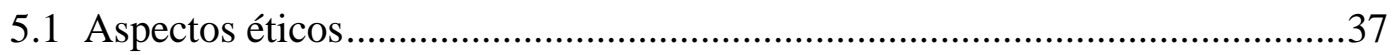

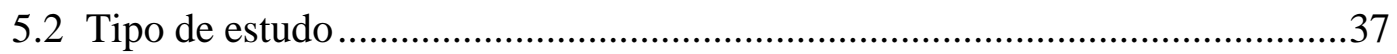

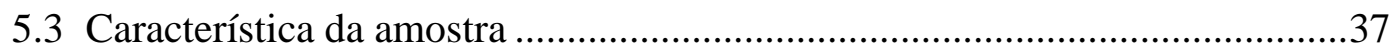

5.3.1 Critérios de inclusão e exclusão ..........................................................37

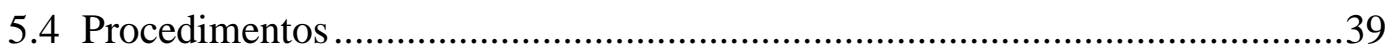

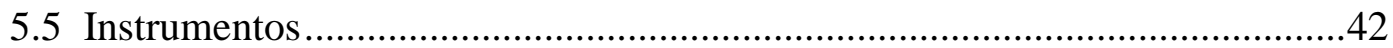

5.5.1 Instrumentos utilizados na seleção da amostra e na avaliação

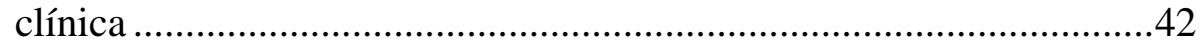

5.5.2 Instrumentos utilizados na avaliação cognitiva.................................44

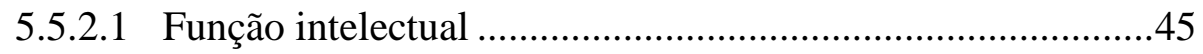


5.5.2.3 Atenção ..............................................................................46

5.5.2.4 Memória .............................................................................47

5.5.2.5 Funções visoespaciais, visoconstrutivas e

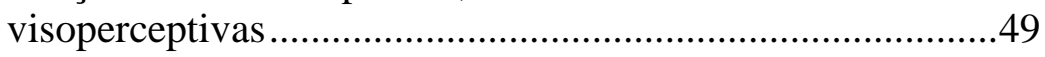

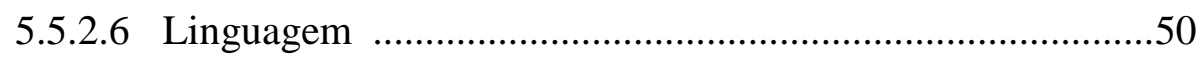

5.6 Aquisição de imagens por ressonância magnética (RM) …..........................50

5.6.1 Processamento das imagens pela morfometria baseada em voxels

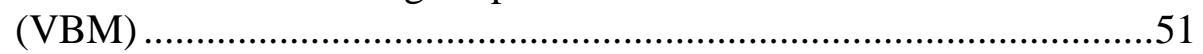

5.6.2 Processamento das imagens por tensores de difusão (DTI) ................53

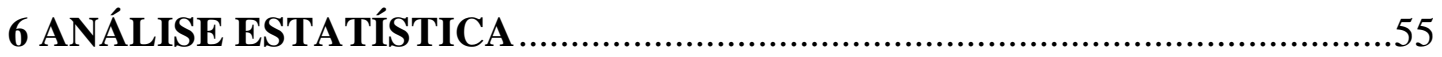

6.1 Análise estatística dos dados demográficos, clínicos e cognitivos ................57

6.2 Análise estatística dos dados das imagens pela morfometria baseada em

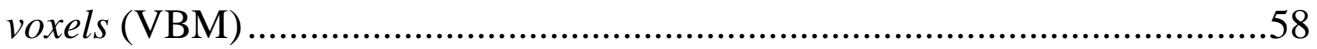

6.3 Análise estatística dos dados das imagens por tensores de difusão (DTI) ......60

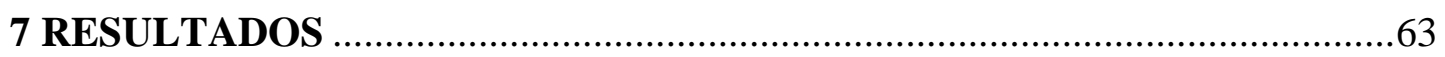

7.1 Seleção da amostra e etapas das avaliações ................................................65

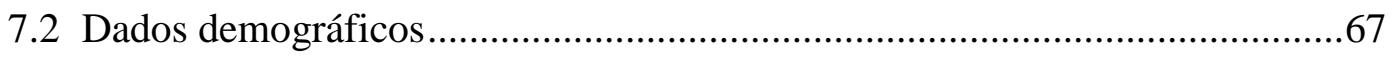

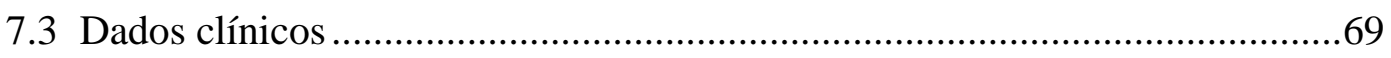

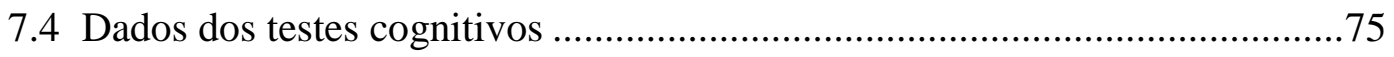

7.5 Dados das imagens pela volumetria baseada em voxels (VBM) ....................78

7.6 Dados das imagens por tensores de difusão (DTI) .....................................82

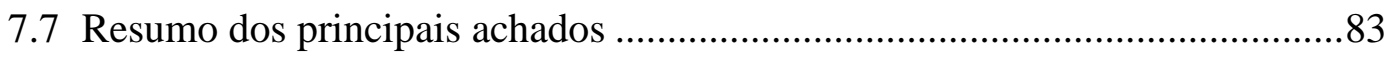

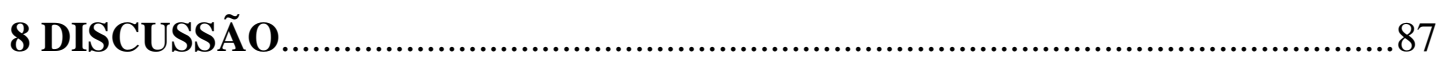

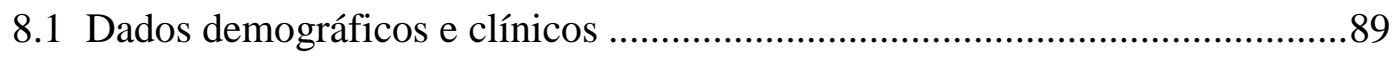

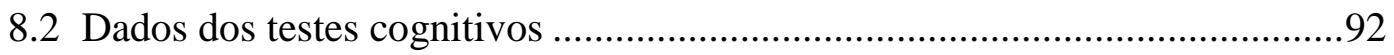

8.3 Dados das imagens pela volumetria baseada em voxels (VBM) ....................94

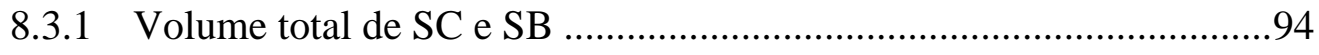

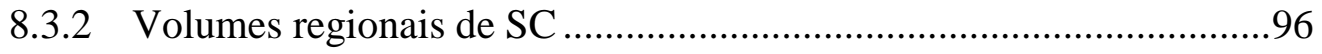

8.4 Dados das imagens por tensores de difusão (DTI) .......................................99

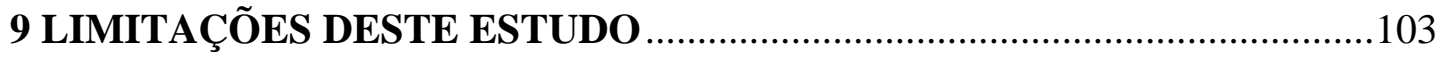

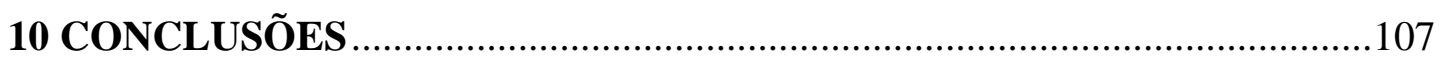

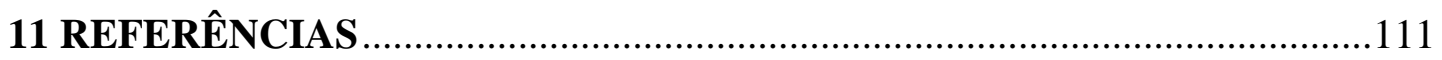




\section{Listas}

SIGLAS

AF anisotropia fracionada

ASRS Adult ADHD Self-Report Scale

BA Área de Broadmann

BAI Inventário de Ansiedade Beck

CA Cíngulo anterior

CC Corpo caloso

CCA Córtex do cíngulo anterior

COF Córtex órbito frontal

CPFDL Córtex pré-frontal dorso lateral

DSM Manual Diagnóstico dos Transtornos Mentais

DTI Imagem por tensor de difusão (DifusionTensor Image)

GDS Escala para avaliação de depressão geriátrica (Geriatric Depression Scale)

LPI Lobo parietal inferior

MAC-Q Questionário sobre Percepção Subjetiva de Perda de Memória (Memory Complaint Questionaire)

MD média de difusividade

MEEM Mini Exame do Estado Mental

pFWE Valor de p após correção por comparações múltiplas

RM Ressonância magnética

ROIs regiões de interesse a priori

SB Substância branca

SC Substância cinzenta

TBSS Estatística espacial baseada em tratos (Tract-based spatial statistics)

TDAH Transtorno de déficit de atenção e hiperatividade 
VBM

Voxel

VSB

VSC

morfometria baseada em voxel (Voxel-Based Morphometry)

Elemento de volume tridimensional da imagem

Volume de substância branca

Volume de substância cinzenta 
FIGURAS

Figura 1 - Fluxograma da seleção da amostra e etapas das avaliações.................66

Figura 2 - MEEM - Variabilidade de respostas nos dois grupos (TDAH e

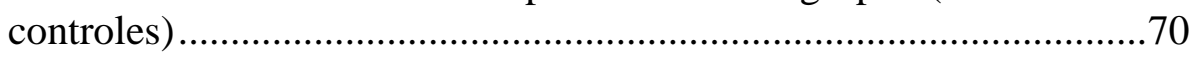

Figura 3 - $\quad$ Cluster com redução no volume de substância cinzenta (VSC) na comparação entre os grupos TDAH e controles evidenciado na análise exploratória em todo o cérebro. 
TABELAS

Tabela 1 - Critérios diagnósticos para o TDAH - DSM-5 …...............................6

Tabela 2 - Dados demográficos da amostra ..................................................67

Tabela 3 - Escalas de avaliação psiquiátrica ..................................................69

Tabela 4 - Correlação de Pearson entre ASRS (Grupo TDAH) e as variáveis sexo, idade, GDS e BAI.................................................... 71

Tabela 5 - $\quad$ Apresentação sintomatológica do grupo TDAH .................................72

Tabela 6 - Condições clínicas e uso de medicações ............................................73

Tabela 7 - Análises dos dados cognitivos ajustados para idade, GDS e BAI ......75

Tabela 8 - Correlação de Pearson entre ASRS (Grupo TDAH) e testes cognitivos (ajustados para idade) ..................................................76

Tabela 9 - Distribuição das médias e desvios padrão por grupo e por sexo

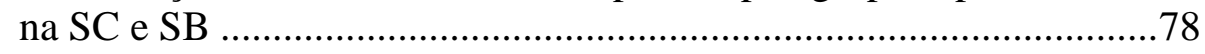

Tabela 10 - Correlações de sintomas do TDAH, de depressão e de ansiedade em regiões de interesse da SC previstas a priori (ajustadas para idade e sexo)

Tabela 11 - Correlações de sintomas do TDAH, de depressão e de ansiedade e AF em fibras da SB (ajustadas para idade e sexo) 


\section{Resumo}

Klein M. Características clínicas, neuropsicológicas e morfológicas cerebrais de idosos com transtorno de déficit de atenção e hiperatividade (TDAH) - comparação com idosos sem TDAH [dissertação]. São Paulo: Faculdade de Medicina, Universidade de São Paulo; 2018.

INTRODUÇÃO: O transtorno do déficit de atenção com hiperatividade (TDAH) é um transtorno do neurodesenvolvimento ainda pouco estudado na população idosa. Déficits em funções atencionais, executivas e de memória, além de anormalidades neuroanatômicas, são observados em indivíduos adultos com TDAH. Entretanto, em idosos com TDAH tais alterações ainda são pouco estudadas. OBJETIVOS: Investigar características clínicas e neuropsicológicas, alterações no volume da substância cinzenta (SC) e da substância branca (SB) cerebral, assim como alterações em microestruturas da SB em idosos com TDAH comparando com idosos sem TDAH. MÉTODOS: A amostra foi composta por 63 indivíduos, sendo $28 \mathrm{com}$ TDAH (19 mulheres), diagnosticados conforme o DSM-IV e 35 controles (29 mulheres) com idade $\geq 65$ anos. Na avaliação clínica utilizaram-se as seguintes escalas e entrevistas: Mini Mental State Examination (MMSE); Adult ADHD SelfReport Scale (ASRS-18) ; Kiddie Schedule for Affective Disorders and Schizophrenia for School-Age Children/Present and Lifetime Version (K-SADS-PL); Inventário Beck de Ansiedade (BAI); Geriatric Depression Scale (GDS); Structural Clinical Interview for DSM-IV (SCID); Informant Questionnaire on Cognitive Decline in the Elderly (IQCODE) e o Memory Complaint Questionnaire (MAC-Q). Os instrumentos utilizados na testagem cognitiva visaram avaliar o QI estimado, as funções atencionais, executivas e de memória e, adicionalmente tempo de reação e variabilidade de respostas, funções visoespaciais/visoconstrutivas e visoperceptivas. As imagens de ressonância magnética (RM) foram adquiridas em aparelho de $1.5 \mathrm{~T}$. Duas sequências de imagens foram obtidas. Uma pela técnica da volumetria baseada no voxel (VBM) para comparação de volumes da SC e SB e a outra, por imagem por tensor de difusão (DTI), para comparação dos valores de anisotropia fracionada (AF). RESULTADOS: O grupo TDAH apresentou maior frequência de repetência escolar e de vezes repetidas, menor frequência de aposentadoria formal, mais divórcios; mais sintomas de depressão e ansiedade, maior frequência de uso atual de antidepressivo. Houve uma correlação positiva entre sintomas de desatenção e hiperatividade/impulsividade e de depressão e ansiedade. Houve uma correlação negativa entre idade e sintomas de TDAH. Os grupos não se diferenciaram estatisticamente nos testes cognitivos e houve uma tendência de correlação entre sintomas de desatenção e os resultados dos testes de atenção. Sintomas de depressão influenciaram a memória operacional, memória episódica e função visoespacial. Mais sintomas de ansiedade refletiram uma maior variabilidade no tempo de respostas. Na neuroimagem, homens com TDAH apresentaram um volume total de SC menor que os homens do grupo controle. Os grupos não se diferenciaram quanto ao volume de SB. O grupo TDAH apresentou um cluster de volume de SC menor no giro frontal medial orbital direito e que se estende em direção ao giro frontal superior 
medial, giro frontal superior e o córtex do cíngulo anterior subgenual. Sintomas de desatenção se correlacionaram negativamente com o volume da SC do cíngulo anterior (bilateralmente) e positivamente com o volume do cerebelo esquerdo. Sintomas de Hiperatividade/impulsividade se correlacionaram negativamente com volume da SC em região do córtex órbito-frontal esquerdo. Sintomas de depressão se correlacionaram negativamente com o volume de SC do caudado (bilateralmente) e positivamente com o volume de SC na região parietal inferior direita. Os grupos não se diferenciaram quanto aos valores da AF. Sintomas de ansiedade se correlacionaram positivamente com AF nos tratos do corpo caloso e do fascículo longitudinal superior. CONCLUSÃO: O presente estudo evidenciou correlatos neurais em regiões relacionadas às funções atencionais, ao controle executivo e ao processamento afetivo no idoso com TDAH, sugerindo que prejuízos em regiões fronto-estriatal e fronto-parietal-cerebelar verificados em adultos com TDAH persistem na velhice. Os achados reforçam os conhecimentos sobre o TDAH em idosos, sugerindo um desempenho cognitivo objetivo comparável aos controles sem o transtorno, uma redução dos sintomas centrais com o aumento da idade, embora mantendo uma funcionalidade mais prejudicada e comorbidades.

Descritores: transtorno do déficit de atenção com hiperatividade; idoso; envelhecimento; imagem por ressonância magnética; imagem de tensor de difusão; neuropsicologia. 


\section{Abstract}

Klein M. Clinical, neuropsychological and brain morphology of elderly with Attention Deficit and Hyperactivity Disorder (ADHD) - compared to elderly without $A D H D$ [dissertation]. São Paulo: "Faculdade de Medicina, Universidade de São Paulo"; 2018.

INTRODUCTION: Attention-deficit/hyperactivity disorder (ADHD) is a neurodevelopmental disorder that has not yet been studied in the elderly population. Deficits in attentional, executive and memory functions, in addition to neuroanatomical abnormalities, are found in younger individuals with ADHD. However, in elderly with ADHD such changes are still poorly studied. OBJECTIVES: To investigate clinical and neuropsychological characteristics, changes in cerebral gray matter (GM) and white matter (WM) volumes, as well as alterations in WM microstructures in elderly with ADHD compared with elderly without ADHD. METHODS: The sample consisted of 63 individuals, 28 ADHD (19 women) according to DSM-IV criteria and 35 controls ( 29 women) aged $\geq 65$ years. In the clinical evaluation the following scales and interviews were used: Mini Mental State Examination; Adult ADHD Self-Report Scale (ASRS-18); Kiddie Schedule for Affective Disorders and Schizophrenia for School-Age Children / Present and Lifetime Version (K-SADS-PL); Beck Anxiety Inventory (BAI); Geriatric Depression Scale (GDS); Structural Clinical Interview for DSM-IV (SCID); Informant Questionnaire on Cognitive Decline in the Elderly (IQCODE) and the Memory Complaint Questionnaire (MAC-Q). The neuropsychological instruments aimed to access estimated IQ, attention, executive and memory functions and, additionally, response time and response variability, visuospatial/visuoconstructive and visuoperceptive functions. Magnetic resonance imaging (MRI) was acquired in a 1.5-T equipment. Two image sequences were obtained. One by the voxel-based volumetry (VBM) technique for comparison of GM and WM volumes and the other by diffusion tensor imaging (DTI), for comparison of fractional anisotropy (FA) values. RESULTS: The ADHD group presented a higher frequency of subjects with school repetition and number of times repeated, lower frequency of formal retirement, more divorces; more depressive and anxiety symptoms, a higher frequency of current antidepressant. There was a positive correlation between inattention and hyperactivity/impulsivity symptoms and depressive and anxiety symptoms. There was a negative correlation between age and ADHD symptoms. The groups did not differ statistically in the cognitive tests and there was a tendency of correlation between symptoms of inattention and the results of the attention tests. Symptoms of depression influenced working and episodic memory and visuospatial function. More anxiety symptoms reflected on a greater variability in response time. In neuroimaging, men with ADHD had a lower total GM volume than men in the control group. The groups did not differ regarding the WM volume. The ADHD group presented a cluster of lower GM volume in the right frontal medial orbital gyrus extending towards to frontal superior medial, frontal superior and the subgenual anterior cingulate cortex. Inattention symptoms negatively correlated with 
GM volume in both the right and left anterior cingulate cortex and positively correlated with the left cerebellum volume. Hyperactivity/impulsivity symptoms correlated negatively with the left inferior frontal orbital gyrus. Depression symptoms correlated negatively with the caudate (bilaterally) and positively with the right inferior parietal region. The groups did not differ regarding the FA values. Anxiety symptoms correlated positively with FA in corpus callosum and superior longitudinal fasciculus tracts. CONCLUSION: The present study showed neural correlates in regions related to functions, such as attention, executive control, and affective processing, suggesting that impairments in frontostriatal and frontoparietalcerebellar areas observed in adults with ADHD persist into old age. Our findings reinforce the knowledge about ADHD in elderly, indicating an objective cognitive performance comparable to normal controls, a reduction of central symptoms, although maintaining a more impaired functionality and comorbidities.

Descriptors: attention deficit disorder with hyperactivity; aged; aging; magnetic resonance imaging; diffusion tensor imaging; neuropsychology. 
1 Introdução 



\section{INTRODUÇÃO}

\subsection{Transtorno de Déficit de Atenção e Hiperatividade (TDAH)}

O TDAH é um transtorno do neurodesenvolvimento, caracterizado por um persistente padrão de desatenção, hiperatividade e impulsividade. Tem uma apresentação clínica heterogênea, com prejuízos funcionais associados a vários déficits neurocognitivos, com impacto importante na vida do portador. $\mathrm{O}$ transtorno ocorre universalmente em cerca de $5 \%$ das crianças e $2,5 \%$ dos adultos ${ }^{1}$. Segundo o estudo de Caye et al. $^{2}$, as taxas de persistência na vida adulta variam amplamente entre os estudos longitudinais, sendo a mais baixa de $4 \%$ e a mais alta de $76 \%$. Esta heterogeneidade nas taxas de persistência seria atribuída a vários fatores metodológicos intrinsecamente relacionados ao diagnóstico de TDAH e envolvem o critério diagnóstico, características da amostra (origem clínica ou populacional e faixa etária) e fontes de informação ${ }^{2}$.

Os indivíduos adultos com TDAH relatam dificuldade com organização, planejamento, estabelecimento de prioridades, administração de finanças e do tempo, atividades que exijam manutenção da atenção, pouca capacidade de escuta, baixa tolerância à frustração, baixa persistência, entre outras características relacionadas às funções executivas. A hiperatividade pode levar à execução de várias atividades simultaneamente, ou à sensação subjetiva de inquietude. A impulsividade pode levar a rompimentos de relacionamentos de forma mais intempestiva, abandonos impensados de emprego e direção perigosa de veículos ${ }^{1,3}$. O resultado a longo prazo do TDAH na infância tem sido motivo de preocupação. Klein et al. ${ }^{4}$ realizaram em 2012 um estudo prospectivo de 33 anos de segmento com uma amostra de 135 homens com TDAH e 136 homens sem o transtorno, avaliados até os 41 anos. Eles verificaram que, com exceção de depressão e ansiedade, os probandos tiveram resultados significativamente piores que os controles ao longo da vida em todas as áreas avaliadas (social, educacional, ocupacional, econômica, mais hospitalizações psiquiátricas e encarceramentos), demonstrando a importância de se estender o 
monitoramento e o tratamento de crianças com TDAH. Além disso, ao longo da vida, o TDAH tem sido associado a um significativo risco de mortalidade por suicídio e morbidade na vida adulta ${ }^{5}$.

A grande maioria dos estudos com o TDAH foi realizada com amostras masculinas ou predominantemente masculinas. Alguns estudos sugerem que as diferenças sexuais são sutis, mas importantes e são encontradas no perfil dos sintomas, na neuropatologia e no curso clínico do TDAH. Em comparação com homens com TDAH, as mulheres com TDAH seriam mais propensas a terem dificuldades com sintomas de desatenção do que os sintomas de hiperatividade e impulsividade, e muitas vezes recebem um diagnóstico de TDAH significantemente mais tarde do que os homens ${ }^{6}$. Uma maior gravidade dos sintomas de TDAH tem sido atribuída aos homens em relação às mulheres ${ }^{7}$. Existem evidências de que a flutuação dos níveis hormonais possa explicar, parcialmente, algumas diferenças quanto ao início de apresentação dos sintomas, as taxas de prevalência do TDAH em homens e mulheres, além de afetar os sintomas e o tratamento do TDAH em mulheres. O estrogeneo, por exemplo, pode estimular o aumento nos receptores de dopamina na área estriatal do cérebro ${ }^{6}$, o que estaria co-ocorrendo com um funcionamento anormal do sistema dopaminérgico no circuito fronto-estriatal implicado no $\mathrm{TDAH}^{8}$. Por outro lado, uma revisão da literatura englobando 73 estudos, sugere que muitas diferenças sexuais (relacionadas à persistência do TDAH no adulto, à prevalência, comorbidades, funcionamento cognitivo, prejuízos e resposta ao tratamento) estariam, parcialmente, atribuídas a artefatos metodológicos, como vieses de referência, desafios no diagnóstico e questões estatísticas, ou influenciadas por questões sócio-culturais ${ }^{9}$.

A presença de comorbidades, mencionada anteriormente, é comum tanto na população infantil quanto em adultos com TDAH. Uma pesquisa bibliográfica direcionada a clínicos, para recomendações sobre o diagnóstico e tratamento das condições comórbidas com TDAH no adulto, verificou uma estimativa de prevalência de co-ocorrência do TDAH com depressão entre $9 \%$ e $50 \%$ de casos conforme o estudo ${ }^{10}$. No estudo de Cumyn et al. ${ }^{11}$ eles verificaram que adultos com TDAH quando comparados a controles, apresentam taxas mais altas de comorbidades (como transtornos do humor e ansiedade, abuso de substâncias e 
transtorno de personalidade) e homens e mulheres apresentam diferenças na coocorrência com alguns transtornos. Os homens mostraram mais propensão para personalidade antisocial e taxas atuais mais altas de abuso de drogas do que as mulheres, enquanto as mulheres apresentaram taxas mais altas no passado. As mulheres também apresentaram taxas mais altas no passado para anorexia e bulimia e taxas mais altas atuais para transtorno do pânico.

As causas do TDAH ainda não são totalmente esclarecidas, mas atribui-se a múltiplos fatores, envolvendo vários fatores de risco genético e ambiental sendo que nenhum fator isoladamente é suficiente para causar o transtorno. Esta multifatoriedade de causas é consistente com a apresentação heterogênea do TDAH, o qual é associado a várias comorbidades psiquiátricas, a prejuízos em vários domínios cognitivos, além de uma variedade de anormalidades na estrutura e funcionalidade cerebral $^{12}$.

Desde as primeiras referências científicas ao TDAH há mais de um século $^{12-14}$, o corpo de conhecimento sobre o transtorno tem aumentado exponencialmente, tanto na infância quanto na vida adulta, construindo uma base firme para que futuros estudos possam esclarecer a etiologia e a fisiopatologia do TDAH, além de avançar no diagnóstico e na terapeutica desse transtorno ${ }^{12}$. Apesar disso, o TDAH sempre esteve envolvido em debates e controvérsias quanto à questão diagnóstica e de tratamento ${ }^{15}$, o que pode ser atribuído, em parte, a já mencionada heterogeneidade na expressão dos sintomas e etiologia ainda a ser esclarecida. Uma das questões debatidas é se o TDAH deveria ser considerado como uma categoria qualitativamente distinta, ou seja, o transtorno difere qualitativamente da variação normal, com a descontinuidade nos processos de risco subjacente em torno do limite diagnóstico, ou, se seria bem conceituado como uma dimensão, diferindo da normalidade somente em intensidade e expressando um continuum na relação de risco para o transtorno, encontrando-se no extremo de gravidade deste continuum ${ }^{16}$. Apesar das controvérsias, alguns estudos como de análise taxométrica ${ }^{17}$, de neuroimagem $^{18}$, sobre traços de personalidade e sintomas clínicos de TDAH $^{19}$ e neurocognitivos $^{16,20}$, tem dado suporte a um modelo dimensional do TDAH. A despeito de todos esses debates, o diagnóstico do TDAH é confiável quando 
realizado através dos critérios operacionais, sendo facilitado pelo uso de escalas de classidicação e entrevistas padronizadas, porém mantém-se essencialmente clínico ${ }^{12}$.

Segundo o Diagnostic and statistical manual of mental disorders $5^{\mathrm{a}}$. Ed.(DSM-5) ${ }^{1}$, para o diagnóstico, vários sintomas (Tabela 1) clinicamente significantes devem estar presentes antes dos 12 anos de idade, sendo um mínimo de seis sintomas na infância para desatenção e/ou hiperatividade-impulsividade e de cinco para adolescentes mais velhos e adultos (17 anos ou mais).

\section{Tabela 1 - Critérios diagnósticos para o TDAH - DSM - 5}

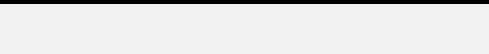 \\ DESATENÇÃO \\ a) Frequentemente não presta atenção em detalhes ou comete erros por descuido em tarefas escolares, no trabalho ou durante outras atividades (p. ex., negligencia ou deixa passar detalhes, o trabalho é impreciso). \\ b) Frequentemente tem dificuldade de manter a atenção em tarefas ou atividades lúdicas (p.ex., dificuldade de manter o foco durante aulas, conversas ou leituras prolongadas).}

c) Frequentemente parece não escutar quando alguém lhe dirige a palavra diretamente (p.ex., parece estar com a cabeça longe, mesmo na ausência de qualquer distração óbvia).

d) Frequentemente não segue instruções até o fim e não consegue terminar trabalhos escolares, tarefas ou deveres no local de trabalho (p. ex., começa as tarefas, mas rapidamente perde o foco e facilmente perde o rumo).

e) Frequentemente tem dificuldade para organizar tarefas e atividades (p. ex., dificuldade em gerenciar tarefas sequenciais; dificuldade em manter materiais e objetos pessoais em ordem; trabalho desorganizado e desleixado; mau gerenciamento do tempo; dificuldade em cumprir prazos)

f) Frequentemente evita, não gosta ou reluta em se envolver em tarefas que exijam esforço mental prolongado (p. ex., trabalhos escolares ou lições de casa; para adolescentes mais velhos e adultos, preparo de relatórios, preenchimento de formulários, revisão de trabalhos longos).

g) Frequentemente perde coisas necessárias para tarefas ou atividades (p. ex., materiais escolares, lápis, livros, instrumentos, carteiras, chaves, documentos, óculos, celular).

h) Com frequência é facilmente distraído por estímulos externos (para adolescentes mais velhos e adultos, pode incluir pensamentos não relacionados).

i) Com frequência é esquecido em relação a atividades cotidianas (p. ex., realizar tarefas, obrigações; para adolescentes mais velhos e adultos, retornar ligações, pagar contas, manter horários agendados) a) Frequentemente remexe ou batuca as mãos ou os pés ou se contorce na cadeira.

b) Frequentemente levanta da cadeira em situações em que se espera que permaneça sentado (p. ex., sai do seu lugar em sala de aula, no escritório ou em outro local de trabalho ou em outras situações que exijam que se permaneça em um mesmo lugar)

c) Frequentemente corre ou sobe nas coisas em situações em que isso é inapropriado. (Nota: Em adolescentes ou adultos, pode se limitar a sensações de inquietude.)

d) Com frequência é incapaz de brincar ou se envolver em atividades de lazer calmamente.

e) Com frequência "não para", agindo como se estivesse "com o motor ligado" (p. ex., não consegue ou se sente desconfortável em ficar parado por muito tempo, como em restaurantes, reuniões; outros podem ver o indivíduo como inquieto ou difícil de acompanhar).

f) Frequentemente fala demais.

g) Frequentemente deixa escapar uma resposta antes que a pergunta tenha sido concluída (p. ex., termina frases dos outros, não consegue aguardar a vez de falar)

h) Frequentemente tem dificuldade para esperar a sua vez (p. ex., aguardar em uma fila).

i) Frequentemente interrompe ou se intromete (p. ex., mete-se nas conversas, jogos ou atividades; pode começar a usar as coisas de outras pessoas sem pedir ou receber permissão; para adolescentes e adultos, pode intrometer-se em ou assumir o controle sobre o que outros estão fazendo). 
Quanto à apresentação dos sintomas pode se dar de forma "Combinada" (preenche os critérios para desatenção e hiperatividade-impulsividade), "Predominantemente desatenta" e "Predominantemente hiperativa-impulsiva". O transtorno pode apresentar-se também com "remissão parcial", quando todos os critérios foram preenchidos no passado, mas nem todos os critérios atuais (últimos seis meses) são preenchidos e os sintomas ainda resultam em prejuízos no funcionamento em algum (s) dos âmbitos já citados ${ }^{1}$. A gravidade atual dos sintomas e o seu impacto na funcionalidade, pode ser especificada como:

-Leve: Poucos sintomas, se algum, estão presentes além daqueles necessários para fazer o diagnóstico, e os sintomas resultam em não mais do que pequenos prejuízos no funcionamento social ou profissional;

-Moderado: Sintomas ou prejuízo funcional entre "leve" e "grave" estão presentes, $\mathrm{e}$

-Grave: Muitos sintomas além daqueles necessários para fazer o diagnóstico estão presentes, ou vários sintomas particularmente graves estão presentes, ou os sintomas podem resultar em prejuízo acentuado no funcionamento social ou profissional. (DSM-5, 2013; pg. 60)

Alguns estudos ${ }^{21-23}$ verificaram que a idade está associada ao declínio global dos sintomas do TDAH e diferenças relatadas nas taxas de remissão de sintomas refletem melhor a definição usada para remissão que propriamente o curso da doença. Pode variar conforme a definição de remissão: sindrômica (apresentam menos sintomas que aqueles exigidos para o diagnóstico de TDAH conforme DSM$\mathrm{IV}^{24}$ - menos que 8 em 14 sintomas), sintomática (apresentam um número menor de sintomas que o requerido para um diagnóstico subliminar - menos que cinco sintomas) e funcional (menos que cinco sintomas e sem prejuízo funcional). Embora a definição de remissão possa afetar a taxa de remissão de sintomas centrais do TDAH, a desatenção demonstra ser mais persistente que hiperatividade ou impulsividade dentro de todas as definições ${ }^{21}$.

Sintomas de desregulação emocional tem sido considerados como uma característica psicopatológica de alta prevalência em adultos com TDAH. O conceito de desregulação emocional está relacionado à baixa tolerância à frustração, irritabilidade e labilidade emocional. A frequência desses sintomas é comparável à 
frequência dos sintomas centrais de desatenção, hiperatividade e impulsividade do TDAH, embora esses sintomas não estejam incluídos no $\operatorname{DSM}^{1,24}$ e na Classificação Internacional de Transtornos Mentais e de Comportamento (CID-10) ${ }^{25}$ como sintomas centrais do $\mathrm{TDAH}^{26}$. Porém, recentemente uma mega-análise ${ }^{27}$ encontrou evidências de redução no volume da amígdala de pessoas com TDAH quando comparadas a controles. Essa área liga o TDAH a problemas de regulação emocional, sugerindo um embasamento neurobiológico para a inclusão da desregulação emocional como parte do fenótipo nuclear do TDAH.

\subsubsection{Funções neurocognitivas no TDAH}

O TDAH na infância é associado a um funcionamento prejudicado em vários domínios cognitivos, como no funcionamento executivo envolvendo controle cognitivo, no processamento de recompensa e processamento temporal ${ }^{28}$. Estes déficits estão envolvidos principalmente com os circuitos dorsal frontoestriatal, ventral frontoestriatal e fronto-cerebelar, respectivamente ${ }^{12,28,29}$. No adulto com TDAH persistente, os prejuízos descritos são similares ${ }^{28}$.

Vários estudos reportam uma heterogeneidade com relação à performance cognitiva, sendo vista como uma característica fundamental do transtorno ${ }^{12,28-30} \mathrm{e}$ inclui performances dentro dos padrões normativos até déficits em múltiplos domínios neuropsicológicos ${ }^{12,28}$. Mostert et al. $^{28}$ verificaram em seu estudo uma variabilidade de desempenho no grupo com TDAH, tendo como extremos alguns pacientes $(11 \%)$ que não mostraram escores deficientes, enquanto outros (5\%) mostraram-se severamente prejudicados (mais de $40 \%$ dos escores prejudicados). A maioria dos pacientes (62\%) estavam levemente prejudicados e $23 \%$ estavam moderadamente prejudicados (entre 20 e $40 \%$ dos escores deficitários). Embora a heterogeneidade também foi observada nos controles saudáveis, os pacientes com TDAH tiveram escores deficientes em uma maior proporção de variáveis (média dos controles $=9.16 \% \pm 9.23 ;$ média TDAH $=15.82 \% \pm 13.55)$.

Como grupo, um dos achados cognitivos mais consistentes nos últimos anos, refere-se a uma maior variabilidade no tempo de reação de respostas quando 
comparados a controles, o qual é verificado através de uma ampla gama de tarefas envolvendo velocidade motora, tomada de decisão, inibição comportamental, memória operacional, entre outras ${ }^{31-34}$. Tem sido atribuído aos sistemas frontoestriatais, um papel crucial na variabilidade intraindividual de respostas verificadas em uma mesma sessão de avaliação, principalmente relacionadas ao tempo de reação de respostas $^{31}$. Além disso, encontram-se déficits relacionados à memória operacional $^{28,35}$, controle inibitório ${ }^{28,36,37}$, flexibilidade ${ }^{36}$, estratégia e fluência verbal $^{37}$, atenção ${ }^{28,36,38,39}$ e memória ${ }^{36,37,40}$. Os déficits de memória no TDAH podem refletir uma disfunção de processos subjacentes à aquisição de memória, como atenção, funcionamento executivo, memória operacional, autorregulação ou motivação ${ }^{36,37,40}$.

\subsubsection{Estruturas cerebrais envolvidas nas disfunções cognitivas no TDAH}

O TDAH tem sido associado a reduções no volume global e regional do cérebro. A maior parte das investigações no campo da neuroimagem, visando busca de correlatos anatômicos para as disfunções cognitivas apresentadas no TDAH, foram realizadas na população infantil ${ }^{41,42}$. As anormalidades mais comumente encontradas em crianças e adolescentes estariam relacionadas à diminuição no volume cerebral total (com lateralização no hemisfério direito) ${ }^{41}$, caudado $^{41,43}$, putamen, globo pálido direito ${ }^{43,44}$ e cerebelo $^{41}$. Sowell et al. ${ }^{45}$ reportam, além de uma redução de SC em regiões do córtex pré-frontal dorsolateral (bilateralmente), um aumento de SC em regiões parietais inferiores e temporais posteriores ao comparar adolescentes com TDAH e controles saudáveis. Shaw et al., ${ }^{46}$ reportam um marcado atraso na maturação cortical em crianças com TDAH, mais proeminentemente em regiões pré-frontais (importantes para o controle de processos cognitivos como a atenção e planejamento motor), mas que progridem de forma regionalmente similar em ambos os grupos, controles e TDAH.

Recentes estudos, de desenho transversal ${ }^{47}$ e longitudinal $^{48}$ com amostras envolvendo crianças, adolescentes e jovens adultos com TDAH (7-29 anos e 6-28 
anos, respectivamente), confirmam uma redução no volume total da SC, principalmente em áreas frontais do cérebro.

Segundo alguns autores ${ }^{43,49,50}$, as diferenças encontradas em estruturas subcorticias, como putamen e caudado, parecem desaparecer com o aumento da idade. A meta-análise conduzida por Frodl et al., ${ }^{43}$ reporta redução de volume em regiões subcorticais (globo pálido, putamen e caudado) para crianças com TDAH e redução de volume no córtex do cíngulo anterior para adultos com TDAH. Entretanto, vários estudos de adultos com TDAH, comparados a controles saudáveis, tem demonstrado redução de volume no caudado ${ }^{51-54}$, enquanto um estudo conduzido por Moreno-Alcázar et al. ${ }^{42}$ reporta um aumento no volume de substância cinzenta (VSC) do caudado. Uma recente mega análise transversal ${ }^{27}$ com participantes com idade mediana de 14 anos (de 4 a 63 anos) verificou que pessoas com TDAH quando comparadas a controles, tem significativamente volumes menores no accumbens, amígdala, caudado, hipocampo, putamen e volume intracranial. Para globo pálido e tálamo eles não encontraram diferenças entre TDAH e controles e nem entre crianças e adultos com TDAH. As diferenças nos volumes subcorticais no TDAH são mais proeminentes em crianças. Quando os casos controles foram estratificados por idade, as diferenças entre os adultos não aparece. Através de uma análise exploratória de modalagem ao longo da vida (exploratory lifespan modeling), eles também sugerem um atraso maturacional em crianças (até 14 anos) e um atraso de degeneração em adultos (21-63 anos) nas regiões subcorticais que se apresentam mais reduzidas a partir da quarta década de vida no TDAH.

Apesar de as anormalidades cerebrais estarem mais bem estabelecidas nos estudos com crianças e adolescentes, em adultos os resultados são mais heterogêneos ${ }^{42,53}$. Almeida Montes et al. ${ }^{55}$ sugerem que as anormalidades observadas em adultos com TDAH representariam mais um neurodesenvolvimento anormal do que um atraso no desenvolvimento. Além das anormalidades na região do caudado $^{42,51-54}$, estudos com regiões de interesse a priori (ROIs), definidas manualmente e através de VBM, encontraram anormalidades em regiões como no córtex órbito-frontal $^{56}$; giro frontal inferior ${ }^{57,58}$; giros médio e superior occipital ${ }^{58}$; córtex pré-frontal dorsolateral $^{42,52}$; córtex do cíngulo anterior ${ }^{42,52,58-60}$; lóbulo parietal inferior $^{52}$; putamen $^{42,52}$; tálamo $^{54}$; cerebelo ${ }^{52,54,61,62}$; área motora suplementar 


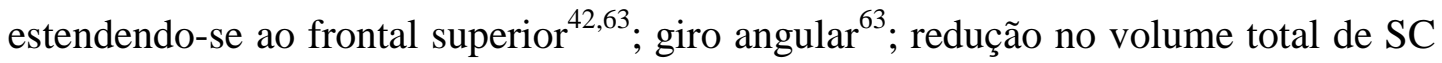
cerebral $^{64}$ e no córtex visual ${ }^{65}$. No conjunto, esses estudos sugerem alterações nas estruturas cerebrais, com predominância de redução nas regiões implicadas no TDAH.

Anormalidades na SB também são verificadas no TDAH. Alguns estudos comparando crianças e adolescentes com TDAH e controles, mostram uma redução no volume total e regional de $\mathrm{SB}^{49}$ e no esplênio do corpo caloso ${ }^{41}$. Diferentemente, Narr et al. ${ }^{66}$ encontraram um maior volume de substância branca (VSB) em crianças e adolescentes com TDAH. No estudo de revisão de Vaidya ${ }^{67}$ é reportado uma redução no VSB ocorrendo um aumento linear dos 4 aos 22 anos de idade. Assim como para o VSC, os resultados dos estudos sobre o VSB em adultos com TDAH são bastante heterogêneos. Seidman et al. ${ }^{64}$ encontraram um significante aumento no volume total de SB em adultos com TDAH (mas não no volume global considerando a SC). Outros pesquisadores, como Amico et al. ${ }^{60}$ e Onnink et al. ${ }^{53}$ não encontraram diferenças no volume total de SB quando comparados aos controles.

Nos últimos anos, uma crescente literatura comparando pacientes com TDAH e controles saudáveis, através da técnica de imagem de RM por tensor de difusão (DTI), tem explorado o papel da SB em anormalidades de sua conectividade e3,68-72. $^{\text {. }}$ A utilização da imagiologia de tensor de difusão permite estimar a orientação das vias da substância branca a partir de estimativas de perfil de difusão de água em cada voxel cerebral. Baseia-se na teoria de que a água encontrada nos tecidos apresenta propriedades de difusão anisotrópicas, ou seja, a difusão não é igual em todas as direções $^{73}$. A anisotropia de difusão fornece um mecanismo de contraste que permite a estimativa da orientação dos feixes de substância branca pelas direções dos picos no perfil de difusão. As aferições são realizadas em múltiplas direções, e, por meio da decomposição tensorial, são extraídas as difusividades paralelas e perpendiculares das fibras, as quais são utilizadas para calcular índices como a anisotropia fracional (AF), a difusividade radial (RD), axial (DA) e a média de difusividade (MD) ${ }^{74}$. A AF tem sido interpretada como um índice de "integridade da substância branca", o qual quantifica a anisotropia direcional de difusividade, sendo esse o índice de interesse em nosso estudo. Vários fatores podem causar mudanças na $\mathrm{AF}$, como morte celular, mudança na mielinização, aumento extra ou intracelular de água, entre outras. 
Quando um feixe de axônios apresenta valores alterados para alguma das métricas extraídas pelo método de DTI, assume-se que esse trato esteja com algum tipo de alteração na sua microestrutura ${ }^{73}$.

Os estudos do TDAH com DTI mostram anormalidades na integridade macroestrutural e microestrutural da substância branca em pacientes com o transtorno. No entanto, conclusões robustas também ainda não foram obtidas através desta técnica, devido em parte, à heterogeneidade de metodologias ${ }^{75-77}$. Achados conflitantes caracterizando o TDAH, sugerem tanto valores mais altos de AF quanto mais baixos ${ }^{72,78}$ e distintos subtipos de apresentação do TDAH podem apresentar anormalidades em regiões diferentes ${ }^{79}$. Um dos achados mais consistentes sobre alterações em medidas de DTI em crianças e adolescentes encontra-se no corpo caloso $^{72}$. Na revisão de van Ewijk et al. $^{75}$ contendo os primeiros estudos com crianças, adolescentes e adultos com TDAH comparados a controles saudáveis, as alterações na integridade de SB foram mais evidentes na coroa radiada anterior direita, fórceps menor direito perto do corpo caloso, cápsula interna bilateral e cerebelo esquerdo. Chen et al. ${ }^{77}$, realizaram uma meta-análise e verificaram nos estudos que utilizaram estatísticas espaciais baseadas em tratos [tract-based spatial statistics (TBSS)] reduções de AF identificadas no esplênio do corpo caloso, cíngulo, estrato sagital e tapetum. Já nos achados da meta-análise realizada por Aoik et al. ${ }^{72}$, referentes aos estudos que utilizaram o TBSS, eles encontraram uma AF mais baixa no corpo caloso (istmo e meio do corpo posterior), no fascículo fronto-occiptal inferior direito e fascículo longitudinal superior esquerdo. Não encontraram aumento de AF em nenhuma região do cérebro em indivíduos com TDAH comparados a controles.

Considerando os resultados individuais de alguns estudos com amostras de adultos com TDAH, encontram-se reduções de AF em regiões como: pré-frontal órbito medial da $\mathrm{SB}^{80}$, coroa radiada ${ }^{76,81}$, fascículo longitudinal superior ${ }^{68,71,81}$, fascículo longitudinal inferior ${ }^{82}$, radiação talâmica ${ }^{71,76,81}$, cápsula interna, estrato sagital $^{81}$, feixes do cíngulo ${ }^{68,80}$, corpo caloso ${ }^{71,76}$, fascículos uncinado e frontoocciptal inferior $^{69}$. Alguns estudos reportam aumento na AF em regiões como giro frontal superior, giro frontal médio, giro pós-central, giro do cíngulo, giro temporal 
médio $^{63}$, giro temporal superior ${ }^{63,80}$, porção posterior do fascículo inferior frontoocciptal $^{58}$ e fórceps menor ${ }^{83}$.

Pironti el. ${ }^{58}$, sugere em seu estudo, que as alterações neuroanatômicas no TDAH verificadas na literatura em geral, estão localizadas em redes neurais que atendem a atenção e funções executivas, como o córtex pré-frontal dorsolateral, cerebelo, lóbulo parietal inferior e córtex do cíngulo anterior, incluindo anormalidades da substância branca no feixe do cíngulo e fascículos longitudinal inferior e superior.

\subsection{Envelhecimento cognitivo normal}

O envelhecimento cognitivo decorre de alterações no metabolismo de células neuronais com atrofia de grupos neuronais, redução da atividade sináptica, aumento da atividade glial, diminuição de determinados grupos de receptores e um acúmulo de produtos metabólicos. Estas alterações podem ser responsáveis pelas mudanças nas funções cognitivas e comportamentais dos idosos ${ }^{84}$. Segundo Hartshorne e Germine $^{85}$, é necessário entender como e quando a mudança cognitiva ocorre ao longo da vida para se entender o desenvolvimento normal e anormal, assim como o curso do envelhecimento. Mesmo os indivíduos que não apresentam um comprometimento cognitivo leve (CCL) ou qualquer processo de doença degenerativa podem apresentar sutis mudanças cognitivas com o envelhecimento ${ }^{86,87}$.

A trajetória do envelhecimento cognitivo é bastante heterogênea e diferenças socioeconômicas e educacionais podem intensificar as diferenças cognitivas entre idosos $^{86}$. Além disso, alterações em neurotransmissores de dopamina (DA) são encontradas em idosos e uma modulação disfuncional de DA pode contribuir para um aumento na variabilidade de performance cognitiva em adultos mais velhos ${ }^{88}$. Apesar de essa variabilidade no desempenho cognitivo, verifica-se na literatura algumas características cognitivas relacionadas às mudanças que chegam com o envelhecimento normal, como o declínio gradual ao longo do tempo no desempenho 
em medidas de velocidade de processamento, em funções executivas ${ }^{89}$ como o controle inibitório, aumento da vulnerabilidade atencional ${ }^{90}$ e na memória ${ }^{89,91}$, sendo que as primeiras funções mencionadas teriam algum impacto nos processos da memória $^{86}$.

Algumas teorias de perspectiva cognitivista procuram explicar o mecanismo básico relacionado às dificuldades dos idosos. Estudos de imagem por ressonância magnética funcional têm sido amplamente utilizados para vincular o declínio cognitivo relacionado ao envelhecimento com padrões de função cerebral alterada. Segundo Sala-Llonch et al. ${ }^{87}$, há um relativo consenso sobre um aumento da atividade cerebral, relacionada à idade, no córtex pré-frontal, enquanto os achados relativos a uma redução de ativação são localizados de forma mais heterogênea no cérebro. As duas teorias mais clássicas desenvolvidas através de estudos de neuroimagem funcional apresentam as hipóteses de um processo de "desdiferenciação" e "compensação", explicados em três principais modelos cognitivos, conforme a seguir:

1) Modelo HAROLD (Hemispheric asymmetry in older adults): Refere-se a uma redução da assimetria hemisférica em adultos mais velhos, apresentando um padrão menos lateralizado de ativação em tarefas quando comparados a pessoas mais jovens, verificado durante tarefas de memória episódica, memória semântica, memória operacional, percepção e controle inibitório. Esse tipo de ativação em áreas frontais pode resultar de uma reorganização global das redes neurocognitivas, bem como de mudanças neurais regionais. Essas mudanças levam a uma atividade cerebral bilateral e pode refletir tanto processos compensatórios, quanto processos de desdiferenciação (para revisão ver Cabeza, 2002) ${ }^{92}$. A compensação se refere a capacidade de pessoas mais velhas recrutarem níveis mais altos de ativação, em comparação com pessoas mais jovens, em algumas regiões cerebrais (frequentemente em regiões frontais) para compensar déficits funcionais localizados em outras regiões cerebrais. Enquanto o processo de desdiferenciação reflete uma perda de especificidade funcional nas regiões cerebrais que estão envolvidas durante o desempenho de uma tarefa ${ }^{87}$. 
2) Modelo CRUNCH (Compensation-Related Utilization of Neural Circuits Hypothesis): Postula que pessoas mais velhas apresentam um recrutamento neural mais alto em níveis cognitivos que normalmente em indivíduos mais jovens se apresentam com menor atividade cerebral. Funções de controle executivo mediadas por regiões pré-frontais laterais e inferiores (exemplo: atenção seletiva, flexibilidade cognitiva, inibição) podem ser recrutadas de forma adaptativa para enfrentar os desafios de mudar as demandas ambientais e de $\operatorname{tarefas}^{93}$.

3) Modelo PASA (Posterior-Anterior Shift with Aging) que se refere ao déficit que pessoas mais velhas apresentam para ativar regiões na linha média do córtex parietal acompanhadas de atividade aumentada no córtex frontal medial, verificadas em tarefas como recordação episódica e visoperceptiva $^{94}$.

Há ainda, modelos conceituais mais integrativos como o STAC (The Scaffolding Theory of Aging and Cognition), cujo objetivo é integrar evidências da neuroimagem estrutural e funcional para explicar as diferenças de idade na função cognitiva, incorporando os efeitos de uma ampla gama de fatores biológicos e neurofisiológicos associados ao envelhecimento normal e delinear sua interação dinâmica com fatores de proteção e processos compensatórios supostamente atuante no cérebro mais velho. Esta teoria representa o cérebro como uma estrutura dinamicamente adaptativa que muda de maneira positiva e negativa com a idade. $\mathrm{O}$ modelo sugere que é possível melhorar a atividade de "plataformas" neurais através de algumas intervenções explícitas que incluem várias atividades de estilo de vida, como exercícios, engajamento intelectual e novos aprendizados, e intervenções de treinamento cognitivo mais formais (para revisão ver Reuter-Lorenz e Cappell, $2014)^{95}$.

Segundo um estudo realizado por Fjell e Walhovd ${ }^{96}$, as reduções das habilidades cognitivas estão mediadas por mudanças neuroanatômicas, sendo que, $25 \%$ a $100 \%$ das diferenças verificadas entre jovens e adultos mais velhos relativas às funções cognitivas (envolvendo velocidade de processamento, funções executivas 
e memória episódica) puderam ser explicadas por diferenças na estrutura cerebral entre os grupos.

\subsubsection{Alterações de estruturas cerebrais no envelhecimento normal}

O cérebro humano muda com a idade e o envelhecimento normal associa-se com significante atrofia cerebral. O padrão e a trajetória de mudança variam entre as regiões cerebrais e entre indivíduos e as razões para essas diferenças ainda não são totalmente esclarecidas ${ }^{97}$. Estudos neuromorfométricos também variam em métodos de medidas, critérios de demarcação de região cerebral a ser estudada e de seleção de amostra. Vários estudos transversais de volumes de regiões cerebrais associam o envelhecimento cerebral a uma generalizada redução do volume cerebral, sendo que as regiões corticais polimodais (especialmente pré-frontal) são mais significantemente afetadas que o resto do neocorte ${ }^{98}$ embora alguns estudos reportem que áreas temporais sofrem reduções ao longo do tempo de magnitude comparável às mudanças frontais ${ }^{97-99}$. No estudo de Bergfield et al. ${ }^{100}$, o envelhecimento saudável está associado a um padrão regionalmente distribuído de atrofia de substância cinzenta envolvendo as regiões frontais mediais (bilateral) insula/perisilviana, cingulado anterior e, em menor extensão, pré-frontal dorsolateral bilateral, temporal lateral, parietal e caudado. As regiões do cerebelo (bilateral), polo temporal, e talâmicas (direita) apresentam relativa preservação.

Abedelahi et al. ${ }^{101}$, investigaram o volume do putamen e caudado e os efeitos de idade, sexo e diferenças hemisféricas. Ao compararem adultos jovens e idosos saudáveis, verificaram um encolhimento bilateral no putamen relacionado à idade em ambos os sexos. Putamen e caudado foram significativamente menores em idosos do que em indivíduos mais jovens. Houve diferenças de volume estatisticamente significativas entre homens e mulheres, com uma assimetria à direita relacionada ao envelhecimento em ambos os sexos. Os homens apresentaram um maior volume nessas estruturas que as mulheres, embora os autores citem uma inconsistência de resultados na literatura. 
Um estudo sobre o desenvolvimento cerebral e envelhecimento, verificou que padrões convergentes de mudança de regiões cerebrais que ocorrem na adolescência e na velhice, particularmente nas áreas pré-frontais mediais, sugerem que os córtices desenvolvidos tardiamente são especialmente vulneráveis à atrofia no envelhecimento. Nesse estudo, encontraram também uma tendência de reduções em estruturas subcorticais na velhice que excederam as reduções corticais, enquanto no desenvolvimento ocorreu o contrário ${ }^{99}$.

Além das mudanças corticais, verifica-se também alterações na SB no envelhecimento normal, embora sejam poucas e com menos redução de volume que na SC. Em contraste aos resultados volumétricos, estudos de microestruturas da SB com imagem por tensor de difusão (DTI) mostram-se mais sensíveis para detectar os efeitos degenerativos do envelhecimento. Diferenças relacionadas à idade ocorrem tanto em medidas globais da integridade da substância branca (por exemplo, AF) como em medidas de componente (por exemplo, de DA e DR), especialmente em regiões pré-frontais ${ }^{102}$.

Em um estudo de Teipel et al. ${ }^{103}$, idosos saudáveis mostraram um declínio de integridade (declínio de AF), ao longo de 13 a 18 meses de acompanhamento, em feixes de fibras intracorticais em áreas como o corpo caloso, fascículo longitudinal superior, fascículo uncinado, fascículo fronto-occiptal inferior e feixes do cíngulo. As reduções envolveram predominantemente o corpo caloso. Já no estudo de Sullivan et al. ${ }^{102}$ no qual investigaram o corpo caloso, não foi detectado declínio nessa estrutura. Malykhin et al. ${ }^{104}$ encontraram uma redução à partir dos 20 anos de idade na $\mathrm{AF}$ em tratos de SB da área frontal orbital medial. Não foi verificado lateralidade em medidas de $\mathrm{AF}$ em todos os tratos da SB pré-frontal, e nenhum efeito da idade nos valores de AF entre os hemisférios.

Um estudo transversal de Westlye et al. ${ }^{105}$ realizado em 2010 com 430 sujeitos saudáveis com uma média de idade da amostra total de 41,6 $\pm 21,9$ (8 a 85 anos) teve como objetivo delinear a idade das trajetórias do volume de SB e índices de DTI. Eles utilizaram regressões não paramétricas para ajustar as trajetórias de idade e estimar o tempo de desenvolvimento máximo e deterioração do envelhecimento. Não houve correlação entre sexo e idade e eles verificaram que as 
trajetórias para o volume de SB e os parâmetros de difusão são marcadamente diferentes e ambos seguem trajetórias não-lineares. Eles sugerem que o volume total de SB atingiria seu pico aproximadamente aos 50 anos, sendo que, em algumas regiões, o volume total de SB aumenta até cerca dos 60 anos antes do início do processo de deterioração. Ocorre um crescimento linear nas regiões frontal, parietal, e na SB profunda até o máximo estimado, enquanto a região occipital e a SB do cíngulo permanecem relativamente estáveis antes de diminuir na senescência. No entanto, a AF global atinge seu pico em torno de 30 anos, estabilizando até aproximadamente a quarta década, passando por um período de pequena diminuição linear até aproximadamente 65 anos, com uma subseqüente aceleração de sua diminuição. Os dados de DTI mostraram uma curva trifásica (aumento, estabilidade, declínio) para radiação talâmica anterior, no feixe do cíngulo dorsal, no fórceps menor e fórceps maior, fascículos longitudinais inferiores e superiores e fascículo uncinado. O cíngulo para-hipocampal mostrou uma trajetória menos clara. Os achados também mostraram uma maturação precoce no trato córticoespinhal e um desenvolvimento prolongado nos feixes do cíngulo dorsal e para-hipocampal. Além disso, a deterioração relativamente tardia observada nos feixes do cíngulo dorsal e para-hipocampal e fascículo uncinado não fornece amplas evidências em apoio a uma teoria simples de deterioração de SB no envelhecimento baseada na hipótese do last-in-first-out, ou seja, regiões que amadurecem mais tarde, degeneram mais precocemente ao longo da vida, como sugerido, por exemplo, nos estudos de Sullivan et al. ${ }^{102}$ e Tamnes et al. ${ }^{99}$.

Vários estudos de DTI tem contribuído para distinguir alterações do envelhecimento normal e alterações patológicas do cérebro humano e suas relações com a integridade da substância branca ${ }^{106}$. O papel das mudanças macroestruturais da substância branca (como atrofia e lesões) no declínio cognitivo tem sido cada vez mais reconhecido, mas na população idosa essas alterações macroestruturais não explicam sozinhas a variabilidade na cognição. Os resultados de um estudo holandês de base populacional envolvendo 860 idosos com idades entre 61 e 92 anos fornece forte apoio para a relação entre a integridade da SB e velocidade de processamento e concluem que diferenças na integridade da $\mathrm{SB}$, relacionadas à idade, refletem mais um processo fisiopatológico do que o envelhecimento em $\mathrm{si}^{107}$ e concordam com 
uma revisão de estudos com DTI, o qual refere que, independentemente da idade, a variação na integridade da SB está correlacionada com o desempenho cognitivo, principalmente em testes que dependem da velocidade de processamento da informação e ao funcionamento executivo ${ }^{106}$.

\subsection{Transtorno de Déficit de Atenção e Hiperatividade no Idoso}

Somente nos últimos anos pesquisadores começaram investigar o TDAH em idosos e reportam sua persistência nesta faixa etária ${ }^{22,23,108-110}$.

Seja porque as coortes de estudos longitudinais em andamento ainda não envelheceram, seja pelas dificuldades metodológicas encontradas nesse tipo de estudo, faltam estudos prospectivos/longitudinais no TDAH que verifiquem a trajetória dos sintomas através da vida adulta jovem para a meia idade e, principalmente, até o envelhecimento. Objetivando responder parte dessa questão, dois primeiros estudos, um realizado por Biederman et al. ${ }^{111}$ em 2011 e outro por Bramham et al. ${ }^{112}$ em 2012, investigaram jovens e adultos de meia idade (entre 18-55 e 16-50, respectivamente) com TDAH. Foram estudos transversais, nos quais separaram a amostra em grupos por década. Biederman et al. ${ }^{111}$, verificaram que a performance cognitiva não melhora nem piora através do ciclo da vida, enquanto no estudo de Bramham et al. ${ }^{112}$ houve uma melhora em atenção seletiva e resposta inibitória, embora possam continuar a apresentar prejuízo funcional quando não tratados.

Até 2005 não havia literatura publicada sobre o TDAH fazendo referência à sua persistência na velhice. O primeiro estudo de base populacional envolvendo pacientes idosos com TDAH ${ }^{108}$ objetivou determinar a prevalência de TDAH em adultos (18 a 75 anos) na Holanda. Eles encontraram uma taxa de 2,5\%, entretanto, não reportaram uma estimativa específica para pessoas com idade igual ou acima de 65 anos. O primeiro estudo de prevalência envolvendo somente idosos (65-80 anos), foi conduzido em 2009 por Guldberg-Kjär e Johansson ${ }^{22}$, no qual a taxa estimada foi 
de 3.3\%. Posteriormente, Michielsen et al. ${ }^{110}$ fizeram outro estudo de prevalência, envolvendo apenas idosos, reportando taxas próximas ao estudo de Guldberg-Kjär \& Johansson $^{22}$. Michielsen et al. ${ }^{110}$ encontraram uma taxa estimada de prevalência de 2,8\% para TDAH sindrômico [ou seja, apresentação do diagnóstico pleno na época da pesquisa] e 4,2\% para TDAH sintomático [ou seja, diagnóstico pleno na infância e a presença de pelo menos quatro (de oito) sintomas nos últimos seis meses]. Nesse mesmo estudo verificaram que idosos mais jovens (60-70 anos) reportaram mais sintomas do que os idosos mais velhos (71-94 anos). Esses achados são corroborados pelo estudo de Das et al. ${ }^{23}$, no qual verificaram que os sintomas do TDAH diminuem com a idade e suas relações com coocorrência de transtornos do humor e performance cognitiva também mudam. Nesse estudo, os autores estimaram uma taxa de 2,2\% de prevalência entre idosos de 68 a 74 anos. Sintomas de depressão e ansiedade persistem na velhice de pessoas com TDAH e, relativo a controles sem o transtorno, idosos com TDAH apresentam mais sintomas depressivos ${ }^{113}$. As análises longitudinais do estudo de Michielsen et al. ${ }^{113}$ mostraram que respondentes com maiores escores de sintomas de ADHD relataram um aumento de sintomas depressivos ao longo de seis anos, enquanto os pacientes com menos sintomas de TDHA permaneceram estáveis. Das et al. ${ }^{23}$ encontraram menos sintomas nos idosos com TDAH (68-74 anos) quando comparados a pessoas de meia idade (48-52 anos) com TDAH. Estes autores, consideram que uma das razões para um aparente declínio nos níveis de sintomas do TDAH em idosos, deve-se ao fato de os sintomas serem menos discerníveis de outras mudanças gerais relacionadas com a idade e destacam ainda, a necessidade de um diagnóstico e tratamentos mais adequados para as comorbidades do TDAH e transtornos do humor nessa faixa etária.

Os déficits cognitivos em idosos com TDAH podem atuar como fatores confundidores em um diagnóstico diferencial, uma vez que podem apresentar características similares aos idosos com transtorno neurocognitivo leve (TNC leve) ou mesmo um transtorno neurocognitivo maior (TNC maior), apesar de essas condições se diferenciarem do TDAH por terem início tardio ${ }^{1,114}$. Neste contexto, um estudo retrospectivo ${ }^{115}$ teve como objetivo verificar a associação entre TDAH, TNC leve e doença de Alzheimer ou demência por corpúsculos de Lewy. Estes estudiosos encontraram um risco mais alto para demência por corpúsculos de Lewy, mas não 
para a doença de Alzheimer, em pacientes que apresentaram sintomas para TDAH na infância. Porém, este achado deve ser considerado com cautela uma vez que não houve uma clara explicação para a associação. Por outro lado, um estudo conduzido por Ivanchack et al. ${ }^{114}$ em 2012, não encontrou associação entre TDAH e TNC leve ou demência.

Ainda há um limitado número de estudos publicados sobre o TDAH em idosos e a maioria deles pertencem a um mesmo grupo de estudiosos ${ }^{110,113,116-121}$ e derivam de uma mesma amostra ( $n=208$ controles e 23 sujeitos com TDAH). O TDAH no idoso foi associado a doenças crônicas físicas e auto percepção da saúde mais prejudicada, mas não encontraram associação com características de estilo de vida (como consumo de álcool, cigarro, problemas com sono e índice de massa corporal) ${ }^{119}$. Quanto ao funcionamento cognitivo, sujeitos com TDAH apresentaram uma performance mais baixa, quando comparados a controles, somente em atenção/memória de trabalho e este resultado foi mediado por sintomas de depressão ${ }^{120}$. Das et al. ${ }^{23}$ também havia verificado que os sintomas de depressão são preditores mais fortes do desempenho cognitivo e medeiam o efeito dos sintomas do TDAH na cognição de idosos com TDAH. Altos escores de sintomas de TDAH foram associados com aumento dos sintomas de depressão ao longo do tempo ${ }^{113}$. Segundo Semeijn et al. ${ }^{121}$, a depressão é parcialmente explicada pelos efeitos de eventos adversos durante a vida dessas pessoas (pessoas mais velhas com TDAH tiveram mais conflitos sérios do que pessoas mais velhas sem o transtorno). Além disso, eles apresentam autoestima e sensação de domínio mais baixas e nível mais alto de neuroticismo ${ }^{116}$. Estes idosos referem um funcionamento social com menos membros familiares em sua rede social, menos frequência de casamentos e mais frequência de divórcios, mais solidão emocional, mais participação em atividades recreacionais e nível mais baixo de renda ${ }^{117}$. Em um estudo qualitativo, foi vericado que o impacto negativo do TDAH na qualidade de vida dos idosos (relacionado a baixa auto-estima, sentimento de não ser compreendido, necessidade de estar sempre ativo, consequências da desatenção e impulsividade, entre outros), parece diminuir com a idade. Porém, algumas razões para explicar essa percepção foram dadas pelos próprios idosos entrevistados, como desenvolvimento de estratégias ao longo da vida para lidar com suas dificuldades, treino da memória para lidar com o esquecimento 
(como consequência da desatenção) e aprenderam a "pensar antes de agir" devido a várias consequências negativas. Além disso, outros fatores são sugeridos pelos estudiosos, como o fato de alguns idosos estarem aposentados e/ou terem menos exigência relacionada a trabalho, mudanças neurobiológicas normais que chegam com o envelhecimento e podem diminuir a manifestação de certos sintomas como a impulsividade, aumento de resiliência a eventos adversos na velhice e problemas de saúde que dificultam estarem mais ativos ou a agirem impulsivamente ${ }^{118}$. O impacto cumulativo negativo dos sintomas do TDAH no âmbito profissional, econômico, social e do bem-estar na vida de idosos com TDAH foi também verificado anteriormente por Brod et al. ${ }^{122}$.

Outras contribuições encontradas na literatura ${ }^{109,123}$, envolvendo questões sobre diagnóstico e tratamento nessa faixa etária, encorajam futuros estudos. Os estudos existentes sobre o TDAH no idoso oferecem evidencias de que o transtorno pode não só persistir na velhice, mas ser identificado e tratado.

Até o momento, não há estudos sobre alterações em estruturas cerebrais (macro e micro estruturas) envolvendo apenas idosos com TDAH e com idade $\geq 65$ anos e não se sabe como as mudanças que chegam com o processo de envelhecimento poderiam impactar o cérebro dessas pessoas, uma vez que algumas das estruturas cerebrais mais afetadas no envelhecimento normal (como o córtex frontal) também estão implicadas no TDAH. 
2 Justificativa 



\section{JUSTIFICATIVA}

O Transtorno de Déficit de Atenção e Hiperatividade (TDAH) está associado a vários déficits neuropsicológicos e compartilha de algumas similaridades com as mudanças cognitivas e de estruturas cerebrais que ocorrem no processo de envelhecimento. Essa condição de similaridades torna mais complexo o diagnóstico do TDAH e os sintomas podem ser confundidos com um transtorno neurocognitivo (TNC) leve, assim como podem também mascarar um processo de declínio cognitivo patológico. A busca de elucidação de aspectos clínicos, de padrão de funcionamento cognitivo e de estruturas cerebrais, em idosos com o TDAH, é necessária para o entendimento da fisiopatologia, do desenvolvimento do transtorno com relação aos limites de funcionamento cognitivo ao se sobrepor ao envelhecimento e pode contribuir para o avanço na abordagem diagnóstica e terapêutica nessa faixa etária. 



\section{Objetivos}





\section{OBJETIVOS}

\subsection{Objetivo geral}

Verificar se idosos com TDAH, apresentam características clínicas, neuropsicológicas e morfológicas cerebrais distintas daquelas de idosos sem o TDAH.

\subsection{Objetivos específicos}

a) Identificar características clínicas dos idosos com TDAH;

b) Verificar se há diferenças no perfil neuropsicológico comparando idosos com e sem TDAH;

c) Verificar pela VBM se há diferenças volumétricas na SC e SB comparando idosos com e sem TDAH;

d) Verificar pelo DTI se há diferenças na anisotropia fracionada (AF) na SB comparando idosos com e sem TDAH. 

4 Hipóteses 



\section{HIPÓTESES}

A hipótese geral desse estudo é de que idosos com TDAH, quanto às funções cognitivas e de estruturas cerebrais, apresentam maior prejuízo quando comparados a idosos sem o transtorno.

Como hipóteses específicas:

a) As funções executivas, atencionais e de memória em idosos com TDAH apresentam mais prejuízo do que em idosos sem TDAH;

b) O volume de substância cinzenta (VSC) total e o volume de substância branca (VSB) total são menores em idosos com TDAH do que em idosos sem TDAH;

c) Os volumes de substância cinzenta (VSC) de regiões e de estruturas cerebrais relacionadas ao TDAH [córtex pré-frontal dorsolateral (CPFDL), córtex órbito frontal (COF), lobo parietal inferior (LPI), gânglios da base (putamen, caudado e globo pálido, conjuntamente), córtex do cíngulo anterior (CCA), amígdala, hipocampo e cerebelo] são menores em idosos com TDAH, do que em idosos sem TDAH;

d) A integridade da substância branca (SB) [verificada por meio da mensuração da anisotropia fracionada $(\mathrm{AF})]$ em regiões relacionadas ao TDAH (cíngulo, corpo caloso (corpo e esplênio), porção retrolenticular da capsula interna, coroa radiada (anterior, superior e posterior), radiação talâmica posterior, estrato sagital (incluindo fascículo longitudinal inferior e fascículo fronto-occiptal), fascículo longitudinal superior e tapetum, apresenta alterações em idosos com TDAH quando comparados a idosos sem TDAH; 

5 Casuística e Métodos 



\section{CASUÍSTICA E MÉTODOS}

\subsection{Aspectos éticos}

O presente estudo foi aprovado pelo Comitê de Ética para Análise de Projetos de Pesquisa (CAPPesq) sob protocolo n ${ }^{\circ}$ 0598/11.

Foi obtido um Termo de Consentimento Livre e Esclarecido (anexo) dos participantes da pesquisa, bem como foram seguidas as normas e procedimentos já vigentes no HC-FMUSP quanto ao atendimento da amostra estudada.

\subsection{Tipo de estudo}

Analítico transversal.

\subsection{Características da amostra}

\subsubsection{Critérios de inclusão e exclusão}

A amostragem foi obtida por conveniência e a seleção dos participantes segue os seguintes critérios:

\section{a) Grupo TDAH:}

- Critérios de inclusão: Idade igual ou acima de 65 anos, de ambos os sexos, com escolaridade mínima de 4 anos e que preencham, pelo 
DSM-IV, os critérios para TDAH, com exceção do critério de início de sintomas antes de 7 anos e a quantidade de sintomas atuais considerados no diagnóstico clínico.

Para o diagnóstico do TDAH, foi utilizado o conceito de persistência de sintomas tanto sindrômica (diagnóstico "cheio", com todos os critérios) quanto sintomática (sintomas persistem parcialmente, mas mantém prejuízo), utilizando-se como ponto de corte um número de manifestações de 4 sintomas atuais, tendo como base o critério utilizado em estudo pioneiro envolvendo pessoas idosas que referiram sintomas de TDAH na infância ${ }^{108}$.

Foram incluídos somente os sujeitos que apresentaram exemplos claros de suas dificuldades desde a infância e/ou tivessem informante (como irmãos, primos e amigos) que pudesse corroborar com as informações.

- Critérios de Exclusão: Sujeitos com menos de 65 anos, com memos de 4 anos de estudo, com histórico de uso crônico de substância psicoativa/álcool; com deficiências auditivas e visuais não corrigidas; doenças pulmonares crônicas (DPOC); doenças cardiovasculares clinicamente significativas ou descompensadas; marca passo; clips (aneurisma); com histórico de retardo mental; quadro demencial (ou apresentar queixa de perda de memória recente); esquizofrenia; Transtorno Bipolar; Transtorno Esquizoafetivo; condições médicas ou neurológicas, atuais ou pregressas que possam prejudicar o funcionamento cognitivo - incluindo, mas não limitadas a: acidente vascular cerebral (AVC); trauma crânio encefálico (TCE); epilepsias, tumores cerebrais, encefalites); condições médicas não tratadas e não compensadas que interfiram significativamente na cognição, como exemplo: anemia grave.

Não será critério de exclusão: quadros de ansiedade e depressão leves, uma vez que na população idosa essas condições são comuns. 
b) Grupo controle:

- Critérios de inclusão: Idade igual ou acima de 65 anos, de ambos os sexos, com escolaridade mínima de 4 anos, sem história e manifestações atuais de TDAH.

- Critérios de exclusão: São utilizados os mesmos critérios do grupo TDAH.

O cálculo do tamanho da amostra foi realizado através do Nomograma de Altman ${ }^{124}$ utilizando-se como referência nível de significância estatística de $\alpha=5 \%$ e poder estatístico de 0,80 [1 - $\beta$ ] o qual indica uma amostra de aproximadamente 80 (oitenta) sujeitos (40 para cada grupo - TDAH e controle) com estatística de tamanho de efeito capaz de detectar uma diferença padronizada de 0,62 entre os grupos em termos de exames neuropsicológicos.

\subsection{Procedimentos}

A divulgação da pesquisa para recrutamento dos sujeitos foi realizada através do Departamento de Comunicação do Instituto de Psiquiatria (IPq), utilizando-se dos seguintes canais: murais e TV internos, site IPq, site da Associação Brasileira de Déficit de Atenção (ABDA) e no site Portal da $3^{\mathrm{a}}$ idade $^{1}$.

Também foi realizada uma abordagem direta com entrega de folders em alguns departamentos do HC-FMUSP como Geriatria, Grupo de Assistência Multidisciplinar ao Idoso Ambulatorial - GAMIA e alguns clubes e instituições voltadas à terceira idade, nos quais foram expostos a importância e o objetivo do estudo, a forma como é realizada a pesquisa e o convite para participação. Periodicamente, um release foi enviado para algumas páginas de grupos do Facebook relacionados a pessoas idosas e de pessoas com TDAH (como os grupos,

\footnotetext{
${ }^{1}$ Disponível em: http://www.portalterceiraidade.com.br/
} 
"Gerontologia" (5.675 membros); "TDAH na vida adulta" (12.952 membros) e “Tenho TDAH e agora ?” (2.942 membros).

Os voluntários também foram rastreados entre os familiares de primeiro grau dos pacientes adultos (ex.: pais, tios e primos) e crianças (ex.: avós) portadores de TDAH, atendidos pelo Programa de Déficit de Atenção e Hiperatividade no adulto (PRODATH) e no Ambulatório para Distúrbios Hiperativos e Déficit de Atenção crianças e adolescentes (ADHDA) do Instituto de Psiquiatria do HC-FMUSP.

Foi criado um endereço de email para os primeiros contatos (idosotdah@gmail.com) e divulgou-se também um número de telefone celular. A triagem seguiu os seguintes passos:

- 1a . etapa: Os interessados, abordados pessoalmente ou contatados por telefone passam por investigação dos principais critérios de inclusão e exclusão (como idade, anos de escolaridade, histórico de traumatismo crânio encefálico, acidente vascular cerebral, etc). Após essa seleção é realizado o agendamento presencial para a triagem.

- 2a . etapa: Assinatura no Termo de Consentimento Livre e Esclarecido (TCLE); Preenchimento do Protocolo de Identificação e aplicação de escalas de rastreio para avaliação do estado mental dos sujeitos, para sintomas de depressão e ansiedade e sintomas de TDAH, utilizando-se os instrumentos descritos no item 5.5.1. Para o Grupo I (com TDAH), foram selecionados os sujeitos que atingiram pontuação para diagnóstico de TDAH.

- 3a etapa: Entrevista/avaliação clínica psiquiátrica estruturada para investigação e diagnóstico do TDAH (segundo critérios DSM-IV) e outras condições psiquiátricas. Avaliação das condições médicas e apreciação dos instrumentos aplicados na $2^{\mathrm{a}}$. etapa. Solicitação de exames laboratoriais como: Hemograma, TSH e T4 livre, B12, uréia, creatinina, testes de função hepática (enzimas hepáticas), VDRL, colesterol, triglicérides, glicemia jejum, ácido úrico, e outros que individualmente se fizerem necessário para investigar possíveis fatores que possam interferir significativamente no funcionamento cognitivo. Após a avaliação clínica, são selecionados os idosos diagnosticados com TDAH e os controles, os quais são encaminhados para os exames de ressonância magnética. Em situações de dúvida quanto ao diagnóstico, o 
sujeito foi reavaliado por outro psiquiatra participante da pesquisa e decidido através de consenso.

- 4⿳. .etapa: Realização dos exames de ressonância magnética (RM) por morfometria baseada em voxel (VBM) e por imagem por Tensor de Difusão (DTI). Não havendo achados que comprometessem a pesquisa (como alterações não relacionadas ao envelhecimento normal), os voluntários eram encaminhados para a etapa final de avaliação neuropsicológica.

- 5a etapa: Avaliação neuropsicológica (com a aplicação dos testes, questionários e escalas citados no item 5.5.2, a qual foi realizada em duas sessões de aproximadamente noventa minutos cada.

Os processos de triagem, avaliação clínica e avaliação neuropsicológica foram realizados por profissionais do Programa Déficit de Atenção e Hiperatividade no Adulto - PRODATH junto ao Instituto de Psiquiatria do HC-FMUSP. Os exames de Ressonância Magnética foram realizados no Laboratório de Neuroimagem (LIM21) do IPQ-HC-FMUSP. A triagem e coleta dos dados ocorreram entre janeiro de 2013 e julho de 2017 para ambos os grupos (TDAH e controle). Os participantes se voluntariaram ao longo da pesquisa e vieram de diversos lugares não limitados a cidade de São Paulo. Para a realização de todas as etapas, os sujeitos compareceram por aproximadamente 4 vezes ao HC-FMUSP com dia e hora marcados para as entrevistas, avaliações e exames. Aos participantes foi oferecida toda a avaliação já mencionada, a possibilidade de tratamento/acompanhamento dos casos diagnosticados com TDAH. Na avaliação psiquiátrica e/ou física dos indivíduos, caso fossem constatados sintomas e/ou diagnósticos de outros transtornos clínicos e/ou psiquiátricos, além do TDAH, foram instruídos a procurar atendimento ou encaminhados para atendimento dentro do complexo do HC-FMUSP.

A Fundação de Apoio à Pesquisa do Estado de São Paulo (FAPESP) (nr. 2012/03311-4) financiou parcialmente os valores referentes aos exames laboratoriais, de neuroimagem e ajuda de custo para os participantes e para o pesquisador executante da pesquisa. 


\subsection{Instrumentos}

\subsubsection{Instrumentos utilizados na seleção da amostra e na avaliação clínica}

- Protocolo de Identificação (triagem): Foi elaborado para esse estudo e contempla questões sociodemográficas, assim como para rastreio de saúde física e mental.

- Mini-Exame do Estado Mental (MEEM) ${ }^{125}$. É um instrumento de rastreio do funcionamento cognitivo global amplamente utilizado mundialmente. É composto por questões que avaliam a orientação temporal e espacial, retenção/registro de dados, atenção e cálculo, memória, linguagem e praxia. $\mathrm{O}$ escore pode variar de $0 \mathrm{a}$ 30 pontos. Ponto de corte: 24. Objetivo: Teste de rastreio para detectar comprometimento cognitivo.

- Adult ADHD Self-Report Scale - ASRS-18 (versão 1.1) ${ }^{126}$. É uma escala que possui 18 itens que contemplam os sintomas para TDAH do critério A do DSM-IV modificados para o contexto da vida adulta. Está dividida em duas partes, sendo parte A (desatenção) e parte B (hiperatividade) com 9 itens cada para verificar a frequência dos sintomas nos últimos seis meses, através de uma escala likert (com as opções: nunca, raramente, algumas vezes, frequentemente e muito frequentemente). A pontuação total vai de 0 a 36 . A escala foi submetida à validação semântica em nosso meio por Mattos et al. ${ }^{127}$. Objetivo: Escala de autoavaliação para quantificar sintomas atuais de TDAH no adulto.

- Kiddie Schedule for Affective Disorders and Schizophrenia for School-Age Children/Present and Lifetime Version (K-SADS-PL). Versão brasileira por Brasil $^{128}$. É uma entrevista psiquiátrica semiestruturada designada para avaliar episódios atuais e passados de psicopatologia em crianças e adolescentes de acordo com critérios do DSM-III e DSM-IV, incluindo o TDAH. Objetivo: Utilizada 
parcialmente neste estudo, para rastreio e investigação de sintomas do TDAH na infância e adolescência.

- Inventário de Ansiedade Beck (BAI-Beck Anxiety Inventory) ${ }^{129}$. Questionário de autoavaliação constitído por 21 itens que são afirmações descritivas para medir a severidade da ansiedade. Utiliza uma escala do tipo likert (com as opções: nunca, levemente, moderadamente e gravemente). A pontuação total vai de 0 a 63 , sendo as interpretações das pontuações de 0 à 10: grau mínimo de ansiedade; 11 à 19: ansiedade leve; 20 à 30: ansiedade moderada e 31 à 36: ansiedade severa. Objetivo: Avaliar sintomas de ansiedade.

- Geriatric Depression Scale (GDS - 15) - versão reduzida ${ }^{130}$. Escala para avaliação de Depressão Geriátrica (Almeida; Almeida, 1999). A Escala para avaliação de Depressão Geriátrica (GDS) é um dos instrumentos mais frequentemente utilizado para detecção de depressão em idosos e envolve 15 questões com respostas "sim" ou "não", com ponto de corte igual a 5, sendo que, de 5 à 10 caracteriza depressão de leve à moderada e, se igual ou maior que 11, caracteriza depressão grave.

- Strutctural Clinical Interview for DSM-IV - Clinical Version (SCID-CV) ${ }^{131}$. A SCID inicia-se por uma seção de revisão geral, que segue o roteiro de uma entrevista clínica não-estruturada. Em seguida a entrevista é dividida em módulos que correspondem às categorias diagnósticas maiores. Os critérios diagnósticos estão presentes no próprio corpo do instrumento. Embora as perguntas sejam estruturadas, a pontuação se refere ao julgamento clínico do entrevistador, com relação à presença ou não de determinado critério, preponderando sobre a resposta dada pelo paciente. Objetivo: Utilizado para rastreio de sintomas psiquiátricos fundamentados no DSM-IV.

- Informant Questionnaire on Cognitive Decline in the Elderly (IQCODE) - versão reduzida - $\mathrm{BR}^{132}$. Instrumento utilizado para detecção do declínio cognitivo com base 
no relato do informante. $\mathrm{O}$ informante é questionado a respeito das funcionalidades e capacidades cognitivas do familiar com queixa de memória, com perguntas simples de memória e atividades de vida diária, comparando o seu desempenho atual com o dos últimos dez anos. As perguntas estão organizadas numa escala tipo likert com cinco opções: 1 - muito melhor; 2 - um pouco melhor; 3 - não houve mudança; 4 um pouco pior e 5 - muito pior. O resultado final é obtido pela soma ponderada dos itens, dividindo-os pelo total de itens da escala e varia de 1 a 5 . Ponto de corte: 3.27/3.30.

- Memory Complaint Questionaire- MAC-Q ${ }^{133}$. Questionário sobre Percepção Subjetiva de Perda de Memória. Esse instrumento consta de seis perguntas, com respostas tipo likert que refletem situações abrangentes do cotidiano sobre o uso de memória atual, comparadas com a memória aos 40 anos de idade. Nas cinco primeiras perguntas as pontuações variam de um a cinco pontos. A sexta pergunta apresenta pontuações com os valores de dois, quatro, seis, oito e dez. A pontuação máxima é de 35 , sendo que quanto maior a pontuação, maior é a percepção de perda de memória. Objetivo: Avaliar a percepção subjetiva do sujeito sobre perda de memória comparando a si próprio á quarenta anos atrás.

\subsubsection{Instrumentos utilizados na avaliação cognitiva}

Os testes escolhidos para a avaliação cognitiva contemplam os domínios cognitivos mais prejudicados em comum, verificados em estudos com sujeitos com TDAH e na população idosa (como exemplo: funções executivas, atenção, memória e tempo de reação de respostas), Os testes foram agrupados para compor cinco fatores de acordo com o domínio cognitivo que cada um pretende medir, baseado em teorias e suporte da literatura sobre testagem cognitiva (como exemplo: Straus et al. ${ }^{134}$, LezaK et al. ${ }^{135}$, Kalkut, $2010^{136}$, Lange et al. ${ }^{137}$ A descrição dos testes utilizados para avaliar o quociente intelectual (QI) estimado e os testes que compõem cada fator, encontra-se a seguir: 


\subsubsection{Função intelectual}

- Quociente Intelectual (QI) Estimado - WAIS-III: Wechsler Adult Intelligence Scale $^{138}$. Objetivo: Verificar medida estimada da inteligência através dos subtestes Vocabulário e Raciocínio Matricial.

\subsubsection{Funções executivas}

- Wisconsin Card Sorting Test - WCST - 64: CV2 ${ }^{139}$. Versão computadorizada e consiste de quatro cartões de estímulos apresentados no computador de frente para o sujeito. O primeiro cartão com um retângulo vermelho, o segundo com duas estrelas verdes, o terceiro com cruzes amarelas e o quarto com quatro círculos azuis. $\mathrm{O}$ sujeito deve combinar outras cartas (um total de 64) com desenhos similares a aquelas dos estímulos, variando em cor, forma e número. A cada tentativa de combinação o computador avisa se a resposta está certa (right) ou errada (wrong). Um máximo de 6 combinações é esperado para as 3 categorias. Utilizado para avaliar função executiva. Objetivo: Avaliar Flexibilidade Mental, capacidade de formação de conceitos abstratos não verbais e de automonitorização.

- Fluência Verbal - categorias: semântica (animais) e fonêmica-FAS ${ }^{134}$. Objetivo: Avaliar respectivamente, a capacidade de produção espontânea de palavras e produção espontânea sob restrição semântica e controle mental.

- Stroop Test - Versão Victória ${ }^{134}$. Consiste de três cartões brancos, cada um contendo seis linhas com quatro colunas. No primeiro cartão essas linhas são compostas por retângulos coloridos e o sujeito deve simplesmente falar a cor de cada retângulo da esquerda para a direita até a última linha, o mais rápido que conseguir. O segundo cartão contém palavras (neutras) escritas coloridas. O sujeito deve falar a cor da impressão de cada palavra da mesma forma que nos retângulos e assim também no terceiro cartão, porém nesse último cartão as palavras são nomes de cores 
e o sujeito precisa inibir essa resposta para falar as cores da impressão das palavras. A pontuação é computada pelo tempo de execução e quantidade de erros. Objetivo: Avaliar inibição de respostas preponderantes (controle inibitório).

- Sequiência letra e número - subteste WAIS-III ${ }^{140}$ : Objetivo: Avaliar memória operacional - habilidade para manipulação dos estímulos verbais.

- Dígitos - Ordem Inversa (OI) - subteste do WAIS-III ${ }^{140}$. Uma série de sequências de números é lida para o examinando e o mesmo deve repeti-los na ordem inversa. Mais sequências equivalem a uma maior pontuação. Objetivo: Avaliar memória operacional - habilidade para manipulação dos estímulos verbais.

- Span Visoespacial - Ordem inversa (OI)- subteste $\mathrm{WMS}^{141}$. Cubos fixados em uma prancha são apontados em ordem indireta e o examinando deve apontar os cubos na sequência inversa a qual foi mostrada. Mais sequências equivalem a uma maior pontuação. Objetivo: Avaliar memória operacional - habilidade para manipulação dos estímulos visuais.

\subsubsection{Atenção}

- Dígitos Ordem Direta (OD)-subteste WAIS-III ${ }^{140}$. Subteste da escala Wechsler. Uma série de sequências de números é lida para o examinando e o mesmo deve repeti-los na mesma ordem. Mais sequências equivalem a uma maior pontuação. Objetivo: Avaliar a amplitude/capacidade de atenção, span de evocação verbal.

- Span visoespacial - Ordem direta - subteste $\mathrm{WMS}^{141}$. Cubos fixados em uma prancha são apontados em ordem direta (OD). O examinando deve apontar os cubos na mesma sequência que foi mostrada pelo examinador. Mais sequências equivalem 
a uma maior pontuação. Objetivo: Verificar a amplitude/capacidade de atenção, span de evocação visual.

- Conners' Continuous Performance Test II (CPT II V.5 $)^{142}$. Objetivo: Programa computadorizado para sistema operacional Windows para avaliar a capacidade de atenção sustentada (entre outras medidas) sobre estímulos visuais. É solicitado ao examinando para clicar na barra de espaço quando letras começarem a aparecer na tela do computador, exceto a letra "X". A pessoa deve abster-se de clicar se a letra "X" for apresentada. As medidas utilizadas para as comparações nesse estudo foram: erros por omissão (atribuído à desatenção), erros por comissão (atribuído à impulsividade/controle inibitório), CPT-Hit RT (tempo de reação total de resposta/velocidade de processamento) e CPT-variabilidade (variabilidade de respostas).

- Trail Making test-TMT $T^{134}$. A tarefa é composta por duas partes, sendo a execução de ambas cronometrada. Consiste de duas folhas, uma contendo círculos com números, os quais devem ser ligados em ordem crescente utilizando-se caneta. $\mathrm{Na}$ outra folha deve-se ligar de forma intercalada números e letras, sendo os números em ordem crescente e as letras em ordem alfabética. Objetivo: Avaliar a capacidade de atenção seletiva e sequenciamento (Parte A); atenção dividida sobre dois estímulos concorrentes (número e letra) (Parte B).

\subsubsection{Memória}

- Memória lógica I e II - subteste WMS-III ${ }^{141}$. Duas estórias curtas são contadas e devem ser reproduzidas imediatamente e após passagem de tempo, porém a segunda história é contada uma segunda vez e também dever ser evocada imediatamente. São pontuados os conteúdos/frases evocadas corretamente na evocação imediata e as de evocação tardia. Objetivo: Avaliar memória episódica (verbal) de evocação imediata e tardia dentro de um contexto lógico (estórias). 
- Figura Complexa de Rey $^{134}$. Figura abstrata complexa apresentada ao examinando para que o mesmo faça uma cópia do desenho e, após intervalo de tempo, é solicitado para que reproduza de memória o desenho. Objetivo: avaliar memória visoespacial.

- Rey Auditory Verbal Learning Test (RAVLT) ${ }^{143}$. Consiste de uma lista de 15 substantivos (lista A) que é lida em voz alta para o sujeito com um intervalo de um segundo entre as palavras por cinco vezes consecutivas, cada uma delas seguida por um teste de evocação imediata. Após a quinta tentativa, apresenta-se uma lista de interferência, também de 15 palavras sendo seguida de um teste de lembrança. Em seguida pede-se ao sujeito que recorda as palavras da lista A, sem que ela seja reapresentada. Depois de um intervalo de 20 minutos, o sujeito deve evocar espontaneamente o que lembra da lista A. Por último é avaliada a memória de reconhecimento, apresentando-se uma lista que contém todas as palavras da primeira e da segunda lista entre outras palavras não lidas. $\mathrm{O}$ examinando deve identificar as que pertence a lista $\mathrm{A}$ (primeira lista). A pontuação obtida da primeira à quinta evocação imediata serve de base para se verificar a curva de aprendizagem. Além disso, pode-se calcular a velocidade de esquecimento. Objetivo: Avaliar a aprendizagem de novas informações, memória episódica verbal (evocação imediata e tardia), suscetibilidade à interferência, reconhecimento dos estímulos verbais e velocidade de esquecimento.

- Brief Visuospatial Memory Test - Revised (BVMT-R) ${ }^{144}$. O teste consiste na apresentação de uma folha contendo seis figuras geométricas simples, as quais são apresentadas três vezes consecutivas e o sujeito deve reproduzir (como eram e onde estavam na folha) de memória logo após cada apresentação. Após passagem de tempo (20 minutos), é solicitado ao sujeito que reproduza de memória as figuras. Em seguida apresenta-se várias figuras contendo as que foram apresentadas posteriormente entre outras seis que não foram apresentadas. $O$ sujeito deve reconhecer as que foram apresentadas Objetivo: Avaliar a aprendizagem de novas 
informações e memória episódica visoespacial (evocação imediata e tardia) e reconhecimento dos estímulos verbais

\subsubsection{Funções visoespaciais/visoconstrutivas e visoperceptivas}

- Cubos - subteste WAIS-III ${ }^{140}$. È solicitado ao examinando que use os cubos para reproduzir os modelos bidimensionais apresentados. Cada cubo tem dois lados brancos, dois lados vermelhos e dois lados metade vermelho e metade branco. O grau de dificuldade do padrão é progressivo, com modelos compostos de dois cubos até os mais complexos com nove cubos. Objetivo: Avaliar a habilidade visoconstrutiva, capacidade para analisar, sintetizar e reproduzir estímulo visual abstrato bidimensional, percepção e organização visual, coordenação visomotora e visoconstrutiva.

- Completar figuras - subteste WAIS-III ${ }^{140}$. Este teste consiste em mostrar figuras ao examinando, o qual deve apontar ou nomear a parte principal que está faltando nela, devendo responder cada questão dentro do tempo limite de 20 segundos.

Objetivo: Visopercepção de partes essenciais de objetos.

- Figuras Complexas de Rey: Teste de Cópia e de Reprodução de Memória de Figuras Geométricas Complexas. Padronização brasileira por Oliveira e Rigoni $(2010)^{145}$. Figura abstrata complexa apresentada ao examinando para que o mesmo faça uma cópia do desenho e, após intervalo de tempo, é solicitado para que reproduza de memória o desenho. Objetivo: Avaliar o planejamento, organização visoespacial na fase de cópia de figura geométrica complexa. 


\subsubsection{Linguagem}

- Vocabulário - subteste WAIS-III ${ }^{140}$. Neste teste, o examinando deve definir, oralmente, o significado de cada palavra apresentada na lista de palavras e lida ao mesmo tempo lida pelo examinador em voz alta.

- Boston Naming ${ }^{146}$. Consiste em 60 figuras as quais o sujeito precisa nomeá-las. É pontuado se a resposta for dada em até 20 segundos. Após cada falha de resposta, é dada uma pista semântica (exemplo: para que é usado tal objeto) caso não reconheça a figura e se o erro persistir é dada (após mais 20 segundos) uma outra pista fonêmica (onde se fala a primeira sílaba do nome da figura). O total é a soma das respostas espontâneas corretas mais as respostas corretas dadas após as pistas. Objetivo: Avaliar habilidade para nomeação de objetos comuns.

\subsection{Aquisição de imagens por ressonância magnética}

Nesse estudo as imagens de ressonância magnética (RM) foram analisadas por duas técnicas: Morfometria Baseada em voxel [voxel-based morphometry (VBM)] otimizada e por Imagem de Tensor de Difusão [Diffusion Tensor Imaging (DTI)].

Tanto as imagens dos sujeitos do grupo TDAH quanto dos controles foram obtidas com o mesmo aparelho GE sigma de 1,5 $\mathrm{T}$ localizado no Instituto de Psiquiatria da USP (IPQ).

Os dados morfológicos foram adquiridos utilizando uma sequência ponderada em T1 (Magnetization-Prepared Rapid Gradient Echo-MPRAGE) com os seguintes parâmetros: tempo de repetição $(\mathrm{TR})=2,400 \mathrm{~ms}$; tempo de eco $(\mathrm{TE})=3,65 \mathrm{~ms}$; número de amostragens $(\mathrm{NEX})=1$; campo de visão $(\mathrm{FOV})=240 \mathrm{~mm}$; ângulo de inclinação $($ flip angle $)=8^{\circ}$; aquisição de matriz $=192 \times 192$ pixels; espessura de 
corte $($ slice thickness $)=1,2 \mathrm{~mm}$ (sem espaços entre os cortes); tamanho do voxel = $1,25 \times 1,25 \times 1,2 \mathrm{~mm}$; resultando em 160 fatias cobrindo todo o cérebro.

A sequência por DTI foi adquirida utilizando um monitor cardíaco, uma bobina para exames de cabeça com 12 canais e tecnologia de aquisição de imagem paralela. A DTI é baseada em aquisição de imagem ecoplanar (echo-planar image EPI) e consiste em uma imagem sem gradiente de difusão $\left(b=0 \mathrm{~s} / \mathrm{mm}^{2}\right.$ ), além de imagens ponderadas em difusão (diffusion-weighted images - DWI), obtidas ao longo de 64 direções não colineares $\left(b=1,000 \mathrm{~s} / \mathrm{mm}^{2}\right)$ usando os seguintes parâmetros: TR $=8,000 \mathrm{~ms}, \mathrm{TE}=110 \mathrm{~ms}, \mathrm{NEX}=2, \mathrm{FOV}=240 \mathrm{~mm}$, matriz $=120 \times 120$ pixels, espessura de cortes $=2.7 \mathrm{~mm}$ (sem espaços entre os cortes); tamanho do voxel = $2.0 \times 2.0 \times 2.7 \mathrm{~mm}$, resultando em 50 fatias cobrindo todo o cérebro.

As duas sequências foram adquiridas em até 40 minutos. Além delas, também foram obtidas duas outras sequências que estavam incluídas no protocolo: (1) sequência turbo transaxial de spin-echo, ou seja, aumento das potências dos impulsos de radiofrequência emitidos no plano perpendicular com o eixo longo do corpo humano, ponderadas em T2 (com 24 fatias, espessura da fatia $=5 \mathrm{~mm}$ e lacuna de 1 $\mathrm{mm}$ ); e (2) uma sequência transaxial com fluido de recuperação da inversão atenuada (fluid attenuated inversion recovery - FLAIR) (com 24 fatias, espessura da fatia $=5$ mm e lacuna de $1 \mathrm{~mm}$ ). A inspeção das imagens do conjunto de dados de cada sujeito foi realizada visualmente por um neurorradiologista especializado com o objetivo de identificar qualquer lesão cerebral, tais como tumores, lesões silenciosas, acidente vascular cerebral e artefatos que pudessem interferir no processamento e análise de imagens.

\subsubsection{Processamento das imagens pela morfometria baseada em voxels (VBM)}

As imagens de RM foram processadas através do programa Statistical Parametric Mapping (SPM) versão 12 (Wellcome Trust Center of Neuroimaging, 
Londres, Reino Unido $^{2}$ ) implantado sobre a plataforma do programa MATLAB 2012a (MathWorks, Sherborn, $\mathrm{MA}^{3}$ ). Primeiramente, todas as imagens anatômicas foram reorientadas para a convenção neurológica e a comissura anterior definida como ponto de origem adequado ao padrão tridimensional espacial de coordenadas $\mathrm{X}$ y z $(0,0,0)$ e a orientação aproximada ao espaço do Instituto Neurológico de Montreal (MNI 152). A seguir, as imagens foram segmentadas em substância cinzenta (SC); substância branca (SB) e liquor cefalorraquidiano (LCR), usando o procedimento de segmentação unificada descrito por Ashburner e Friston (2005). ${ }^{147}$ Posteriormente, as imagens foram processadas empregando a caixa de ferramenta 'DARTEL' (The Diffeomorphic Anatomical Registration Using Exponentiated Lie Algebra ${ }^{4}$ ). O registro de imagens difeomorfas implementadas prevê melhor precisão anatômica comparada aos métodos anteriores de VBM. Ao normalizar espacialmente as imagens segmentadas, este procedimento maximiza a sensibilidade e precisão da localização, registrando as imagens estruturais individuais para um modelo customizado assimétrico derivado das imagens estruturais ponderadas em T1 dos participantes, ao invés de um modelo de imagens baseado em uma amostra diferente $^{148}$. Essas imagens totalmente normalizadas foram refatiadas com a interpolação trilinear para um tamanho e voxel final de $2 \times 2 \times 2 \mathrm{~mm}^{3}$. Uma etapa adicional de modulação consistiu na multiplicação de cada imagem espacialmente normalizada da SC e da SB por seus volumes relativos antes e após a normalização, garantindo, assim, que a quantidade total de SC e SB em cada voxel fosse preservada. Por fim, as imagens da SC e da SB resultantes foram suavizadas usando um (filtro) kernel Gaussian FWHM (full-width at half-maximum) de $8 \mathrm{~mm}$ para assegurar uma distribuição normal dos dados como exigido pelos testes estatísticos paramétricos.

\footnotetext{
${ }^{2}$ Disponível em: http://www.fil.ion.ucl.ac.uk/spm.

${ }^{3}$ Disponível em: http://www.mathworks.com/products/matlab.

${ }^{4}$ Disponível em: http://dbm.neuro.uni-jena.de/vbm/.
} 


\subsubsection{Processamento das imagens por tensores de difusão (DTI)}

As propriedades anisotrópicas e da difusividade cerebral foram inferidas por meio dos dados da DTI, cujos procedimentos para aquisição dos índices quantitativos são descritos a seguir.

Primeiramente, as imagens obtidas foram convertidas do formato DICOM para o formato NiFTI (Neuroimaging Informatics Technology Iniciative) empregando a ferramenta "dcm2nii" do programa MRICron". As direções de gradientes [vetores de difusão (bvecs)] e seus respectivos b-valores (bvals) foram previamente extraídos da sequência adquirida pelo equipamento de ressonância magnética. Esses procedimentos possibilitam calcular alguns índices escalares, como a anisotropia fracional (AF), média de difusividade (MD), difusividade radial (DR) e a difusividade axial (DA) ${ }^{74}$. Em seguida, utilizando-se o programa FSL (FMRIB software library ${ }^{6}$ ), foi realizada a correção das distorções provocadas pelos gradientes suscetíveis à difusão, assim como para a correção de movimentos, tendo como guia o volume b0. Na sequência executou-se a segmentação automatizada, com o objetivo de remover os tecidos extra cerebrais e, após essa etapa, as medidas de autovalores e autovetores foram estimadas, para serem calculados os índices de AF, os quais foram utilizados neste estudo e refletem o grau de direcionalidade de difusão da água, permitindo verificar a integridade das fibras.

Após o processamento inicial pelo FSL, o processamento dos tratos das fibras foi efetuado utilizando o programa TBSS (Tract-Based Spatial Statistics), método que funciona sobre o software FSL. Os mapas gerados da AF dos sujeitos foram alinhados uns com os outros, baseados nas deformações e com o registro não linear da função B-Splines. Essa aproximação é escolhida em razão da capacidade de selecionar graus intermediários de liberdade, sendo uma alternativa útil para alinhar o trato no esqueleto. Em seguida, a imagem alvo foi alinhada para o espaço anatômico padronizado MNI, e cada imagem foi normalizada espacialmente para o

\footnotetext{
${ }^{5}$ Disponível em : http://people.cas.sc.edu/rorden/mricron/main.html

${ }^{6}$ Disponível em : http://fsl.fmrib.ox.ac.uk/fsl/fslwiki/FSL
} 
espaço padrão do MNI, combinando parâmetros de transformações não lineares e lineares, e interpolada para uma dimensão final de voxel igual a $1 \times 1 \times 1 \mathrm{~mm}^{3}$. Calculou-se então, a imagem média para gerar um esqueleto da média da AF (skeletonisation) definindo-se o voxel com maior valor ao longo de uma linha da $\mathrm{AF}$ perpendicular à direção do trato como sendo o centro desse trato. Esta investigação é feita em todos os voxels localizados perpendicularmente na direção de um trato específico (mais detalhes, consultar Smith et al., 2006) ${ }^{149}$.

Na esquematização do esqueleto, o limiar de significância para o esqueleto da AF foi fixado em 0,2 com o propósito de excluir regiões de AF média ou baixa. Posteriormente, os dados da AF alinhados de cada sujeito foram projetados sobre o esqueleto. Essa metodologia é concebida ao pesquisar os valores mais altos da AF dos sujeitos que estão na direção perpendicular ao trato, dentro da média do esqueleto da AF. Este procedimento é essencial para o algoritmo de processamento, uma vez que remove o efeito das variabilidades espaciais entre os sujeitos.

Após todo o processamento com as técnicas VBM e DTI foi possível realizar comparações entre grupos através de modelos estatísticos. 
6 Análise Estatística 



\section{ANÁLISE ESTATÍSTICA}

\subsection{Análise estatística dos dados demográficos, clínicos e cognitivos}

A análise estatística foi realizada através do programa Statistical Package for the Social Sciences - SPSS (versão 25) para Windows.

Primeiramente, foi realizada uma análise exploratória/descritiva dos dados da amostra total bem como separadamente por grupo. Para os dados categoriais, a medida resumo foi a frequiência dos indivíduos em cada categoria. Para as variáveis contínuas, as medidas resumo utilizadas são: mínimo, máximo, média e desvio padrão. As variáveis categoriais foram analisadas por testes não paramétricos tais como Qui-quadrado ou Teste de Fischer. Para as variáveis contínuas foi utilizado Teste-t para os dados que apresentam distribuição normal, ou, caso contrário, pelo Teste Mann-Whitney. A associação entre as variáveis contínuas foi analisada através do coeficiente de correlação de Pearson e entre as variáveis ordinais através do coeficiente de Spearman e de seus testes de significância. Para todas as análises foi utilizado o nível de significância de $5 \%$.

As variáveis "idade", escore total das escalas GDS (depressão) e BAI (ansiedade), as quais se diferenciaram entre os grupos, foram utilizadas como covariáveis.

Para a análise dos resultados dos testes cognitivos, conforme mencionado anteriormente (item 5.5.2) optou-se pela criação de cinco fatores definidos a priori com um resumo de pontuação para os principais domínios cognitivos (atenção, memória, funções executivas, funções visoespaciais/visoperceptiva/visoconstrutiva e linguagem). Essa medida visa a redução do erro Tipo 1, uma vez que o resultado se torna mais sensível aos efeitos do tratamento estatístico ${ }^{150}$. As variáveis individuais de cada teste aplicado foram padronizadas, ou seja, convertidas para $z$-escore e esses foram somados para a construção das cinco novas variáveis. Em seguida, realizou-se análises de variância na comparação das médias dos escores entre os grupos. 
Adicionalmente, análises de correlação foram realizadas entre os testes cognitivos e os sintomas de TDAH (ASRS), depressão (GDS) e ansiedade (BAI).

\subsection{Análise estatística dos dados das imagens pela morfometria baseada em voxels $(\mathrm{VBM})$}

Os volumes totais da SC e SB, foram calculados utilizando-se o software MATLAB (MATrics LABoratory) por meio do roteiro get_totals script ${ }^{7}$ implementado para o SPM12, que emprega as imagens segmentadas no espaço nativo de cada sujeito. Para quantificar diferenças nas análises dos volumes totais dos compartimentos cerebrais de substância cinzenta (SC) e substância branca (SB), foi empregado o modelo linear geral (GLM) usando o programa SAS ${ }^{\circledR}$ University Edition (version: university.cny.sas.com@ sas:university-6p.2/6p.2.4d9732411a6d-11) para comparar as médias dos dois grupos, com e sem TDAH. Idade e sexo foram consideradas como covariáveis.

Para a análise cerebral total, somente voxels com valores acima do limite absoluto de $\mathrm{p}=$ 0,05 na diferenciação da SC e SB com outros tecidos foram incluídos, como também os volumes de SC e SB foram inseridos como fatores de confusão em suas respectivas análises de covariância. Primeiramente, a análise estatística das imagens foi realizada através de investigação, para cada voxel do volume cerebral, de diferenças significativas para volumes regionais de SC e SB. As comparações entre os dois grupos, foi realizada através de amostras independentes voxel a voxel por $t$ test $(\mathrm{p} \leq 0,05)$. Idade e sexo foram consideradas variáveis confundidoras, sendo controladas nas análises. Além disso, a medida de volume cerebral total foi incluída como variável confundidora para corrigir para atrofia cortical. O conjunto dos resultados voxel a voxel das comparações constituíram mapas estatísticos (SPM) empregando um limiar não corrigido de valor de $\mathrm{p}<0,001$. Somente regiões com

\footnotetext{
${ }^{7}$ Disponível em: http://www.cs.ucl.ac.uk/staff/g.ridgway/vbm/get totals.m.)
} 
clusters de tamanho mínimo de 10 voxels foram reportados. Cada mapa estatístico foi então inspecionado para identificação de regiões onde haveria redução ou aumento de SC e SB no grupo de sujeitos com TDAH em comparação aos controles normais.

Uma segunda análise incluiu a delimitação através da ferramenta "small volume correction" (SVC) das regiões nas quais há hipótese a priori (ROIs) de ser encontrada diferença significativa entre os grupos baseada em estudos anteriores com TDAH. Devido ao caráter exploratório do presente estudo, as ROIs foram investigadas bilateralmente. As ROIs referentes à SC verificadas em estudos anteriores com TDAH $^{27,42,43,52,56,58-61}$ e investigadas nesse estudo, são as seguintes: córtex pré-frontal dorsolateral (CPFDL), córtex órbito frontal (COF), lobo parietal inferior (LPI), gânglios da base (putamen, caudado e globo pálido, conjuntamente), córtex do cíngulo anterior (CCA), amígdala, hipocampo e cerebelo. Cada região de SC foi espacialmente delimitada pela aplicação de máscaras, com base nos volumes anatômicos de interesse, que estão disponíveis na caixa de ferramentas SPM de marcação anatômica automática ${ }^{8}$, conforme a seguir: giros frontal superior e médio, giros frontal inferior triangular e opercular para compor o CPFDL; giro frontal inferior orbital (região orbital do COF); giros angular e supramarginal para compor o LPI; giro do cíngulo anterior (AC); hipocampo; amigdala; gânglios da base (compreendendo caudato, putamen e pálido) e cerebelo.

A análise dos volumes regionais de SB, empregando a ferramenta SVC, explorou as ROIS que apresentam alterações na sua integridade verificadas em estudos por DTI com TDAH ${ }^{68,76,81}$, sendo elas: corpo caloso (corpo e esplênio do corpo caloso), porção retrolenticular da capsula interna, coroa radiada (anterior, superior e posterior), radiação talâmica posterior, estrato sagital, fascículo longitudinal superior, cíngulo e tapetum.

Adicionalmente, análises de correlação foram performadas entre os sintomas de desatenção (ASRS-A), hiperatividade (ASRS-B), depressão (GDS) e ansiedade (BAI) e os volumes de $\mathrm{SC}$ e $\mathrm{SB}$. Foram reportados os achados que resistiram à

\footnotetext{
${ }^{8}$ Disponível em: http://www.gin.cnrs.fr/AAL
} 
comparação múltipla com limiar estatístico de voxel para $\mathrm{p} \leq 0,050$ corrigido para comparações múltiplas.

\subsection{Análise estatística dos dados das imagens por tensores de difusão (DTI)}

Para que a análise estatística dos dados do processamento das imagens fosse conduzida, eles foram transportados para o programa SPM. Somente voxels com valores acima de um valor absoluto $\mathrm{p}=0,05$ foram incluídos. Em seguida, mensurações "voxel a voxel" nos valores de AF das imagens obtidas foram realizadas em todo o cérebro.

As comparações entre os dois grupos para investigar diferenças (aumento ou diminuição) de volume, foi realizada através de amostras independentes voxel a voxel por $t$-test $(\mathrm{p} \leq 0,05)$.

Idade e sexo foram considerados como fatores confundidores sendo controlados nas análises. Os resultados estatísticos destas análises com limiar definido de $\mathrm{p}<0,001$ foram exibidos como SPMs no espaço anatômico padrão. O conjunto dos resultados voxel a voxel para cada um dos contrastes (comparações) mencionados anteriormente constitui um SPM t, empregando um limiar não corrigido ao nível de $\mathrm{p} \leq 0,001$. Resultados não a priori foram considerados significativos se resistissem ao nível de $\mathrm{pFWE} \leq 0,05$ (corrigido para múltiplas comparações). Além disso, somente regiões com, no mínimo, 10 voxels contíguos foram reportadas. Posteriormente cada mapa estatístico foi inspecionado quanto à presença de clusters de diferenças significativas em regiões em que as alterações volumétricas nos valores da $\mathrm{AF}$ haviam sido previstas a priori, empregando a ferramenta SVC, com a finalidade de limitar o número total de voxels incluídos nas análises. Cada região foi circunscrita pela composição das imagens espacialmente normalizadas nas ROIs definidadas pelo atlas de tractografia da SB (Johns Hopkins

University-JHU) $^{151,152}$. Máscaras com as ROIs foram usadas para cada hemisfério cerebral, envolvendo as regiões em que as diferenças a priori foram identificadas em 
estudos de neuroimagem sobre o TDAH por DTI, que verificaram alterações nos valores de AF nas seguintes ROIs: cíngulo, corpo caloso (corpo e esplênio), porção retrolenticular da capsula interna, coroa radiada (anterior, superior e posterior), radiação talâmica posterior, estrato sagital (incluindo fascículo longitudinal inferior e fascículo fronto-occiptal), fascículo longitudinal superior e tapetum.

Foram reportados os resultados pressupostos a priori, que sobrevivessem a um limiar estatístico com $\mathrm{p} \leq 0,05$, corrigido para múltiplas comparações (Family Wise Error/FWE). Somente regiões com, no mínimo, 10 voxels contíguos foram descritas. Adicionalmente, análises de correlação foram performadas entre os sintomas de desatenção, hiperatividade/impulsividade, depressão e ansiedade e a AF das ROIs da SB. 

7 Resultados 



\section{RESULTADOS}

7.1 Seleção da amostra e etapas das avaliações

A seleção da amostra foi realizada conforme demonstrado na Figura 1 a seguir. 


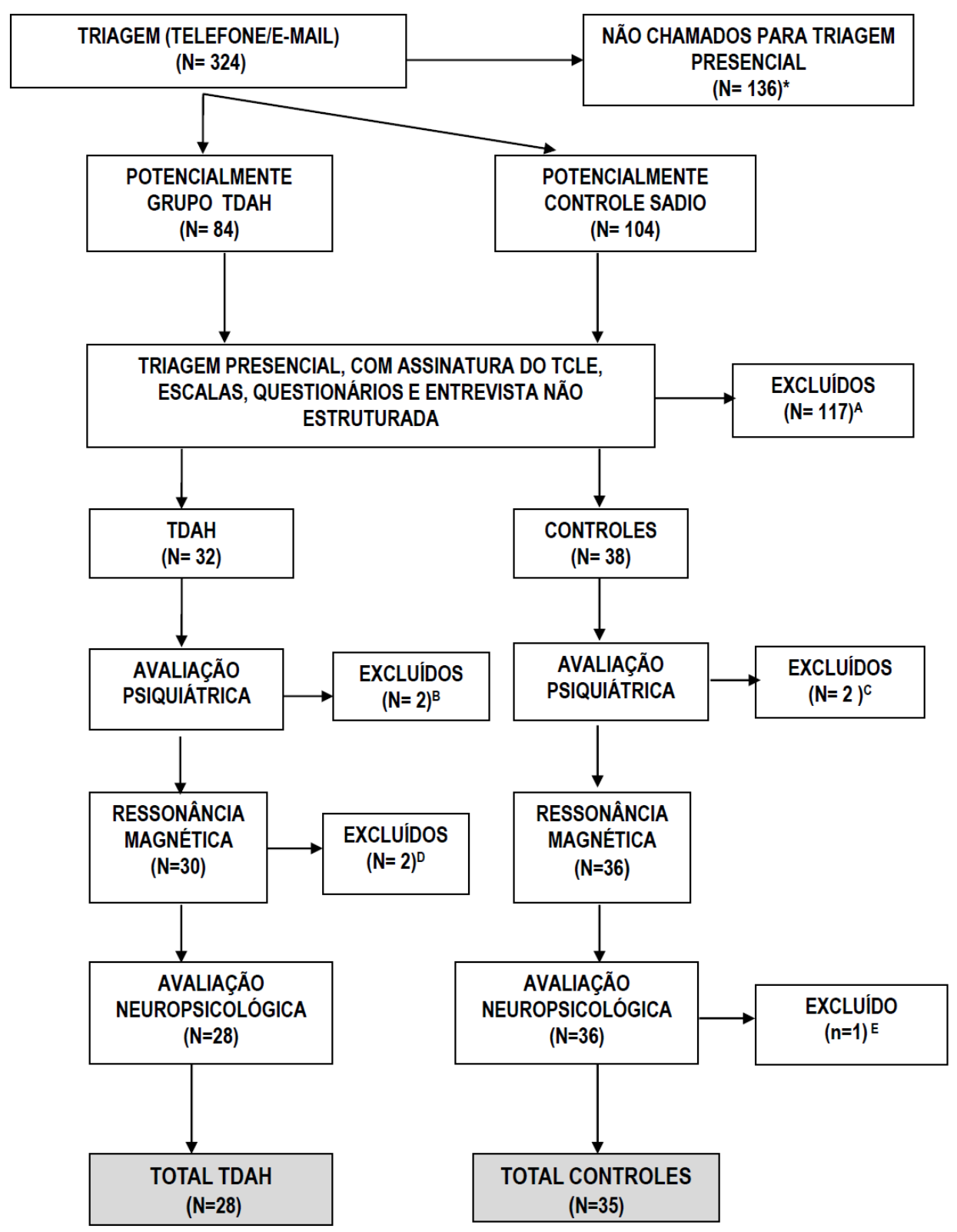

LEGENDA (Figura 1): Motivos de não inclusão/exclusão:

$\mathrm{N}=$ quantidade de sujeitos.

* = Não preencheram critérios mínimos para triagem presencial; não conseguiriam participar por residirem em outra cidade e/ou não terem disponibilidade para ir ao Instituto de Psiquiatria onde foi realizada a pesquisa; ou simplesmente por recusa.

A = Deficiência auditiva não corrigida; doenças cardiovasculares clinicamente significativas; depressão grave; doença pulmonar crônica (DPOC), falta de lembrança e/ou ausência de informações que comprovem a presença de sintomas do TDAH na infância apesar da queixa de dificuldades crônicas (para grupo TDAH); declínio de memória recente percebido por informantes.

$\mathrm{B}=$ Presença de comorbidade com Transtorno Obsessivo Compulsivo; diagnóstico de narcolepsia (não comentado na triagem).

$\mathrm{C}=$ Presença de Transtorno Obsessivo Compulsivo/acumulação em grau moderado à grave .

$\mathrm{D}=$ Presença de alterações significativas na neuroimagem: um caso com hipótese diagnóstica de CADASIL (cerebral autosomal dominant arteriopathy with subcortical infarcts and leukoencephalopathy) e um caso de Hidrocefalia de Pressão Normal.

$\mathrm{E}=$ Dificuldades para realizar algumas tarefas da bateria de avaliação neuropsicológica.

\section{Figura 1 - Fluxograma da seleção da amostra e etapas das avaliações}




\subsection{Dados demográficos}

A amostra foi constituída por 63 participantes, sendo $28(44,4 \%)$ diagnosticados com TDAH (Grupo clínico) e 35 sem o TDAH (Grupo controle). Ela é predominantemente feminina $(76,2 \%)$, porém os grupos não se diferenciaram na distribuição do sexo.

Os dados demográficos com a descrição estatística da amostra são apresentados na Tabela 2.

Tabela 2 - Dados demográficos da amostra

\begin{tabular}{|c|c|c|c|}
\hline & $\begin{array}{l}\text { TDAH } \\
(n=28)\end{array}$ & $\begin{array}{l}\text { CONTROLE } \\
(n=35)\end{array}$ & $P$-value \\
\hline Idade, média \pm DP & $66,8 \pm 3,1$ & $69,0 \pm 4,1$ & $<0,001^{\mathrm{b}}$ \\
\hline Sexo & & & $0,165^{\mathrm{a}}$ \\
\hline Feminino, $\mathrm{n}(\%)$ & $19(67,9)$ & $29(82,9)$ & \\
\hline Masculino, n (\%) & $9(32,1)$ & $6(17,1)$ & \\
\hline Escolaridade (anos), média \pm DP & $13,8 \pm 5,4$ & $14,6 \pm 3,7$ & $0,580^{\mathrm{b}}$ \\
\hline Repetência escolar/acadêmica, n (\%) & $21(75,0)$ & $9(25,7)$ & $<0,001^{\mathrm{a}}$ \\
\hline *Quantidade de anos repetidos, média \pm DP & $1,7 \pm 1,4$ & $0,5 \pm 1,2$ & $<0,001^{\mathrm{b}}$ \\
\hline Conseguiram aposentadoria & $13(46,4)$ & $26(74,3)$ & $0,024^{\mathrm{a}}$ \\
\hline Estado civil: & & & $0,022^{\mathrm{a}}$ \\
\hline Casado, n (\%) & $13(46,4)$ & $12(34,3)$ & \\
\hline Separado/Divorciado, n (\%) & $12(42,9)$ & $7(20,0)$ & \\
\hline Viúvo, n (\%) & $2(7,1)$ & $11(31,4)$ & \\
\hline Solteiro, n (\%) & $1(3,6)$ & $5(14,3)$ & \\
\hline
\end{tabular}

NOTA: DP= desvio padrão; $\mathrm{n}=$ quantidade de sujeitos; ${ }^{\mathrm{a}}=$ Teste Qui-quadrado; ${ }^{\mathrm{b}}=$ Teste Mann-Whitney; ${ }^{*}$ anos repetidos nos estudos não foram computados no tempo de escolaridade.

Considerando um nível de significância de 5\% houve diferença entre os grupos com relação à idade, sendo que esta variável foi controlada nas análises estatísticas. O grupo TDAH apresentou uma média mais baixa de idade, porém os grupos não se diferenciaram com relação aos anos de estudos. No grupo TDAH houve mais pessoas que repetiram de ano nos estudos, assim como repetiram mais vezes que os controles. Apresentaram ainda, uma maior frequência de estado 
conjugal "casados", mas também maior frequência de sujeitos "separados/divorciados" quando comparados aos controles. Por outro lado, o grupo controle apresentou maior frequência para "viuvez". 


\subsection{Dados clínicos}

A estatística descritiva dos dados psiquiátricos (resultados das escalas de rastreio) é apresentada na Tabela 3.

Tabela 3 - Escalas de avaliação psiquiátrica

\begin{tabular}{|c|c|c|c|}
\hline & $\begin{array}{c}\text { TDAH } \\
(\mathrm{n}=28) \\
(\text { média } \pm \mathrm{DP})\end{array}$ & $\begin{array}{l}\text { CONTROLE } \\
\quad(n=35) \\
(\text { média } \pm \text { DP })\end{array}$ & $P$-value \\
\hline MEEM (total) & $28,1 \pm 1,3$ & $28,6 \pm 0,9$ & $0,015^{\mathrm{b}}$ \\
\hline Evocação & $2,2 \pm 0,9$ & $2,5 \pm 0,6$ & $0,435^{\mathrm{b}}$ \\
\hline Atenção e cálculo & $4,3 \pm 0,8$ & $4,4 \pm 0,7$ & $0,634^{\mathrm{b}}$ \\
\hline GDS (sintomas atuais de depressão) & $6,3 \pm 3,3$ & $2,4 \pm 2,7$ & $<0,001^{\mathrm{c}}$ \\
\hline BAI (sintomas atuais de ansiedade) & $12,7 \pm 6,7$ & $4,2 \pm 3,6$ & $<0,001^{\mathrm{c}}$ \\
\hline \multicolumn{4}{|l|}{ ASRS - parte A (desatenção) } \\
\hline Quantidade de sintomas & $6,5 \pm 2,0$ & $0,8 \pm 1,0$ & $<0,001^{\mathrm{c}}$ \\
\hline Escore total & $26,8 \pm 4,7$ & $9,4 \pm 5,1$ & $<0,001^{\mathrm{c}}$ \\
\hline \multicolumn{4}{|c|}{ ASRS - parte B (hiperatividade/impulsividade) } \\
\hline Quantidade de sintomas & $4,8 \pm 2,3$ & $0,7 \pm 1,3$ & $<0,001^{\mathrm{c}}$ \\
\hline Escore total & $22,2 \pm 6,6$ & $9,5 \pm 5,4$ & $<0,001^{\mathrm{c}}$ \\
\hline IQCODE & $3,2 \pm 0,2$ & $3,0 \pm 0,3$ & $0,004^{\mathrm{b}}$ \\
\hline MAC-Q & $26,5 \pm 3,3$ & $23,6 \pm 4,9$ & $0,650^{\mathrm{c}}$ \\
\hline
\end{tabular}

NOTA: $\mathrm{DP}=$ desvio padrão; $\mathrm{n}=$ quantidade de sujeitos; MEEM=Mini Exame do Estado Mental; ASRS= Adult ADHD Self Report Scale; GDS = Geriatric Depression Scale; BAI = Beck Anxiety Inventory; IQCODE= Informant Questionnaire on Cognitive Decline in the Elderly; $\mathrm{MAC}-\mathrm{Q}=$ Questionário sobre Percepção Subjetiva de Perda de Memória; ${ }^{\mathrm{b}}=$ Teste Mann-Whitney; ${ }^{\mathrm{c}}=$ ANCOVA (Ajustamento para idade, GDS e BAI).

Os grupos se diferenciaram $(P=0,015)$ quanto à pontuação total do MEEM, no qual o grupo controle pontuou melhor. Porém, ao se analisar, isoladamente, os resultados das variáveis "evocação" e "atenção e cálculo", consideradas críticas tanto para o grupo TDAH quanto para os idosos no geral, eles não se diferenciaram ( $P=0,435$ e $P=0,634$, respectivamente). Uma maior variabilidade nos escores das respostas do MEEM foi verificado (Figura 2) no grupo TDAH, apresentando um mínimo de 25 e máximo de 29 pontos (do total de 30). 


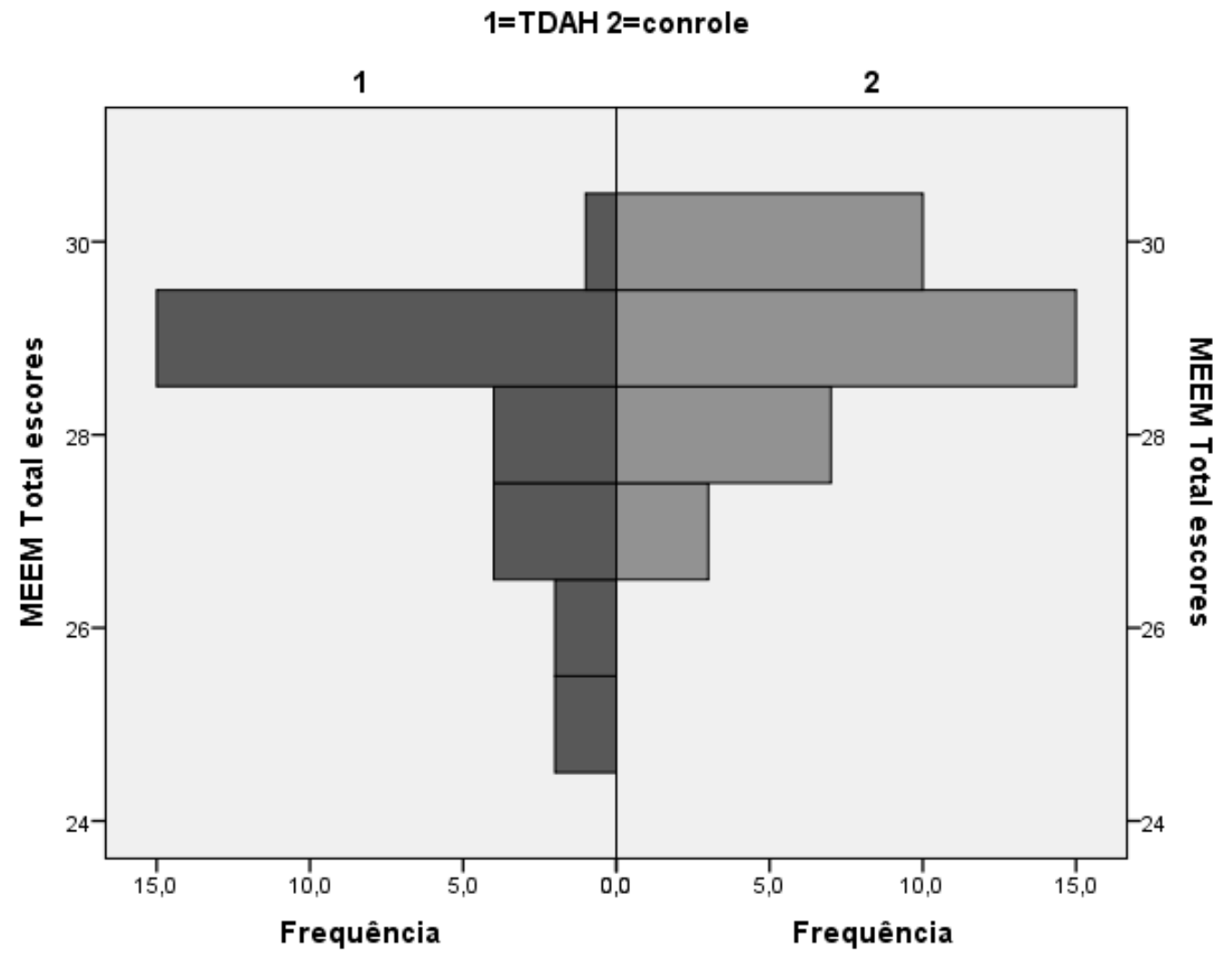

Figura 2 - MEEM - Variabilidade de respostas nos dois grupos (TDAH e controles)

Os resultados das escalas GDS e BAI apresentaram uma diferença significante $(P<0,001)$ entre os grupos, mesmo após ajustamento para idade, com o grupo TDAH apresentando mais sintomas atuais para depressão e ansiedade, ou seja, os sintomas não são influenciados pela idade.

Como era esperado, as médias dos resultados da escala ASRS (parte A e parte B) se diferenciaram significantemente $(p<0,001)$ entre os grupos, mantendo as diferenças após controle de possíveis efeitos de idade, GDS e BAI, conforme Tabela 2. 
Adicionalmente realizou-se uma análise de correlação entre sintomas de desatenção (ASRS- parte A) e hiperatividade/impulsividade (ASRS- parte B) e as covariáveis sexo, idade, GDS e BAI (Tabela 4). Não houve correlação entre sexo e sintomas. Os sintomas de desatenção apresentaram uma correlação significante negativamente associada à idade, ou seja, quanto maior a idade menor a intensidade dos sintomas de desatenção. Os sintomas de hiperatividade/impulsividade apresentaram uma tendência de correlação negativa com a idade. Houve uma significante correlação positiva dos sintomas, tanto de desatenção quanto de hiperatividade/impulsividade, com os sintomas de depressão e ansiedade.

Tabela 4 - Correlação de Pearson entre ASRS (Grupo TDAH) e as variáveis sexo, idade, GDS e BAI

\begin{tabular}{lcc}
\hline \multicolumn{1}{c}{ SINTOMAS } & $r$ & $p$ - value* \\
\hline ASRS - parte A (Desatenção) & & \\
Sexo & 0,13 & 0,306 \\
Idade & $-0,34$ & 0,007 \\
GDS & 0,54 & $<0,001$ \\
BAI & 0,64 & $<0,001$ \\
ASRS - parte B (Hiperatividade/Impulsividade) & & \\
Sexo & 0,07 & 0,576 \\
Idade & $-0,25$ & 0,052 \\
GDS & 0,46 & $<0,001$ \\
BAI & 0,56 & $<0,001$ \\
\hline
\end{tabular}

NOTA: ASRS= Adult ADHD Self Report Scale; GDS= Geriatric Depression Scale; BAI= Beck Anxiety Inventory; $r=$ correlação de Pearson.

No questionário MAC-Q, os resultados mostraram uma diferença significante $(p=0,045)$ entre os grupos, com o grupo TDAH pontuando mais que os controles. Com o ajustamento para a variável idade, a diferença se mantém $(p=0,016)$, porém, ao se controlar as variáveis GDS e BAI, a significãncia não se manteve, sugerindo uma influência negativa dos sintomas de depressão e ansiedade no grupo TDAH sobre a auto percepção relacionada ao funcionamento da memória atual comparada a esse mesmo funcionamento quando eram mais jovens. 
No inventário IQCODE, os informantes do grupo TDAH pontuaram mais, indicando uma percepção de maior comprometimento nesse grupo quando comparado às respostas dos informantes do grupo controle.

A descrição da apresentação dos sintomas atuais do grupo TDAH, encontrase na Tabela 5 .

Tabela 5 - Apresentação sintomatológica do grupo TDAH

\begin{tabular}{lcc}
\hline & $\mathrm{N}=28$ & $\%$ \\
\hline Desatento & 10 & 35,71 \\
Hiperativo-impulsivo & 1 & 3,57 \\
Combinado & 17 & 60,71 \\
\hline
\end{tabular}

NOTA: foram considerados 5 ou mais sintomas de desatenção e/ou hiperatividade atuais durante os últimos seis meses e apresentados como "frequente" ou "muito frequente".

As análises descritivas das informações sobre condições clínicas e uso de medicações, encontram-se na Tabela 6.

Nas análises dos resultados dos dados clínicos, os grupos não se diferenciaram quanto a presença de doenças/condição clínica, mas se diferenciaram quanto ao uso de antidepressivos $(p<0,001)$ com o grupo TDAH apresentando uma maior frequência, sendo um correlato de uma maior frequência quanto a presença de depressão (TDAH: $n=13 / 46,4 \%$ versus grupo controle: $n=3 / 8,6 \% ; p=0,001$ ) verificada durante as avaliações. O tempo de utilização de antidepressivo na amostra variou entre oito meses e cinco anos.

Verificou-se ainda, uma tendência $(p=0,054)$ no grupo TDAH de maior frequência de sujeitos que referiram algum problema cardíaco, demonstrada também pela diferença significativa $(p=0,020)$ entre as proporções em cada um dos grupos, sendo, $21,4 \%(n=6)$ no grupo TDAH e $2,9 \%(n=1)$ no grupo controle. No grupo TDAH, cinco sujeitos já apresentaram arritmia leve, e um dos sujeitos tem implante de stent. No grupo controle, um dos voluntários tem diagnóstico de ponte miocárdica. Todos faziam acompanhamento médico e encontravam-se assintomáticos durante a pesquisa. 
Tabela 6 - Condições clínicas e uso de medicações

\begin{tabular}{|c|c|c|c|}
\hline & $\begin{array}{l}\text { TDAH } \\
(\mathrm{n}=28)\end{array}$ & $\begin{array}{c}\text { CONTROLE } \\
(\mathrm{n}=35)\end{array}$ & $p=$ \\
\hline Diabetes, $\mathrm{n}(\%)$ & $2(7,1)$ & $1(2,9)$ & $0,843^{\mathrm{a}}$ \\
\hline Hipertensão, n (\%) & $12(42,9)$ & $12(34,3)$ & $0,486^{\mathrm{a}}$ \\
\hline Pressão arterial sistólica, média \pm DP & $132,1 \pm 17,4$ & $127,3 \pm 15,9$ & $0,161^{\mathrm{b}}$ \\
\hline Pressão arterial distólica, média \pm DP & $77,9 \pm 9,6$ & $77,8 \pm 6,9$ & $0,721^{\mathrm{b}}$ \\
\hline Hipotensão, n (\%) & $0(0,0)$ & $0(0,0)$ & \\
\hline Hipotireoidismo, n (\%) & $1(3,6)$ & $5(14,3)$ & $0,314^{\mathrm{a}}$ \\
\hline Colesterol alto, n (\%) & $11(39,3)$ & $13(37,1)$ & $0,862^{\mathrm{a}}$ \\
\hline Cefaleia, n (\%) & $5(17,9)$ & $2(5,7)$ & $0,262^{\mathrm{a}}$ \\
\hline Quedas/Desmaios, n (\%) & $1(3,6)$ & $1(2,9)$ & $1,000^{\mathrm{a}}$ \\
\hline Problemas com sono, n (\%) & $10(35,7)$ & $6(17,1)$ & $0,092^{\mathrm{a}}$ \\
\hline Distúrbio Alimentar, n (\%) & $0(0,0)$ & $0(0,0)$ & \\
\hline Artrite reumatoide, $\mathrm{n}(\%)$ & $1(3,6)$ & $2(5,7)$ & $1,000^{\mathrm{a}}$ \\
\hline Artrose, n $(\%)$ & $5(17,9)$ & $4(11,4)$ & $0,717^{\mathrm{a}}$ \\
\hline Câncer, n (\%) & $1(3,6)$ & $6(17,1)$ & $0,194^{\mathrm{a}}$ \\
\hline Problemas cardíacos, n (\%) & $6(21,4)$ & $1(2,9)$ & $0,054^{\mathrm{a}}$ \\
\hline Herpes simplex, n (\%) & $14(50,0)$ & $13(37,1)$ & $0,306^{\mathrm{a}}$ \\
\hline Doença sexualmente transmissível, n (\%) & $1(3,6)$ & $1(2,9)$ & $1,000^{\mathrm{a}}$ \\
\hline Outras doenças*, n (\%) & $10(35,7)$ & $9(25,7)$ & $0,390^{\mathrm{a}}$ \\
\hline Deficiência auditiva (corrigida), n (\%) & $1(3,6)$ & $3(8,6)$ & $0,773^{\mathrm{a}}$ \\
\hline Deficiência visual (corrigida), n (\%) & $25(89,3)$ & $35(100)$ & $0,165^{\mathrm{a}}$ \\
\hline Fumantes, n (\%) & $3(10,7)$ & $1(2,9)$ & $0,453^{\mathrm{a}}$ \\
\hline Ex fumantes, n $(\%)$ & $12(42,9)$ & $15(42,9)$ & $1,000^{\mathrm{a}}$ \\
\hline Reposição hormonal, n (\%) & $3(1,7)$ & $9(25,7)$ & $0,132^{\mathrm{a}}$ \\
\hline Anti hipertensivo, n (\%) & $10(35,7)$ & $11(31,4)$ & $0,720^{\mathrm{a}}$ \\
\hline Antidepressivo, n (\%) & $13(46,4)$ & $2(5,7)$ & $<0,001^{\mathrm{a}}$ \\
\hline Ansiolíticos, n (\%) & $1(3,6)$ & $1(2,9)$ & $1,000^{\mathrm{a}}$ \\
\hline Antiarrítimicos, $\mathrm{n}(\%)$ & $3(10,7)$ & $1(2,9)$ & $0,453^{\mathrm{a}}$ \\
\hline Hipoglicemiantes, n (\%) & $1(3,6)$ & $1(2,9)$ & $1,000^{\mathrm{a}}$ \\
\hline Hipolipemiantes, n (\%) & $8(28,6)$ & $14(40,0)$ & $0,344^{\mathrm{a}}$ \\
\hline Outros medicamentos ${ }^{* *}, \mathrm{n}(\%)$ & $21(75,0)$ & $20(57,1)$ & $0,140^{\mathrm{a}}$ \\
\hline
\end{tabular}

NOTA: DP= desvio padrão; $\mathrm{n}=$ quantidade de sujeitos; ${ }^{\mathrm{a}}=$ Teste Qui-quadrado; ${ }^{\mathrm{b}}=$ Teste $t$ (corrigido para idade e sintomas de depressão/ansiedade); *= artrose, osteopenia, gastrite, hérnia de disco, hérnia de hiato; fibromialgia, rinete alérgica, câncer (sem sinais de doença ativa); $* *=$ vitaminas/polivitamínicos e minerais, fitoterápicos e homeopáticos. 
Quanto ao uso de metilfenidato, quatro sujeitos (14\%) do grupo TDAH referiram uso não contínuo. Um dos participantes fez uso entre 1997 e 2004. Dos outros três, um faz uso há dois anos, outro há três anos e o outro há quatro anos. Nenhum desses sujeitos estava em uso da medicação durante o período das avaliações. 


\subsection{Dados dos testes cognitivos}

Nas análises de variância para a comparação das médias entre os grupos, não se verificaram diferenças significantes, mantendo-se não significantes após controle do efeito das variáveis idade, GDS e BAI (Tabela 7). A ausência de diferenciação entre os grupos se deu tanto para os fatores dos cinco domínios cognitivos, quanto para a os resultados analisados isoladamente e referentes à memória operacional (dígitos ordem inversa e sequência número e letra), tempo de reação total de respostas e variabilidade de respostas do CPT-II, significando que a hipótese alternativa (HA) desse estudo, sobre os idosos com TDAH apresentarem resultados significantemente mais prejudicados nos testes cognitivos, não foi confirmada.

A Tabela 7 apresenta a análise de variância da média das funções cognitivas entre os grupos.

Tabela 7 - Análises dos dados cognitivos ajustados para idade, GDS e BAI

\begin{tabular}{lccc}
\hline \multicolumn{1}{c}{ Testes cognitivos } & $\begin{array}{c}\text { TDAH } \\
(\mathrm{n}=28) \\
\text { QI }\end{array}$ & $\begin{array}{c}\text { CONTROLES } \\
(\mathrm{n}=35)\end{array}$ & pédia \pm DP) \\
Fator: Funções executivas & $115,04 \pm 10,94$ & $113,91 \pm 10,13$ & 0,507 \\
Fator: Atenção & $-0,66 \pm 5,05$ & $0,53 \pm 7,20$ & 0,563 \\
Fator: Memória episódica & $-0,48 \pm 2,59$ & $0,38 \pm 3,34$ & 0,274 \\
Fator:Linguagem & $0,01 \pm 4,38$ & $-0,04 \pm 4,65$ & 0,568 \\
Fator: Funções visoespaciais/Visoconstrutivas & $-0,17 \pm 1,91$ & $0,14 \pm 1,64$ & 0,693 \\
Memória operacional verbal (Dígitos OI) & $5,50 \pm 1,87$ & $6,03 \pm 1,42$ & 0,536 \\
Memória operacional verbal (SNL) & $8,75 \pm 2,06$ & $8,97 \pm 2,77$ & 0,584 \\
CPT - Hit RT (em segundos) & $467,30 \pm 68,34$ & $454,76 \pm 55,02$ & 0,139 \\
CPT - Variabilidade (em segundos) & $10,86 \pm 8,94$ & $9,88 \pm 5,25$ & 0,409 \\
\hline
\end{tabular}

NOTA: DP= desvio padrão; $\mathrm{n}=$ quantidade sujeitos; $\mathrm{QI}=$ Quociente Intelectual; $\mathrm{SNL}=$ Sequência número e letra; $\mathrm{OI}=$ ordem inversa; $\mathrm{CPT}=$ Continuous Performance Test Hit $\mathrm{RT}=($ Reaction time $)$ tempo total de resposta. 
Adicionalmente, foram realizadas análises de correlação entre sintomas da ASRS (parte A e parte B), sintomas de depressão (GDS) e ansiedade (BAI) com os testes cognitivos (Tabela 8). Os resultados de toda a análise mostraram apenas uma tendência à correlação negativa entre sintomas de desatenção e resultados dos testes de atenção, não apresentando associações significativas ou de tendência entre as demais variáveis.

Tabela 8 - Correlação de Pearson entre ASRS (TDAH) e testes cognitivos (ajustados para idade)

\begin{tabular}{llcc}
\hline & \multicolumn{1}{c}{ Testes } & $r$ & $p=$ \\
\hline \multirow{2}{*}{ ASRS - Parte A } & Fator: Funções executivas & $-0,16$ & 0,219 \\
& Fator: Atenção & $-0,25$ & 0,051 \\
& Fator: Memória episódica & 0,04 & 0,780 \\
& Fator: Linguagem & 0,13 & 0,333 \\
& Fator: Funções visoespcial/visoconstrutiva & 0,06 & 0,640 \\
& Memória operacional verbal (Dígitos-OI) & $-0,12$ & 0,361 \\
& Memória operacional verbal (SNL) & $-0,07$ & 0,616 \\
& CPT - Hit RT & 0,09 & 0,501 \\
& CPT - Variabilidade & $-0,17$ & 0,193 \\
Fator: Funções executivas - Parte BR & $-0,06$ & 0,676 \\
& Fator: Atenção & $-0,04$ & 0,775 \\
& Fator: Memória episódica & $-0,00$ & 0,973 \\
& Fator: Linguagem & $-0,00$ & 0,988 \\
Fator: Funções visoespcial/visoconstrutiva & $-0,04$ & 0,793 \\
Memória operacional verbal (Dígitos-OI) & $-0,01$ & 0,946 \\
Memória operacional verbal (SNL) & 0,06 & 0,646 \\
CPT - Hit RT & 0,22 & 0,091 \\
CPT - Variabilidade & $-0,01$ & 0,957 \\
\hline
\end{tabular}

NOTA: $r=$ coeficiente de Pearson; SNL=Sequência número e letra; OI= ordem inversa; CPT=Continuous Performance Test Hit RT $=($ Reaction time $)$ tempo total de resposta. 
$\mathrm{Na}$ análise de correlação dos sintomas de depressão (GDS) com os testes cognitivos verificaram-se correlações negativas com dígitos ordem indireta $(r=-$ $0,35 ; p=0,006)$, sequência número e letra $(r=-0,27 ; p=0,036)$, memória episódica ( $r=-0,29 ; p=0,023)$ e cópia da Figura de Rey (função visoespacial) $(r=-0,34$; $p=0,007)$. Ou seja, mais sintomas de depressão se correlacionaram com escores mais baixos em funções de memória operacional (verbal), memória episódica e função visoespacial envolvendo planejamento.

Os sintomas de ansiedade (BAI) se correlacionaram positivamente ( $r=0,32$; $p=0,012$ ) com a variabilidade de respostas no teste CPT. Ou seja, mais sintomas de ansiedade se correlacionaram com maior variabilidade de respostas. 


\subsection{Dados das imagens pela volumetria baseada em voxels (VBM)}

Três sujeitos do grupo TDAH não conseguiram realizar o exame de neuroimagem devido a sintomas caustrofóbicos. Uma imagem de um dos voluntários do grupo controle foi excluída devido a artefato e não foi possível repetir o exame, resultando na análise das imagens com uma amostra final de 25 sujeitos no grupo TDAH (média de idade $=67 \pm 3,3 / 16$ mulheres) e 34 controles (média de idade $=69$ \pm 4,1 / 28 mulheres), permanecendo uma diferença significante em relação à idade entre os grupos.

A média da soma de voxels da SC (volume total da SC) e da SB (volume total da SB) das imagens segmentadas, totalizaram um volume de SC de 608,74 \pm 40,38 mililitros (mL) no grupo TDAH e de 606,42 $\pm 53,13 \mathrm{~mL}$ no grupo controle, e um volume de SB de 445,27 \pm 58,27 mL para o grupo TDAH e de 433,12 $\pm 42,63 \mathrm{~mL}$ para o grupo controle (teste $t$ não significante). No entanto, verificou-se um efeito significante de interação de sexo e diagnóstico $[\mathrm{F}(1,54)=4,14 ; p=0,047)]$, mostrando uma redução de volume de SC nos homens com TDAH $(p=0,038)$, mas não nas mulheres com TDAH. Não houve diferença entre os grupos para o volume total de SB (Tabela 9). Os volumes dos compartimentos cerebrais (SC e SB) das mulheres, em ambos os grupos, apresentaram-se menores quando comparados aos homens, sendo esse resultado já esperado ${ }^{153}$.

Tabela 9 - Distribuição das médias e desvios padrão por grupo e por sexo na SC e SB

\begin{tabular}{lcccc}
\hline & $\begin{array}{c}\text { TDAH } \\
(\text { Homens }) \\
(\mathrm{n}=9)\end{array}$ & $\begin{array}{c}\text { TDAH } \\
\text { Mulheres }) \\
(\mathrm{n}=16)\end{array}$ & $\begin{array}{c}\text { Controles } \\
(\text { Homens }) \\
(\mathrm{n}=6)\end{array}$ & $\begin{array}{c}\text { Controles } \\
(\text { Mulheres }) \\
(\mathrm{n}=28)\end{array}$ \\
\hline $\mathrm{SC}$ & $628,08 \pm 55,03^{*}$ & $597,85 \pm 25,36$ & $657,03 \pm 61,06^{*}$ & $595,57 \pm 45,48$ \\
$\mathrm{SB}$ & $474,58 \pm 78,55$ & $428,79 \pm 36,55$ & $478,75 \pm 40,39$ & $423,35 \pm 36,83$ \\
\hline
\end{tabular}

NOTA: $*=(p=0.047)$ 
$\mathrm{Na}$ análise exploratória (ANCOVA) em todo o cérebro a procura de diferenças regionais (aumento ou redução) de VSC entre os dois grupos, uma significante diferença foi encontrada após correção para múltiplas comparações. Relativo aos controles, o grupo TDAH apresentou um cluster de voxels de VSC mais reduzido com um pico de significância no giro frontal medial orbital direito ( $p=0,014$ FWE-corrigido, 413 voxels, $\mathrm{t}=5,61, \mathrm{z}=4,96 ; p=0,002$ não corrigido; coordenadas: $\mathrm{x}=12 ; \mathrm{y}=44 ; \mathrm{z}=-8$ ) correspondendo a área de Brodmann (BA) 10, estendendo-se em direção ao giro frontal superior medial, giro frontal superior e o córtex do cíngulo anterior subgenual (Figura 3).
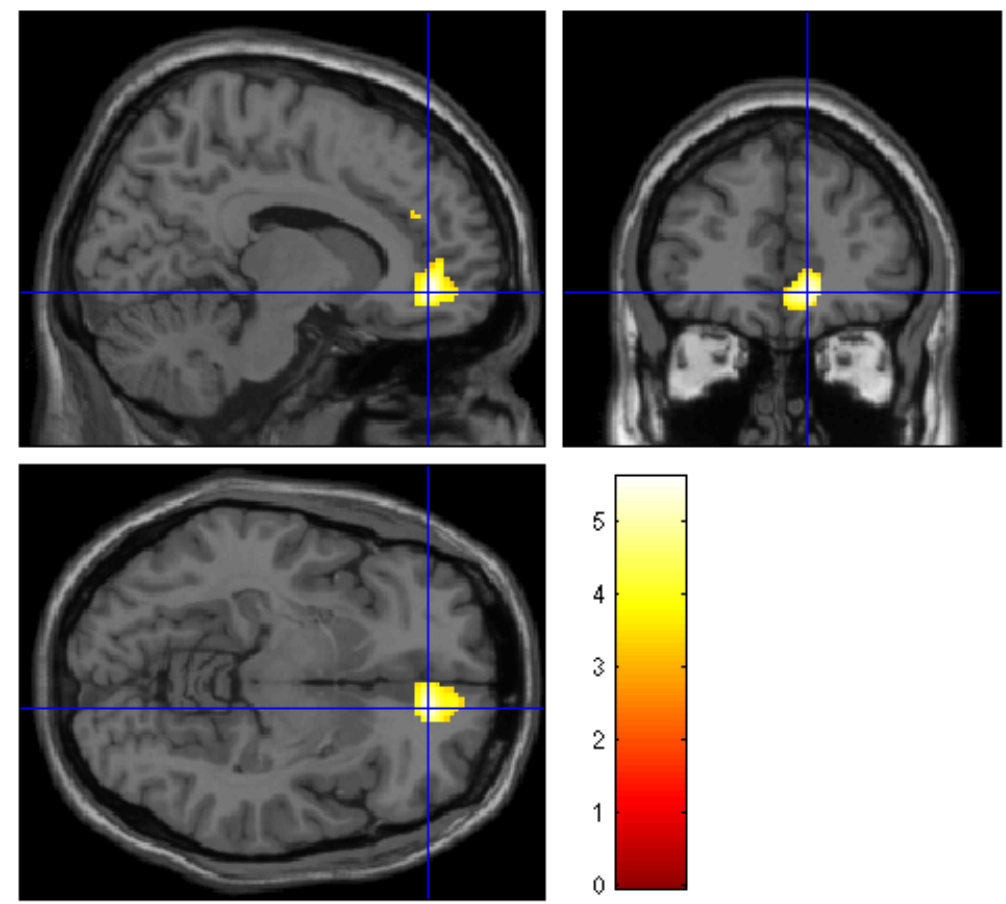

LEGENDA: A intersecção evidencia o pico de significância estatística máxima, ressaltada em amarelo, localizada no giro frontal medial orbital estendendo-se para o giro superior frontal medial, frontal superior e córtex do cíngulo anterior subgenual do hemisfério direito. Esta região apresenta diferença estatisticamente significante para $\mathrm{p} \leq 0,05$ após a correção para comparações múltiplas $(p=0,014 \mathrm{FWE}$-corrigido, 413 voxels, $\mathrm{t}=$ $5,61, z=4,96 ; p=0,002$ não corrigido; coordenadas: $x=12 ; y=44 ; z=-8$ ). A barra colorida representa $o$ valor $T$.

Figura 3 - Cluster com redução no volume de substância cinzenta (VSC) na comparação entre os grupos TDAH e controles evidenciado na análise exploratória em todo o cérebro 
A avaliação do VSC regional entre os grupos, usando a abordagem SVC nas regiões cerebrais previstas a priori (ROIs: CPFDL, COF, LPI, gânglios da base, amigdala, hipocampo e cerebelo), não mostrou diferenças significantes ou que excederam 10 voxels contíguos. Idem para outras regiões do córtex do cíngulo anterior, além da encontrada na análise do cérebro todo.

A análise de correlação não mostrou associações significantes entre sintomas de desatenção, de hiperatividade/ impulsividade, depressão e ansiedade com regiões de SC ao se explorar o volume total de SC. Entretanto, as análises desses efeitos sobre as ROIs (Tabela 10), evidenciam uma correlação negativa significante entre sintomas de desatenção e clusters de VSC no CA (bilateralmente) e positivamente associados com um cluster de VSC no cerebelo esquerdo (região IX do lobo posterior). Os sintomas de hiperatividade/impulsividade foram negativamente associados com um cluster de VSC no COF esquerdo, sub-região correspondendo à BA 47.

Tabela 10 - Correlações de sintomas do TDAH, de depressão e de ansiedade em regiões de interesse da SC previstas a priori (ajustadas para idade e sexo)

\begin{tabular}{|c|c|c|c|c|c|c|}
\hline & ROIs & $\begin{array}{c}\text { MNI* } \\
\text { coordinates } \\
(\mathrm{x}, \mathrm{y}, \mathrm{z})\end{array}$ & Voxels $^{\mathrm{a}}$ & $\mathrm{T}$ & $\mathrm{Z}$ & $\mathrm{p}_{\mathrm{FWE}}=$ \\
\hline \multirow{5}{*}{$\begin{array}{l}\text { ASRS- parte A } \\
\text { (desatenção) }\end{array}$} & \multirow{2}{*}{$\downarrow \mathrm{CA}$ (direito) } & $6,28,-8$ & 81 & 4,99 & 3,97 & 0,008 \\
\hline & & $2,24,28$ & 16 & 4,18 & 3,50 & 0,037 \\
\hline & \multirow{2}{*}{$\downarrow \mathrm{CA}$ (esquerdo) } & $0,36,8$ & 216 & 5,03 & 3,99 & 0,009 \\
\hline & & $0,24,30$ & 37 & 4,96 & 3,96 & 0,010 \\
\hline & $\uparrow$ Cerebelo (esquerdo) & $-6,-48,-32$ & 30 & 5,67 & 4,33 & 0,016 \\
\hline \multirow[t]{2}{*}{$\begin{array}{l}\text { ASRS- parte B } \\
\text { (Hiperatividade/ } \\
\text { Impulsividade) }\end{array}$} & $\begin{array}{l}\downarrow \text { Frontal inferior orbital } \\
\text { (esquerdo) }\end{array}$ & $-44,42,-12$ & 169 & 5,49 & 4,24 & 0,004 \\
\hline & $\downarrow$ Ganglios da base (direito) & $20,10,8$ & 197 & 4,68 & 3,80 & 0,025 \\
\hline \multirow[t]{2}{*}{$\begin{array}{l}\text { GDS } \\
\text { (Depressão) }\end{array}$} & $\begin{array}{l}\downarrow \text { Ganglios da base } \\
\text { (esquerdo) }\end{array}$ & $-16,12,12$ & 392 & 5,87 & 4,42 & 0,003 \\
\hline & $\uparrow$ Parietal inferior (direito) & $52,-38,28$ & 45 & 5,32 & 4,15 & 0,012 \\
\hline
\end{tabular}

NOTA: $\mathrm{CA}=$ Cíngulo Anterior; $\downarrow=$ negativamente correlacionado; $\uparrow=$ positivamente correlacionado; $*$ MNI coordinates = coordenadas de voxel de significância máxima estatística dentro de cada cluster, conforme padrão do Montreal Neurological Institute; $a=$ número de voxels contíguos que excederam o limiar inicial de $\mathrm{p}<0,001$ (corrigido) no mapa paramétrico estatístico; Z-cores = para o voxel de significância máxima estatística dentro de cada cluster; $\mathrm{T}=$ valor do voxel de significância máxima estatística dentro de cada cluster; PFWE: $\leq 0,05$. 
Os escores dos sintomas de depressão foram negativamente correlacionados com clusters de VSC nos gânglios da base (bilateralmente), mais especificamente no caudado. Foram também positivamente correlacionados com um cluster de VSC no LPI direito, mais especificamente, no giro supramarginal (BA 40). Não foi encontrada associação significante entre sintomas de ansiedade e as ROIs.

$\mathrm{Na}$ análise exploratória em todo o cérebro à procura de diferenças regionais (aumento ou redução) de VSB, não foi encontrada diferenças significantes entre os grupos após correção para múltiplas comparações. Também não houve correlações significantes do VSB com sintomas clínicos. 


\subsection{Dados das imagens por tensores de difusão (DTI)}

Os resultados das análises pelo TBSS não apresentaram diferenças significantes entre os grupos quanto à média dos índices de AF nos tratos de fibras de SB no cérebro todo e nas análises das ROIs.

Nas análises de correlações da AF com sinotomas do TDAH, depressão e ansiedade, verificado no cérebro todo, não encontramos associações significantes. Entretanto, encontramos correlações significantes ao se investigar a AF em tratos das ROIs. Os resultados das análises de correlações entre AF e sintomas clínicos, encontram-se na Tabela 11.

Tabela 11 - Correlações de sintomas do TDAH, de depressão e de ansiedade e AF em fibras da SB (ajustadas para idade e sexo)

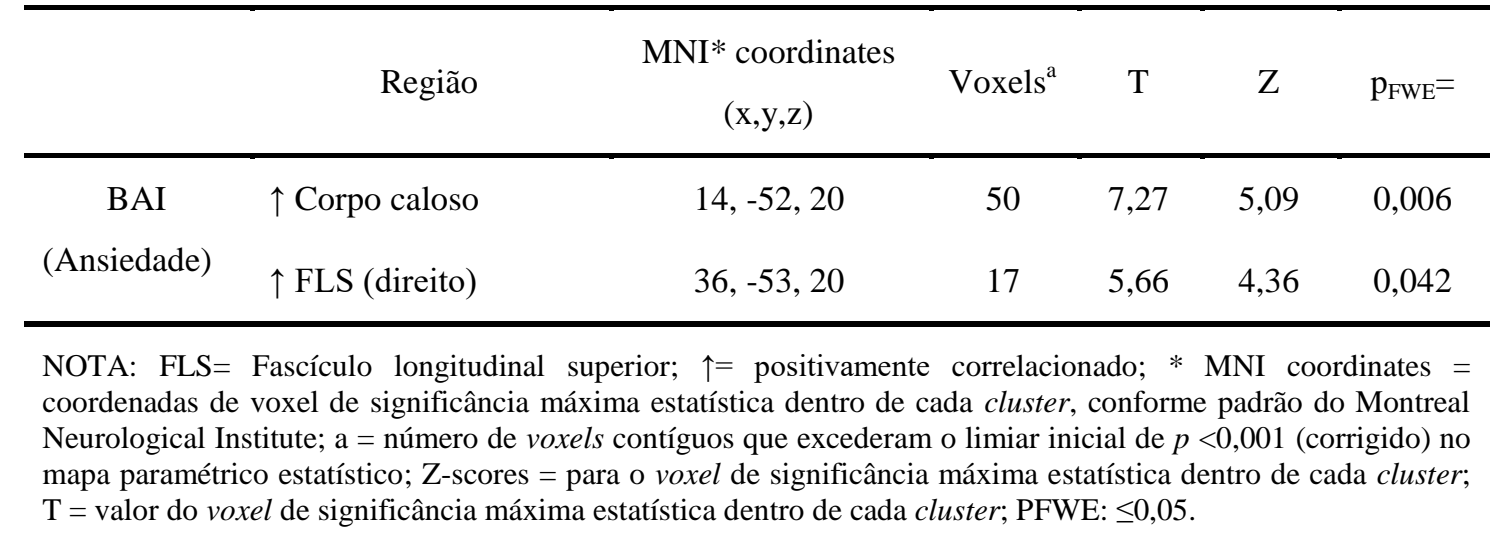

As análises de correlação aplicadas às ROIs mostraram uma correlação positiva entre sintomas de ansiedade e AF no corpo caloso e no fascículo longitudinal superior direito. Não houve correlações significantes entre AF e sintomas clínicos nas demais ROIs (porção retrolenticular da capsula interna, coroa radiada, radiação talâmica posterior, estrato sagital, cíngulo e tapetum). 


\subsection{Resumo dos principais achados}

\section{Dados clínicos:}

A apresentação sintomatológica do TDAH é predominantemente do tipo combinado, seguido do desatento e em menor frequência o hiperativo/impulsivo.

O grupo TDAH apresentou mais sintomatologia para depressão e ansiedade.

Os grupos não se diferenciaram quanto à condição clínica, embora o grupo TDAH apresentou uma tendência de maior frequência de problemas cardíacos (leves e/ou assintomáticos, em acompamnhamento médico) e uma maior frequência no uso de antidepressivos.

O grupo TDAH apresentou um desempenho inferior no computo total do MEEM (porém com escores mínimos acima do ponto de corte) e uma maior variabilidade de respostas. Os grupos não se diferenciaram nos itens "atenção e cálculo" e "evocação".

O grupo TDAH apresentou uma pior autopercepção da memória atual comparada á quando eram mais jovens (MAC-Q) e esta percepção foi influenciada pelos sintomas de depressão e ansiedade.

Os familiares/informantes dos sujeitos do grupo TDAH tiveram uma pior percepção sobre a memória/funcionalidade atual quando os compararam á de dez anos atrás (IQCODE).

Sintomas de desatenção se correlacionaram negativamente com a variável idade e positivamente com os sintomas de depressão e ansiedade. Hiperatividade /impulsividade se correlacionaram positivamente com sintomas de depressão e ansiedade e houve tendência a se correlacionar negativamente coma idade. Não houve correlação dos sintomas do TDAH com o sexo. 


\section{Dados dos testes cognitvos:}

Os grupos não se diferenciaram estatisticamente nos testes cognitivos.

Correlações entre sintomas clínicos e testes cognitivos: Não houve correlação dos sintomas de TDAH com os testes cognitivos, mas verificou-se uma tendência de correlação negativa de escores de desatenção com os testes de desatenção. Os sintomas de depressão apresentaram uma correlação negativa com memória operacional, memória episódica e função visoespacial envolvendo planejamento. Os sintomas de ansiedade apresentaram uma correlação positiva com a variável "variabilidade" do teste CPT.

\section{Dados pelo VBM:}

Diferenças entre os grupos: $\mathrm{O}$ grupo TDAH apresentou um menor volume total de SC com um efeito significativo de interação do sexo por diagnóstico, mostrando um volume mais reduzido nos homens com TDAH, mas não nas mulheres com TDAH. O grupo TDAH também apresentou um cluster de VSC mais reduzido no giro frontal medial orbital direito e que se estende para o giro frontal superior medial, frontal superior e córtex do CA subgenual. Não houve diferenças significativas no VSB total ou regional.

Correlações entre sintomas clínicos, estruturas cerebrais e volume total e regional de SC e SB: A desatenção se correlacionou negativamente com um cluster de VSC no CA (bilateralmente) e positivamente com um cluster de VSC no lobo posterior do cerebelo (região IX). Hiperatividade/impulsividade correlacionou-se negativamente com um cluster de VSC na região frontal inferior orbital esquerda. Depressão se correlacionou negativamente com cluster de VSC nos gânglios da base (caudado) bilateralmente e, positivamente, com um cluster de VSC da região parietal inferior direita. Não houve correlação significante de volume total de SC e SB com sintomas clínicos. 


\section{Dados pelo DTI:}

As análises pelo TBSS não mostraram diferenças significantes nos índices de AF na comparação entre os grupos

Correlações entre sintomas clínicos e AF: Sintomas de ansiedade apresentaram uma correlação positiva com a AF do corpo caloso e do fascículo longitudinal superior direito. Não se verificaram correlações significantes entre sintomas clínicos e demais ROIs dos tratos de SB. 



\section{Discussão}





\section{DISCUSSÃO}

\subsection{Dados demográficos e clínicos}

Os grupos se diferenciaram estatisticamente $(p<0,001)$ quanto a idade (TDAH $=66,8 \pm 3,1$; Controles $=69,0 \pm 4,1$ ), sendo que esta variável foi controlada nas análises posteriores, clínica e cognitiva. A amostra deste estudo é predominantemente feminina, não apresentando diferença estatística na distribuição do sexo. Os grupos mostraram-se também homogêneos quanto aos anos de escolaridade e o QI. Estudos recentes com idosos com TDAH não reportam o quociente intelectual da amostra. Apesar do bom nível intelectual, mais sujeitos do grupo TDAH (75\%) tiveram repetência ao longo dos anos de estudos que o grupo controle $(25,7 \%)$, além de repetirem mais vezes que os do grupo controle (TDAH, média $=1,7 \pm 1,4$; Controles, 0,5 $\pm 1,2$ ). Esses dados corroboram com achados de estudos realizados anteriormente sobre o impacto negativo do TDAH no âmbito educacional em amostras mais jovens ${ }^{1,154}$, inclusive em amostra com QI superior ${ }^{154}$.

Relativamente aos controles, os idosos com TDAH apresentaram uma maior frequência de estado civil "casados", mas também uma maior frequência de separação conjugal/divórcio e menos viuvez. Uma maior frequência de separação conjugal ou que nunca se casaram foi reportada no estudo com idosos de Michielsen et al. ${ }^{117}$. A frequência mais balanceada entre casados e separados/divorciados e uma frequência maior de viuvez no grupo controle, pode sugerir maior estabilidade nos relacionamentos conjugais do que no grupo TDAH.

A apresentação dos sintomas do TDAH teve uma distribuição maior para a apresentação combinada, seguida do desatento e depois hiperativo/impulsivo. Em termos de distribuição percentual, encontra-se próximas às taxas encontradas no estudo com idosos de Michielsen et al. ${ }^{113}$, assim como em estudos com amostras mais jovens ${ }^{71}$. 
Os sintomas de desatenção e hiperatividade/impulsividade verificados pela ASRS apresentaram uma significante correlação negativa com a idade, sendo esse resultado consistente com os achados verificados nos estudos de Michielsen et al. ${ }^{110}$ e Das et al. ${ }^{23}$ sobre uma redução dos sintomas centrais do TDAH em pessoas mais velhas. Tanto os sintomas de desatenção quanto de hiperatividade/impulsividade não se correlacionaram com o sexo, contrariando o resultado de uma revisão de Nussbaum $^{6}$ na qual reportam sutis diferenças entre homens e mulheres com TDAH, porém com uma predominância de sintomas de desatenção em mulheres com TDAH.

Ainda quanto aos sintomas verificados pela ASRS, Das et al. ${ }^{23}$ verificaram que a versão reduzida dessa escala (que consiste na verificação de seis sintomas do TDAH) parece medir a variação com a mesma equivalência, o mesmo constructo psicológico tanto em pessoas de meia idade quanto em idosos. Em nosso estudo, utilizamos a versão completa (com 18 itens) e, embora fosse esperado que a escala diferenciasse os grupos, a diferença foi bastante significante mesmo após o ajustamento estatístico para depressão, ansiedade e idade, sugerindo que a escala, desenvolvida com base nos critérios do DSM-IV e pensada para adultos mais jovens, é válida como instrumento de rastreio de sintomas nesses idosos. A média dos escores relacionados à frequência de desatenção (média=26,8 $\pm 4,7$ ) e de hiperatividade (média=22,2 $\pm 6,6$ ) cuja soma fica acima dos 24 pontos considerado fortemente sugestivo para o TDAH, embora não haja ainda dados normativos para a população brasileira ${ }^{127}$, havendo a necessidade de estudos para se verificar o melhor ponto de corte também para a população idosa.

No Mini Exame do Estado Mental (MEEM), a análise da comparação das médias dos escores entre os grupos, mostraram uma diferença estatisticamente significante. O grupo TDAH apresentou uma pontuação mais baixa e maior variabilidade de respostas (Figura 2) quando comparado ao grupo controle. Porém, essa diferença não é clinicamente relevante, uma vez que dentro dessa variabilidade, os escores mínimos ficaram acima de 24 (ponto de corte sugerido por Folstein et al. ${ }^{125}$ ) não sendo sugestivos de declínio cognitivo. Não se verificaram diferenças entre os grupos ao serem analisadas, isoladamente, as variáveis "memória" e "atenção e cálculo" consideradas críticas, tanto para o grupo TDAH quanto para os idosos no 
geral. Esses resultados sugerem ainda, que na prática clínica, este instrumento provavelmente não tem acurácia para diferenciar idosos com e sem TDAH.

Com relação à percepção dos informantes sobre o desempenho funcional e alterações cognitivas dos sujeitos, verificadas através do IQCODE, a média dos escores, embora apresentou diferença significante $(p=0,004)$ com maior pontuação para o grupo TDAH (média $=3,2 \pm 0,2$ ) fica abaixo de todos os pontos de corte para comprometimento cognitivo para a versão breve, conforme citados no estudo de Jorm $^{155}$, sendo o menor escore de 3,38 e o maior 3,88. Sabe-se que esse questionário tem um aspecto positivo pelo fato de parecer não sofrer influência das habilidades pré-morbidas, mas existem outros desvantajosos, como a possibilidade de os informantes terem dificuldade em distinguir ansiedade e depressão quando de uma piora cognitiva; a possibilidade das respostas sofrerem influência de algumas características, como a saúde mental (ex.: presença de depressão e ansiedade) dos informantes e a qualidade da relação entre informante e sujeito ${ }^{136,155}$. Essas questões devem ser consideradas em uma avaliação clínica individual, uma vez que os idosos com TDAH apresentam mais sintomas para depressão e ansiedade, além de o desgaste nos relacionamentos ser uma característica entre os sujeitos com $\mathrm{TDAH}^{122,156}$ podendo provocar vieses nas respostas.

Nas análises do questionário MAC-Q, a diferença significante não se manteve após ajustamento para depressão (GDS) e ansiedade (BAI) (covariáveis verificadas separadamente e em conjunto), sugerindo que os sintomas de depressão e ansiedade influenciaram a autopercepção sobre declínio da memória no grupo TDAH. Alguns estudiosos do envelhecimento têm sugerido que em idosos, as queixas subjetivas de memória tendem a ser potencializadas por morbidades psicológicas, como depressão e ansiedade ${ }^{157}$, o que pode sugerir uma sobreposição na percepção desses idosos com TDAH. Em um estudo de Fuermaier et al. ${ }^{36}$ eles verificaram que instrumentos de avaliação subjetiva e objetiva da cognição foram considerados sensíveis na revelação de disfunções cognitivas em adultos não-idosos com TDAH e concluem que tanto as medições subjetivas quanto as objetivas são importantes para a prática clínica, mas podem fornecer tipos distintos de informações e capturar diferentes aspectos da cognição. 
Os grupos se diferenciaram significativamente quanto á sintomatologia atual para depressão e ansiedade, verificadas através da GDS e BAI, com o grupo TDAH apresentando mais sintomas, corroborando com um estudo anterior realizado por Semeijn et al. ${ }^{121}$ em idosos com TDAH, sendo congruente também com os achados de estudos sobre comorbidades em amostras mais jovens com TDAH ${ }^{10,11}$. No presente estudo, o grupo TDAH, apresenta também maior frequência no uso atual de antidepressivos, sendo este resultado, um correlato dos sintomas de depressão. No entanto, são pacientes com depressão leve e estavam em remissão dos sintomas ou com sintomatologia leve, conforme verificado pelas pontuações da escala GDS. O mesmo ocorrendo quanto aos sintomas de ansiedade medidos pela BAI (ver Tabela 3). Maior frequência no uso de antidepressivos no grupo de idosos com TDAH quando comparados a controles também foi encontrado no estudo de Semeijn et al. ${ }^{121}$

Os grupos não se diferenciam quanto à presença de doenças físicas e outras condições clínicas, conforme apresentadas (Tabela 6), embora o grupo TDAH apresente uma tendência de maior frequência de problemas cardíacos quando comparado ao grupo controle, com predominância de arritmia leve, porém encontravam-se assintomáticos durante a pesquisa e todos fazem acompanhamento

médico. Esse resultado corrobora parcialmente com o estudo de Semeijn et al. ${ }^{119}$, no qual não encontraram diferença significante entre os grupos para doença física crônica, entretanto verificaram uma associação positiva significativa entre o número de sintomas de TDAH e doenças cardiovasculares.

\subsection{Dados dos testes cognitivos}

A hipótese inicial de que o grupo com TDAH apresentasse maior prejuizo em funções cognitivas, como em funções executivas, atenção e memória, além de maior variabilidade no tempo de reação não se confirmou. Conforme apresentado na Tabela 6, com exceção do fator de memória episódica, o grupo TDAH apresenta resultados inferiores aos controles, porém não são estatísticamente significantes. Os testes analisados individualmente para verificar a memória operacional, também não 
apresentaram diferenças estatisticamente significantes, contrariando alguns estudos com amostras mais jovens ${ }^{12,28,36,158}$. No estudo com idosos realizado por Semeijn et al. ${ }^{120}$, eles verificaram um resultado mais prejudicado da memória operacional no grupo de idosos com TDAH, porém, mediado por sintomas de depressão. Apesar de não encontrarmos diferença significante entre os grupos no presente estudo, nosso resultado está em concordância com o estudo de Semeijn et al. ${ }^{120}$ quanto a correlação negativa de sintomas de depressão com a memória operacional. Além disso, verificamos que sintomas de depressão também se correlacionaram negativamente à memória episódica e função visoespacial envolvendo planejamento.

$\mathrm{Na}$ análise individual do tempo de reação total (CPT- Hit RT) e variabilidade no tempo de reação, verificou-se uma média maior no grupo TDAH, significando um desempenho mais prejudicado, porém as diferenças são pequenas, não apresentando significância estatística. A ausência de diferenciação entre os grupos sobre as médias do tempo de reação total (CPT- Hit RT) está consistente com a maioria de estudos de medidas de tempo de reação (total) com amostras mais jovens, como visto nos estudos de Gmehlin et al. ${ }^{34}$, Kuntsi e Klein ${ }^{31}$ e na revisão meta-analítica de Kofler et al. $^{33}$, embora alguns estudos ${ }^{8,70}$ encontraram um pior desempenho no tempo de reação total (RT) no grupo TDAH utilizando o teste CPT. Por outro lado, a ausência de diferenciação entre os grupos sobre a variabilidade no tempo de reação verificado pelo CPT se difere do encontrado na maioria da literatura ${ }^{8,30,31,33,34}$, os quais indicam uma maior variabilidade no tempo de reação e sugerem essa diferenciação como um possível marcador para o TDAH em amostras mais jovens. No presente estudo, verificamos ainda uma correlação positiva de sintomas de ansiedade com a variabilidade de respostas no teste CPT.

É pouco provável que tenha ocorrido algum impacto nos resultados dos testes cognitivos relacionado ao uso de medicação para o TDAH nos pacientes idosos, tendo em vista a idade e o pouco tempo de uso, além de não estarem medicados no período das avaliações da pesquisa ${ }^{14}$.

Como grupo, os resultados do grupo TDAH comparáveis aos do grupo controle podem refletir uma característica dessa faixa etária, a qual representa uma nova etapa do desenvolvimento. Pode sugerir também que os testes não são 
suficientemente sensíveis para distinguir as deficiências cognitivas nesse período, uma vez que esses idosos trazem queixas sobre seu funcionamento diário. Em um

estudo de Fuermaier et al. ${ }^{36}$ eles verificaram que, tanto a testagem subjetiva (com escalas de autoavaliação sobre funcionamento cognitivo) quanto a testagem psicométrica (avaliação neuropsicológica objetiva) são úteis em revelar disfunções cognitivas em adultos não-idosos com TDAH, porém, as queixas cognitivas subjetivas não poderiam ser previstas por medidas objetivas de cognição e viceversa. Embora ambas sejam importantes na prática clínica, elas podem revelar tipos distintos de informações e diferentes aspectos de funcionamento cognitivo. Nossos achados sobre uma pior autopercepção subjetiva (verificadas pela MAC-Q) e percepção dos informantes (verificadas pelo IQCODE) sobre aspectos da cognição e funcionalidade em contraste com os resultados dos testes objetivos são congruentes com as informações trazidas no estudo de Fuermaier et al. ${ }^{36}$ e indicam a necessidade de futuros estudos incorporarem testes subjetivos com maior validade ecológica na comparação entre grupos com e sem o TDAH.

\subsection{Dados das imagens pela volumetria baseada em voxels (VBM)}

\subsubsection{Volume total de SC e SB}

Um dos objetivos dessa pesquisa foi investigar se idosos com TDAH apresentariam diferenças no volume total e/ou regional na SC e na SB quando comparados a controles. Os resultados confirmaram parcialmente nossas hipóteses, revelando anormalidades quanto ao volume total e regional de SC, mas não para SB. Mesmo com um número pequeno de sujeitos do sexo masculino em nossa amostra, um significante efeito de interação de sexo por grupo foi verificado, mostrando um volume total de SC mais reduzido em homens com TDAH quando comparados aos controles, além de um maior volume total de SC quando comparados com as mulheres em ambos os grupos. Nosso achado é congruente com alguns estudos 
anteriores com amostras mais jovens ${ }^{47,48,64,66}$ que sugerem um volume ou espessura cortical total de SC mais reduzida em pacientes com TDAH. Embora haja estudos que não encontraram diferença significante entre pacientes e controles ${ }^{53,57,60,159}$. Ao contrário do nosso, a maioria dos estudos que reportaram achados sobre anormalidades em estruturas cerebrais no TDAH incluíram predominantemente homens nas amostras e a localização e a progressão dessas anormalidades ao longo da vida e os efeitos de diferenças sexuais sobre essas anormalidades ainda não são bem compreendidos ${ }^{43,55}$. Alguns pesquisadores propõem que existem déficits neurobiológicos regionais distintos subjacentes ao TDAH nos dois sexos ${ }^{6,53,55}$. Almeida Montes et al. ${ }^{55}$ se baseiam na hipótese de um mecanismo disfuncional envolvendo a formação da via neural, arborização axonal e dendrítica e sinaptogênese na infância, seguida por mecanismos disfuncionais de poda sináptica e eliminação competitiva na adolescência até a idade adulta para explicar uma espessura cortical mais reduzida no TDAH. Além disso, uma influência hormonal explicaria as diferenças entre os sexos. As formações sinápticas e os progressos no desenvolvimento do circuito cerebral ocorrem atingindo um pico de espessura aproximadamente aos nove anos de idade. Almeida Montes et al. ${ }^{55}$ verificaram um aumento na espessura cortical em adolescentes do sexo feminino que pode refletir o efeito da indução de estrogênio no brotamento axonal e aumento do número de sinapses. Na idade adulta, não verificou-se excesso de sinapses e uma predominância de redução da espessura cortical foi observada em ambos os sexos, mas foi menos pronunciada no sexo feminino, sugerindo a influência desse hormônio nas diferenças entre os sexos.

Os achados sobre a SB branca na literatura apresentam-se heterogêneos. A ausência de diferenciação no volume total de SB no presente estudo é congruente com alguns estudos em amostras de adultos jovens ${ }^{53,60}$. Por outro lado, difere do estudo de Seidman et al. ${ }^{64}$, o qual reporta um aumento na SB e de alguns estudos com crianças e adolescentes ${ }^{49,66,67}$, os quais reportam significante redução na SB quando comparados a controles. Seidman et al. ${ }^{64}$ fazem algumas considerações sobre o achado discrepante daquele estudo comparado à literatura e algumas dessas considerações também servem ao presente estudo. As amostras dos estudos são diferentes em vários aspectos, como a presença e gravidade de comorbidades 
psiquiátricas, média de QI e fases diferentes de processos de desenvolvimento neurocognitvo ao longo da vida. A SB pode continuar se desenvolvendo para além dos vinte anos de idade ${ }^{45,67,105}$ e mesmo nos estudos de envelhecimento com pessoas saudáveis os resultados ainda não encontram-se bem estabelecidos ${ }^{105}$.

\subsubsection{Volumes regionais de SC}

$\mathrm{Na}$ análise exploratória em todo o cérebro, a procura de diferenças regionais, verificou-se que o grupo TDAH quando comparado ao grupo controle, apresentou um cluster de SC mais reduzido com um pico de voxels de significância estatística no giro frontal orbital medial (BA 10) e que se estende para o giro superior medial frontal, giro superior frontal e córtex do cíngulo anterior subgenual do hemisfério direito. Hesslinger et al. ${ }^{56}$ também encontraram uma redução de SC no córtex órbitofrontal em uma amostra pequena de adultos do sexo masculino, porém no hemisfério esquerdo. Por outro lado, Seidman et $\mathrm{al}^{64}$, falharam ao tentar replicar o achado de Hesslinger et al. ${ }^{56}$ na mesma região no estudo de 2006 e em 2011 encontraram um maior volume de SC no córtex orbito-frontal no grupo TDAH, mas não apresentaram alguma hipótese sobre esse achado. Um menor volume ou menor espessura cortical no córtex pré-frontal direito também tem sido encontrado em estudos anteriores envolvendo amostras de crianças, adolescentes e adultos com TDAH ${ }^{6,42,55}$. Além disso, a redução de VSC verificada também no CA está em concordância com vários outros estudos anteriores ${ }^{42,52,59,60}$, apesar de não haver unanimidade quanto a lateralidade do achado.

Uma meta-análise realizada por Dickestein et al. ${ }^{160}$, verificou que o giro frontal medial (BA 10) teve significantemente mais ativação em sujeitos com TDAH do que os controles, quando se considerou apenas os estudos que examinaram especificamente resposta inibitória. O giro frontal medial (BA 10) em conjunto com o CA, estão envolvidos na avaliação e expressão de emoções negativas e tem um papel regulador em relação às regiões límbicas envolvidas no processamento e gerações de respostas emocionais. Além disso, o CA tem um importante papel no 
controle da cognição (como tomada de decisão, memória operacional), modulação atencional e controle executivo ${ }^{161}$.

Ao se aplicar a análise SVC sobre as ROIs do CPFDL,COF, IPL, hipocampo, amígdala e cerebelo, não se evidenciaram diferenças significantes entre os grupos. A análise SVC sobre a ROI do cíngulo anterior não evidenciou novo achado acima do limite de 10 voxels ou com estatística significante.

A análise de correlação entre os dados clínicos e de neuorimagem, mostrou uma significante correlação negativa de sintomas de desatenção com um cluster no VSC do CA (bilateralmente) e uma correlação positiva com um cluster no VSC do cerebelo esquerdo (lóbulo IX). Este achado é consistente com o resultado da meta análise realizada por Stoodley $^{61}$ na qual encontrou um VSC significantemente reduzido no lóbulo IX (bilateralmente) no grupo TDAH, cujos clusters faziam parte das redes neuronais dorsal e ventral da atenção. Em um outro estudo, clusters de volume em outras regiões cerebelares, como tonsil e culmen, foram negativamente associados com a gravidade de sintomas de desatenção em adultos com TDAH ${ }^{162}$.

Os escores de hiperatividade/impulsividade foram negativamente correlacionados com um cluster no volume do giro frontal orbital inferior (parsorbitalis, BA 47) esquerdo. A BA 47 esquerda, tem sido implicada em tarefas de resposta inibitória ${ }^{160}$. No estudo de Depue et al. ${ }^{57}$, com uma amostra de adultos nãoidosos com TDAH (com a apresentação do tipo combinado na infância), encontraram correlações entre a performance comportamental (sobre três medidas: velocidade de processamento, resposta inibitória e variabilidade de resposta) e a região frontal orbital inferior (no total: pars-orbitalis, pars-opercularis e pars-triangularis). Entretanto, a resposta inibitória foi negativamente correlacionada com o VSC no pars-opercularis. Isto poderia sugerir que distintas regiões do córtex frontal inferior estão envolvidas em ações de inibição motora e outras respostas comportamentais, como aquelas encontradas nos itens de hiperatividade/impulsividade da escala ASRS. Além do mais, as conexões da parte lateral do COF lateral com neurônios dos córtices pré-frontal lateral e do CA são relevantes na tradução de informações motivacionais em ação. Déficits nestas regiões podem resultar em falha no monitoramento de conflitos, levando a impulsividade/hiperatividade e uma 
modulação ineficiente do controle cognitivo e alocação da atenção. ${ }^{62}$. Por outro lado, no estudo de Onnink et al. ${ }^{53}$, com uma amostra de adultos não-idosos, os sintomas de hiperatividade/impulsividade se correlacionaram com o volume do caudado, além de os pacientes homens mostrarem redução no volume do caudado direito quando comparados aos controles e sugerem um distinto déficit neurobiológico subjacente ao TDAH em homens e mulheres.

Com relação aos sintomas comórbidos de depressão e ansiedade verificados no grupo TDAH, apesar de os escores refletirem um estado clínico de depressão e ansiedade leves, verificou-se uma significante associação dos escores de depressão negativamente correlacionados com a região esquerda dos gânglios da base (caudado) e positivamente correlacionados com o LPI (BA 40) direito. Os estudos que investigaram a relação entre depressão maior e mudanças cerebrais em sujeitos com TDAH são escassos e eles não reportam diferenças ou correlações com gânglios da base ou regiões do LPI, nem são conclusivos quanto ao envolvimento de outras regiões, como o hipocampo e amigdala ${ }^{53,60,163,164}$. Mudanças nos gânglios da base são comuns em crianças com TDAH e parece diminuir com o passar do tempo da infância para a vida adulta ${ }^{43}$, mas também encontra-se anormalidades em adultos ${ }^{42,51-}$ ${ }^{54}$, e seu papel sobre problemas na regulação emocional com mais anos de vida ainda não é claro. Além disso, os escores de depressão também foram positivamente correlacionados com o LPI direito. O LPI faz parte de um sistema neural, o qual subserve atenção e inibição comportamental. Anormalidades com um aumento de densidade de SC nos lobos parietais inferiores (bilateralmente) foi encontrado em adolescentes com TDAH, mas sem correlação com sintomas ${ }^{45}$, enquanto uma ativação mais reduzida nessa região em tarefa de controle inibitório foi encontrada em adultos com TDAH quando comparados a controles ${ }^{165}$. Adultos com TDAH referem com mais frequência eventos ruins, aumento de instabilidade e intensidade de emoções negativas na vida diária, assim como mostram respostas equivocadas ou negativas para emoções positivas ${ }^{166}$. Então, uma vez que há estreitas conexões entre região parietal e outras regiões (como CCA e caudado) envolvendo os processos atencionais e inibitórios, uma hipótese para os sintomas de depressão correlacionados positivamente com o volume de um cluster no LPI poderia refletir uma distinta rede neuronal, pelo menos nesse grupo de idosos com TDAH. Porém, mais estudos 
envolvendo sujeitos idosos e não idosos com TDAH são necessários para investigar essa hipótese.

Nós não temos como saber em nosso estudo se os achados verificados na SC representam o resultado de um desenvolvimento anormal, além de um atraso maturacional (corroborando com a hipótese de estudos anteriores) ${ }^{55}$ e/ou o quanto está influenciado (positivamente ou negativamente) pelo envelhecimento. Como mencionado anteriormente, alguns autores sugerem que na velhice algumas áreas do cérebro que se desenvolvem mais tarde na infância se degeneram mais cedo quando comparadas a outras áreas cerebrais ${ }^{99}$ e o nosso principal achado no córtex préfrontal é uma das regiões que mais sofrem atraso maturacional, segundo o estudo de Shaw et al. ${ }^{46}$ Por outro lado, Hoogman et al. ${ }^{27}$ sugerem um atraso maturacional em regiões subcorticais em crianças com TDAH (até 14 anos) e um atraso no início de degeneração em adultos (21-63 anos) com TDAH, nestas mesmas regiões subcorticais, a partir da quarta década de vida. Supondo que futuros estudos confirmem esta hipótese, pacientes com TDAH sofreriam menos o efeito do envelhecimento sobre algumas regiões cerebrais do que nos controles, possivelmente reduzindo as diferenças nas comparações entre grupos. Entretanto, temos que considerar as limitações daquele estudo, discutidas pelos próprios autores, como a questão de um número reduzido de amostras com idade acima de 25 anos e insuficiente dados de efeitos da idade após os 60 anos.

\subsection{Dados das imagens por tensores de difusão (DTI)}

Não foram encontradas diferenças significantes entre os grupos quanto aos valores de AF nos tratos de fibras da SB na análise do cérebro todo, nem nas análises das ROIs. Esse resultado se difere dos resultados de estudos com amostras de adultos jovens ${ }^{68,69,71,76,80,81}$ que encontraram redução de $\mathrm{AF}$ em várias regiões e outros que encontraram aumento na $\mathrm{AF}^{58,63}$, seja na análise do cérebro todo ou na análise das ROIs. Um recente estudo de Bouziane et al. ${ }^{71}$ comparou crianças (10-12 anos) e adultos (23-40 anos) com TDAH do sexo masculino com seus respectivos controles 
em um mesmo estudo e investigou o efeito da modulação da idade no desenvolvimento da SB. Eles não encontraram diferenças nos valores de $\mathrm{AF}$ entre crianças com TDAH e as crianças do grupo controle, enquanto os sujeitos adultos com TDAH tiveram valores de AF reduzidos em várias regiões quando comparados aos controles adultos. Eles sugerem que idade é um fator que afeta a SB do cérebro no TDAH e esse resultado aponta para um processo de ruptura na maturação da SB e estaria de acordo com a literatura que sugere ser o TDAH um transtorno do neurodesenvolvimento. As alterações na estrutura da SB ocorreriam a partir da adolescência, explicando assim as diferenças em adultos com TDAH. Porém, os mecanismos neurobiológicos que causam as mudanças volumétricas e de difusividade no cérebro em desenvolvimento e no envelhecimento ainda não são totalmente entendidas ${ }^{105}$. Assim como na SC, não é conhecido o momento nessa trajetória da SB no qual o cérebro de pessoas com TDAH antinge o desenvolvimento máximo antes da deterioração no envelhecimento e o quanto e como isto pode influenciar positiva ou negativamente as anormalidades já existentes. No estudo de Westlye et al. ${ }^{105}$, como já citado anteriormente, eles verificaram um desenvolvimento prolongado nos feixes do cíngulo dorsal e para-hipocampal e uma deterioração relativamente tardia nessas mesmas estruturas destoando da hipótese de que regiões que amadurecem mais tarde, degeneram mais precocemente ao longo da vida. Considerando o atraso maturacional do cérebro no TDAH, especulamos se o desenvolvimento dos feixes do cíngulo, por exemplo, não seriam ainda mais prolongados do que nos indivíduos saudáveis, uma vez que encontramos redução no volume de SC nessa estrutura, mas não encontramos anormalidades na comparação entre grupos na AF, nem associações entre AF e os sintomas cardinais do TDAH, ou seja, o cíngulo alcançaria mais tardiamente a normalização ou algo próximo disso. $\mathrm{O}$ outro achado adicional de nosso estudo foi encontrado nas análises de correlação entre AF e sintomas clínicos, onde encontramos correlações positivas significantes entre ansiedade e a AF em clusters do FLS (direito) e corpo caloso (Tabela 11). Não encontramos correlações significantes entre sintomas de desatenção, hiperatividade e depressão com AF.

Vários estudos têm encontrado alterações na AF nos tratos do FLS $^{63,68,71,72,80,81}$ e do corpo caloso ${ }^{71,72,76,77}$ e são alguns dos achados mais replicados 
em estudos do TDAH em adultos e crianças. Porém, esses estudos não investigaram associações com comorbidades como depressão e ansiedade e não fica claro se sintomas considerados clinicamente não significantes estariam presentes nas amostras, o que dificulta algum tipo de comparação e inferência.

Embora nem todas as hipóteses do presente estudo foram confirmadas, pela primeira vez, análises de neuroimagem foram realizadas em idosos com TDAH e revelaram anormalidades em estruturas corticais na região pré-frontal, região esta, implicada e bem documentada nos estudos do TDAH. Esse achado foi identificado na análise exploratória de todo o cérebro e, segundo Rubia et al. ${ }^{167}$, estudos que englobam todo o cérebro são os mais adequados para descobrir as anormalidades cerebrais mais sólidas sem limitar necessariamente o volume de busca. Além disso, empregamos parâmetros mais exigentes nas análises das imagens, como o limiar de $\mathrm{p}<0,001$ (corrigido para múltiplas comparações). Não encontramos diferenças em outras regiões de interesse a priori, além do giro do cíngulo, e não temos como comprovar possíveis efeitos do envelhecimento sobre os achados em virtude do modelo transversal dessa pesquisa. Assim, algumas questões ainda permanecem, como: até que ponto um curso alterado (como um atraso no desenvolvimento) em regiões selecionadas do cérebro estaria funcionando como um fator neuroprotetor no envelhecimento? O quanto as possíveis compensações entre os tratos de SB e áreas corticais podem favorecer (ou não) o cérebro de pessoas com o TDAH ou mudar o curso dos sintomas? Diante dessa complexidade, fica evidente o desafio e o longo caminho que ainda precisamos percorrer no entendimento do processo de envelhecimento no TDAH. Há a necessiadde de futuros estudos investigarem os efeitos do envelhecimento levando em consideração algumas teorias que tentam explicar as mudanças cognitivas e estruturais, conforme mencionado anteriormente no texto. 

9 Limitações do Estudo 



\section{LIMITAÇÕES DO ESTUDO}

Algumas limitações devem ser consideradas nesse estudo. Uma delas foi a impossibilidade de quantificar formalmente os sintomas na infância para se verificar a gravidade e tipos de apresentação dos sintomas nesse período. Apesar disso, quase metade da amostra (47\%) teve algum informante (como irmãos, primos, amigos) contemporâneo que corroborou com informações sobre os sintomas na infância. Em não tendo um informante, o critério para inclusão foi a necessidade de o voluntário apresentar relato claro de suas dificuldades na infância. A amostra foi adquirida por conveniência. Pode haver um viés de seleção onde os critérios de inclusão mais restritos propiciaram uma amostra composta por pessoas relativamente preservadas quanto à presença de comorbidades clínicas e/ou psiquiátricas. Por outro lado, a amostra sendo relativamente preservada, permite verificar alterações (na cognição e/ou neuroimagem) que se relacionem mais "pura" e especificamente aos sintomas centrais do TDAH. Além disso, a amostra é relativamente pequena e composta por poucos homens, não sendo possível dividir a amostra para análises por sexo, nem por subtipos de apresentação (desatenção, hiperatividade/impulsividade ou combinação). Também não foi possível dividir a amostra pela presença ou ausência de sintomas comórbidos de depressão e ansiedade. No entanto, devido à alta frequência de depressão (entre outras comorbidades) em adultos com TDAH, pode ser difícil obter amostras de idosos exclusivamente com sintomas centrais de TDAH. Mais estudos são necessários para replicar essas condições e estudos longitudinais seriam mais adequados para responder várias questões levantadas nesse estudo. 

10 Conclusões 



\section{CONCLUSÕES}

No geral, os achados deste estudo são congruentes com estudos anteriores em adultos com TDAH e reforçam a persistência de sintomas clínicos e comportamentais na velhice. Embora o estudo tenha um desenho transversal, os resultados sugerem uma trajetória, sem uma aparente sobreposição das alterações cogntivas que chegam com o envelhecimento, mostrando um desempenho cognitivo menos prejudicado, comparável aos controles sem o transtorno, podendo indicar um prognóstico mais positivo na velhice do que o hipotetizado inicialmente nesse estudo. Mesmo com a influência dos sintomas de depressão sobre a testagem cognitiva objetiva, relacionada à memória operacional, memória episódica e função visoespacial, e da ansiedade sobre a variabilidade de respostas no teste CPT, o grupo TDAH não se diferenciou estatisticamente do grupo controle. O presente estudo é o primeiro a evidenciar correlatos neurais em regiões relacionadas às funções atencionais, ao controle executivo e ao processamento afetivo no idoso com TDAH, sugerindo que prejuízos em regiões fronto estriatal e fronto parietal-cerebelar verificados em adultos com TDAH persistem na velhice, e esses idosos mantém uma funcionalidade mais prejudicada e comorbidades. Mais estudos com amostras maiores e um desenho longitudinal são necessários, o que permitirá que os efeitos modificadores do sexo, subtipos de apresentação e comorbidades também sejam examinados. 

11 Referências 



\section{REFERÊNCIAS}

1. American Psychiatric Association. Diagnostic and statistical manual of mental disorders (DSM-5). 5th. Ed. Washington DC: American Psychiatric Publishing; 2013.

2. Caye A, Swanson J, Thapar A, Sibley M, Arseneault L, Hechtman L, et al. Life span studies of ADHD - conceptual challenges and predictors of persistence and outcome. Curr Psychiatry Rep. 2016;18(12):111.

3. Gobbo MA, Louzã MR. Influence of stimulant and non-stimulant drug treatment on driving performance in patients with attention deficit hyperactivity disorder: A systematic review. Eur Neuropsychopharmacol. 2014;24:1425-43.

4. Klein RG, Mannuzza S, Ramos Olazagasti M a, Roizen Belsky E, Hutchison JA, Lashua-Shriftman E, et al. Clinical and Functional Outcome of Childhood ADHD 33 Years Later. Arch Gen Psychiatry. 2012;69(12):1295-303.

5. Barbaresi WJ, Colligan RC, Weaver AL, Voigt RG, Killian JM, Katusic SK. Mortality, ADHD, and Psychosocial Adversity in Adults With Childhood ADHD: A Prospective Study. Pediatrics. 2013;131(4):637-44.

6. Nussbaum NL. ADHD and female specific concerns: A review of the literature and clinical implications. J Atten Disord. 2012;16(2):87-100.

7. Arnett AB, Pennington BF, Willcutt EG, DeFries JC, Olson RK. HHS Public Access. J Child Psychol Psychiatry. 2015;56(6):632-9.

8. Chuang W, Yeh C, Huang W, Gau S, Shyu J, Ma K. Brain Dopamine Transporter Availability is Associated with Response Time ( RT ) Variability 
in Adults with ADHD. Neuropsychiatry (London). 2017;7(5):522-32.

9. Williamson D, Johnston C. Gender differences in adults with attentiondeficit/hyperactivity disorder: A narrative review. Clin Psychol Rev. 2015;40:15-27.

10. McIntosh D, Kutcher S, Binder C, Levitt A, Fallu A, Rosenbluth M. Adult ADHD and comorbid depression: A consensus-derived diagnostic algorithm for ADHD. Neuropsychiatr Dis Treat. 2009;5:137-50.

11. Cumyn L, French L, Hechtman L. Comorbidity in adults with attention-deficit hyperactivity disorder. Can J Psychiatry. 2009;54(10):673-83.

12. Faraone S V., Asherson P, Banaschewski T, Biederman J, Buitelaar JK, Ramos-Quiroga JA, et al. Attention-deficit/hyperactivity disorder. Nat Rev Dis Prim. 2015;1:1-22.

13. Barkley RA. The Nature of ADHD, Hystory. In: Attention-deficit hyperactivity disorder: a handbook for diagnosis and treatment: Third Edition. New York: Guilford Publications; 2006. p.3-52. Chapter 1.

14. Louzã MR, Cols. Transtorno de déficit de atenção/hiperatividade: Breve história do conceito. In: TDAH - Transtorno de déficit de atenção/hiperatividade ao longo da vida. Porto Alegre: Artmed; 2010. p. 1321.

15. Parens E, Johnston J. Facts, values, and attention-deficit hyperactivity disorder (ADHD): An update on the controversies. Child Adolesc Psychiatry Ment Health. 2009;3(1):1-17.

16. Salum GA, Sonuga-Barke E, Sergeant J, Vandekerckhove J, Gadelha A, Moriyama TS, et al. Mechanisms underpinning inattention and hyperactivity: Neurocognitive support for ADHD dimensionality. Psychol Med. 
2014;44(15):3189-201.

17. Marcus DK, Barry TD. Does attention-deficit/hyperactivity disorder have a dimensional latent structure? A taxometric analysis. J Abnorm Psychol. 2011;120(2):427-42.

18. Shaw P, Gilliam M, Liverpool M, Weddle C, Malek M, Sharp W, et al. Cortical development in typically developing children with symptoms of hyperactivity and impulsivity: Support for a dimensional view of attention deficit hyperactivity disorder. Am J Psychiatry. 2011;168(2):143-51.

19. Nigg JT, John OP, Blaskey LG, Huang-Pollock CL, Willcutt EG, Hinshaw SP, et al. Big Five dimensions and ADHD symptoms: Links between personality traits and clinical symptoms. J Pers Soc Psychol. 2002;83(2):451-69.

20. Lubke GH, Hudziak JJ, Derks EM, van Bijsterveldt TCEM, Boomsma DI. Maternal ratings of attention problems in ADHD: Evidence for the existence of a continuum. J Am Acad Child Adolesc Psychiatry. 2009;48(11):1085-93.

21. Biederman J, Mick E, Faraone S V. Age-dependent decline of symptoms of attention deficit hyperactivity disorder: Impact of remission definition and symptom type. Am J Psychiatry. 2000;157(5):816-8.

22. Guldberg-Kjär T, Johansson B. Old people reporting childhood AD/HD symptoms: Retrospectively self-rated AD/HD symptoms in a population-based Swedish sample aged 6580. Nord J Psychiatry. 2009;63(5):375-82.

23. Das D, Cherbuin N, Easteal S, Anstey KJ. Attention deficit/hyperactivity disorder symptoms and cognitive abilities in the late-life cohort of the PATH through life study. PLoS One. 2014;9(1):e86552.

24. American Psychiatric Association. Diagnostic and statistical manual of mental disorders: DSM-IV-TR. 4th. Ed. Washington DC: American 
Psychiatric Publishing; 1994.

25. Organização Mundial da Saúde. Classificação dos trnastronos mentais e de comportamento da CID-10. Descrições clínicas e diretrizes diagnósticas. Porto Alegre: Artmed; 1993.

26. Corbisiero S, Stieglitz RD, Retz W, Rösler M. Is emotional dysregulation part of the psychopathology of ADHD in adults? ADHD Atten Deficit Hyperact Disord. 2013;5:83-92.

27. Hoogman M, Bralten J, Hibar DP, Mennes M, Zwiers MP, Schweren LSJ, et al. Subcortical brain volume differences in participants with attention deficit hyperactivity disorder in children and adults: a cross-sectional mega-analysis. The Lancet Psychiatry. 2017;4(4):310-9.

28. Mostert JC, Onnink AMH, Klein M, Dammers J, Harneit A, Schulten T, et al Cognitive heterogeneity in adult attention deficit/hyperactivity disorder: A systematic analysis of neuropsychological measurements. Eur Neuropsychopharmacol. 2015;25:2062-74.

29. de Zeeuw P, Weusten J, van Dijk S, van Belle J, Durston S. Deficits in Cognitive Control, Timing and Reward Sensitivity Appear to be Dissociable in ADHD. PLoS One. 2012;7(12).

30. Sjöwall D, Roth L, Lindqvist S, Thorell LB. Multiple deficits in ADHD: Executive dysfunction, delay aversion, reaction time variability, and emotional deficits. J Child Psychol Psychiatry Allied Discip. 2013;54(6):619-27.

31. Kuntsi J, Klein C. Intraindividual variability in ADHD and its implications for research of causal links. Curr Top Behav Neurosci. 2012;9:67-91.

32. Tamm L, Narad ME, Antonini TN, O’Brien KM, Hawk LW, Epstein JN. Reaction Time Variability in ADHD: A Review. Neurotherapeutics. 
2012;9(3):500-8.

33. Kofler MJ, Rapport MD, Sarver DE, Raiker JS, Orban SA, Friedman LM, et al. Reaction time variability in ADHD: A meta-analytic review of 319 studies. Clin Psychol Rev. 2013;33(6):795-811.

34. Gmehlin D, Fuermaier ABM, Walther S, Debelak R, Rentrop M, Westermann $\mathrm{C}$, et al. Intraindividual variability in inhibitory function in adults with ADHD - An Ex-gaussian approach. PLoS One. 2014;9(12):1-19.

35. Kim S, Liu Z, Glizer D, Tannock R, Woltering S. Adult ADHD and working memory: neural evidence of impaired encoding. Clin Neurophysiol. 2014;125(8):1596-603.

36. Fuermaier ABM, Tucha L, Aschenbrenner S, Kaunzinger I, Hauser J, Weisbrod M, et al. Cognitive impairment in adult ADHD-perspective matters! Neuropsychology. 2015;29(1):45-58.

37. Hervey AS, Epstein JN, Curry JF. Neuropsychology of adults with attentiondeficit/hyperactivity disorder: A meta-analytic review. Neuropsychology. 2004;18(3):485-503.

38. Gmehlin D, Fuermaier ABM, Walther S, Tucha L, Koerts J, Lange KW, et al. Attentional lapses of adults with attention deficit hyperactivity disorder in tasks of sustained attention. Arch Clin Neuropsychol. 2016;31(4):343-57.

39. Tucha L, Fuermaier ABM, Koerts J, Buggenthin R, Aschenbrenner S, Weisbrod M, et al. Sustained attention in adult ADHD: time-on-task effects of various measures of attention. J Neural Transm. 2017;124(1):39-53.

40. Skodzik T, Holling H, Pedersen A. Long-term memory performance in adult ADHD: A meta-analysis. J Atten Disord. 2017;21(4):267-83. 
41. Valera EM, Faraone S V., Murray KE, Seidman LJ. Meta-Analysis of structural imaging findings in attention-deficit/hyperactivity disorder. Biol Psychiatry. 2007;61(12):1361-9.

42. Moreno-Alcázar A, Ramos-Quiroga JA, Radua J, Salavert J, Palomar G, Bosch R, et al. Brain abnormalities in adults with Attention Deficit Hyperactivity Disorder revealed by voxel-based morphometry. Psychiatry Res - Neuroimaging. 2016;254(2016):41-7.

43. Frodl T, Skokauskas N. Meta-analysis of structural MRI studies in children and adults with attention deficit hyperactivity disorder indicates treatment effects. Acta Psychiatr Scand. 2012;125(2):114-26.

44. Ellison-Wright I, Ellison-Wright Z, Bullmore E. Structural brain change in attention deficit hyperactivity disorder identified by meta-analysis. $B M C$ Psychiatry. 2008;8:51.

45. Sowell ER, Peterson BS, Thompson PM, Welcome SE, Henkenius AL, Toga AW. Mapping cortical change across the human life span. Nat Neurosci. 2003;6(3):309-15.

46. Shaw P, Eckstrand K, Sharp W, Blumenthal J, Lerch JP, Greenstein D, et al. Attention-deficit/hyperactivity disorder is characterized by a delay in cortical maturation. PNAS. 2007;104(49):19649-54.

47. Noordermeer SDS, Luman M, Greven CU, Veroude K, Faraone S V., Hartman CA, et al. Structural brain abnormalities of attentiondeficit/hyperactivity disorder with oppositional defiant disorder. Biol Psychiatry. 2017;82(9):642-50.

48. Ambrosino S, De Zeeuw P, Wierenga LM, Van Dijk S, Durston S. What can cortical development in attention-deficit/ hyperactivity disorder teach us about the early developmental mechanisms involved? Cereb Cortex. 
2017;27(9):4624-34.

49. Castellanos FX. Anatomic magnetic resonance imaging studies of attentiondeficit/hyperactivity disorder. Dialogues Clin Neurosci. 2002;4(4):444-8.

50. Nakao T, Radua J, Rubia K, Mataix-Cols D. Gray matter volume abnormalities in ADHD: Voxel-based meta-analysis exploring the effects of age and stimulant medication. American Journal of Psychiatry. 2011:168(11):1154-63.

51. Montes LGA, Ricardo-Garcell J, de la Torre LB, Alcántara HP, García RBM, Fernández-Bouzas A, et al. Clinical correlations of grey matter reductions in the caudate nucleus of adults with attention deficit hyperactivity disorder. $J$ Psychiatry Neurosci. 2010;35(4):238-46.

52. Seidman LJ, Biederman J, Liang L, Valera EM, Monuteaux MC, Brown A, et al. Gray matter alterations in adults with attention-deficit/hyperactivity disorder identified by voxel based morphometry. Biol Psychiatry. 2011;69(9):857-66.

53. Onnink AMH, Zwiers MP, Hoogman M, Mostert JC, Kan CC, Buitelaar J, et al. Brain alterations in adult ADHD: Effects of gender, treatment and comorbid depression. Eur Neuropsychopharmacol. 2014;24:397-409.

54. Proal E, Reiss PT, Klein RG, Mannuzza S, Gotimer K, Ramos-Olazagasti MA, et al. Brain Gray Matter Deficits at 33-Year Follow-Up in Adults with Attention-Deficit/Hyperactivity Disorder Established in Childhood. Arch Gen Psychiatry. 2011;68(11):1122-34.

55. Almeida Montes LG, Prado Alcántara H, Martínez García RB, De La Torre LB, Ávila Acosta D, Duarte MG. Brain cortical thickness in ADHD. J Atten Disord. 2012;17(8):641-54. 
56. Hesslinger B, Tebartz van Elst L, Thiel T, Haegele K, Hennig J, Ebert D. Frontoorbital volume reductions in adult patients with attention deficit hyperactivity disorder. Neurosci Lett. 2002;328:319-21.

57. Depue BE, Burgess GC, Bidwell LC, Willcutt EG, Banich MT. Behavioral performance predicts grey matter reductions in the right inferior frontal gyrus in young adults with combined type ADHD. Psychiatry Res. 2010;182(3):231-7.

58. Pironti VA, Lai MC, Müller U, Dodds CM, Suckling J, Bullmore ET, et al. Neuroanatomical abnormalities and cognitive impairments are shared by adults with attention-deficit/hyperactivity disorder and their unaffected firstdegree relatives. Biol Psychiatry. 2014;76(8):639-47.

59. Makris N, Seidman LJ, Valera EM, Biederman J, Monuteaux MC, Kennedy $\mathrm{DN}$, et al. Anterior cingulate volumetric alterations in treatment-naïve adults with ADHD: A pilot study. J Atten Disord. 2010;13(4):407-13.

60. Amico F, Stauber J, Koutsouleris N, Frodl T. Anterior cingulate cortex gray matter abnormalities in adults with attention deficit hyperactivity disorder: A voxel-based morphometry study. Psychiatry Res Neuroimaging. 2011;191(1):31-5.

61. Stoodley CJ. Distinct regions of the cerebellum show gray matter decreases in autism, ADHD, and developmental dyslexia. Front Syst Neurosci. 2014;8(May):1-17.

62. Makris N, Liang L, Biederman J, Valera EM, Brown AB, Petty C, et al. Toward defining the neural substrates of ADHD: A controlled structural MRI study in medication-naïve adults. J Atten Disord. 2015;19(11):944-53.

63. Chaim TM, Zhang T, Zanetti M V., Da Silva MA, Louzã MR, Doshi J, et al. Multimodal magnetic resonance imaging study of treatment-näive adults with 
attention-Deficit/hyperactivity disorder. PLoS One. 2014;9(10):1-13.

64. Seidman LJ, Valera EM, Makris N, Monuteaux MC, Boriel DL, Kelkar K, et al. Dorsolateral Prefrontal and Anterior Cingulate Cortex Volumetric Abnormalities in Adults with Attention-Deficit/Hyperactivity Disorder Identified by Magnetic Resonance Imaging. Biol Psychiatry. 2006;60:107180.

65. Ahrendts J, Rüsch N, Wilke M, Philipsen A, Eickhoff SB, Glauche V, et al. Visual cortex abnormalities in adults with ADHD: a structural MRI study. World J Biol Psychiatry. 2011;12(4):260-70.

66. Narr KL, Woods RP, Lin J, Kim J, Phillips OR, Del'Homme M, et al. Widespread cortical thinning is a robust anatomical marker for attention deficit / hyperactivity disorder (ADHD). J Am Acad Child Adolesc Psychiatry. 2009;48(10):1014-22.

67. Vaidya C. Neurodevelopmental abnormalities in ADHD. Curr Top Behav Neurosci. 2012;9:49-66.

68. Makris N, Buka SL, Biederman J, Papadimitriou GM, Hodge SM, Valera EM, et al. Attention and executive systems abnormalities in adults with childhood adhd: A DT-MRI study of connections. Cereb Cortex. 2008;18(5):1210-20.

69. Shaw P, Sudre G, Wharton A, Weingart D, Sharp W, Sarlls J. White matter microstructure and the variable adult outcome of childhood attention deficit hyperactivity disorder. Neuropsychopharmacology. 2015;40:746-54.

70. Rossi ASU, de Moura LM, de Mello CB, de Souza AAL, Muszkat M, Bueno OFA. Attentional profiles and white matter correlates in attentiondeficit/hyperactivity disorder predominantly inattentive type. Front Psychiatry. 2015;6:122. 
71. Bouziane C, Caan MWA, Tamminga HGH, Schrantee A, Bottelier MA, de Ruiter MB, et al. ADHD and maturation of brain white matter: A DTI study in medication naive children and adults. NeuroImage Clin. 2018; 17:53-59.

72. Aoki Y, Cortese S, Castellanos FX. Research Review: Diffusion tensor imaging studies of attention-deficit/hyperactivity disorder: meta-analyses and reflections on head motion. J Child Psychol Psychiatry Allied Discip. 2018;59(3):193-202.

73. O'Donnel L, Westin CF. An introduction to diffusion tensor image analysis. Neurosurg Clin N Am. 2011;22(2):1-23.

74. Assaf Y, Pasternak O. Diffusion tensor imaging (DTI)-based white matter mapping in brain research: A review. J Mol Neurosci. 2008;34(1):51-61.

75. van Ewijk H, Heslenfeld DJ, Zwiers MP, Buitelaar JK, Oosterlaan J. Diffusion tensor imaging in attention deficit/hyperactivity disorder: A systematic review and meta-analysis. Neuroscience and Biobehavioral Reviews. 2012;19031106.

76. Onnink AMH, Zwiers MP, Hoogman M, Mostert JC, Dammers J, Kan CC, et al. Deviant white matter structure in adults with attention-deficit/hyperactivity disorder points to aberrant myelination and affects neuropsychological performance. Prog Neuropsychopharmacol Biol Psychiatry. 2015;63:14-22.

77. Chen L, Hu X, Ouyang L, He N, Liao Y, Liu Q, et al. A systematic review and meta-analysis of tract-based spatial statistics studies regarding attentiondeficit/hyperactivity disorder. Neurosci Biobehav Rev. 2016;68(37):838-47.

78. Tamm L, Barnea-Goraly N, Reiss AL. Diffusion tensor imaging reveals white matter abnormalities in attention-deficit/hyperactivity disorder. Psychiatry Res - Neuroimaging. 2012;202:150-4. 
79. Svatkova A, Nestrasil I, Rudser K, Goldenring Fine J, Bledsoe J, SemrudClikeman M. Unique white matter microstructural patterns in ADHD presentations - a diffusion tensor imaging study. Hum Brain Mapp. 2016;37(9):3323-36.

80. Konrad A, Dielentheis TF, El Masri D, Bayerl M, Fehr C, Gesierich T, et al. Disturbed structural connectivity is related to inattention and impulsivity in adult attention deficit hyperactivity disorder. Eur J Neurosci. 2010;31(5):9129.

81. Cortese S, Imperati D, Zhou J, Proal E, Klein RG, Mannuzza S, et al. White matter alterations at 33-year follow-up in adults with childhood attentiondeficit/hyperactivity disorder. Biol Psychiatry. 2013; 74(8):591-8.

82. Konrad A, Dielentheis TF, Masri D El, Dellani PR, Stoeter P, Vucurevic G, et al. White matter abnormalities and their impact on attentional performance in adult attention-deficit/hyperactivity disorder. Eur Arch Psychiatry Clin Neurosci. 2012;262(4):351-60.

83. Bode MK, Lindholm P, Kiviniemi V, Moilanen I, Ebeling H, Veijola J, et al. DTI abnormalities in adults with past history of attention deficit hyperactivity disorder: A tract-based spatial statistics study. Acta radiol. 2015; 56(8):990-6.

84. Kieling C, Schuh A, Gonçalves RRF, Chaves MLF. Bases biológicas do envelhecimento cognitivo. In: Cognição e Envelhecimento. Porto Alegre: Artmed; 2006. p. 47-61.

85. Hartshorne J, Germine L. When does cognitive functioning peak? The asynchronous rise and fall of different cognitive abilities across the life span. Psychol Sci. 2015;26(4):433-43.

86. Harada CN, Love MCN, Triebel K. Normal Cognitive Aging. Clin Geriatr Med. 2013;29(4):737-52. 
87. Sala-Llonch R, Bartrés-Faz D, Junqué C. Reorganization of brain networks in aging: a review of functional connectivity studies. Front Psychol. 2015;6(May):1-11.

88. MacDonald SWS, Karlsson S, Rieckmann A, Nyberg L, Backman L. Agingrelated increases in behavioral variability: Relations to losses of dopamine D1 receptors. J Neurosci. 2012;32(24):8186-91.

89. Murman DL. The impact of age on cognition. Semin Hear. 2015;36(3):1-24.

90. Mattos P, Paixão Jr CM. Avaliação cognitiva de idosos: envelhecimento e comprometimento cognitivo leve. In: Avaliação Neuropsicológica. Porto Alegre: Artmed; 2010. p. 247-53.

91. Park DC, Festini SB. Theories of memory and aging: A look at the past and a glimpse of the future. Journals Gerontol - Ser B Psychol Sci Soc Sci. 2017;72(1):82-90.

92. Cabeza R. Hemispheric asymmetry reduction in older adults: The HAROLD model. Psychol Aging. 2002;17(1):85-100.

93. Reuter-Lorenz PA, Cappell KA. Neurocognitive ageing and the compensation hypothesis. Curr Dir Psychol Sci. 2008;17(3):177-82.

94. Davis SW, Dennis N a, Daselaar SM, Fleck MS, Cabeza R. Qué PASA? The posterior-anterior shift in aging. Cereb Cortex. 2008;18(5):1201-9.

95. Reuter-Lorenz PA, Park DC. How Does it STAC Up? Revisiting the scaffolding theory of aging and cognition. Neuropsychol Rev. 2014;24(3):355-70.

96. Fjell AM, Walhovd KB. Structural brain changes in aging: courses, causes and cognitive consequences. Rev Neurosci. 2010;21:187-221. 
97. Raz N, Ghisletta P, Rodrigue KM, Kennedy KM, Lindenberger U. Trajectories of brain aging in middle-aged and older adults: Regional and individual differences. Neuroimage. 2010;51(2):501-11.

98. Fjell AM, McEvoy L, Holland D, Dale AM, Walhovd KB. What is normal in normal aging? Effects of aging, amyloid and Alzheimer's disease on the cerebral cortex and the hippocampus. Prog Neurobiol. 2014;117:20-40.

99. Tamnes CK, Walhovd KB, Dale AM, Østby Y, Grydeland H, Richardson G, et al. Brain development and aging: Overlapping and unique patterns of change. Neuroimage. 2013;68:63-74.

100. Bergfield KL, Hanson KD, Chen K, Teipel SJ, Hampel H, Rapoport SI, et al. Age-related networks of regional covariance in MRI gray matter: reproducible multivariate patterns in healthy aging. Neuroimage. 2010;49(2):1750-9.

101. Abedelahi A, Hasanzadeh H, Hadizadeh H, Joghataie MT. Morphometric and volumetric study of caudate and putamen nuclei in normal individuals by MRI: Effect of normal aging, gender and hemispheric differences. Pol $J$ Radiol. 2013;78(3):7-14.

102. Sullivan E V, Rohlfing T, Pfefferbaum A. Longitudinal study of callosal microstructure in the normal adult aging brain using quantitative DTI fiber tracking. Dev Neuropsychol. 2010;35(3):233-56.

103. Teipel SJ, Meindl T, Wagner M, Stieltjes B, Reuter S, Hauenstein KH, et al. Longitudinal changes in fiber tract integrity in healthy aging and mild cognitive impairment: A DTI follow-up study. $J$ Alzheimer's Dis. 2010;22(2):507-22.

104. Malykhin N, Vahidy S, Michielse S, Coupland N, Camicioli R, Seres P, et al. Structural organization of the prefrontal white matter pathways in the adult and aging brain measured by diffusion tensor imaging. Brain Struct Funct. 
2011;216(4):417-31.

105. Westlye LT, Walhovd KB, Dale AM, Bjørnerud A, Due-Tønnessen P, Engvig A, et al. Life-span changes of the human brain white matter: Diffusion tensor imaging (DTI) and volumetry. Cereb Cortex. 2010;20(9):2055-68.

106. Madden DJ, Bennett IJ, Song AW. Contributions from Diffusion Tensor Imaging. Neuropsychol. 2009;19(4):415-35.

107. Vernooij MW, Ikram MA, Vrooman HA, Wielopolski PA, Krestin GP, Hofman A, et al. White matter microstructural integrity and cognitive function in a general elderly population. Arch Gen Psychiatry. 2009;66(5):545-53.

108. Kooij J, Buitelaar J, van den Oord E, Furer J, Rijnders C, Hodiamont P. Internal and external validity of attention-deficit hyperactivity disorder in a population-based sample of adults. Psychol Med. 2005;35(6):817-27.

109. Silva MA, Louza M. Case of a 67-year-old woman diagnosed with ADHD successfully treated with methylphenidate. J Atten Disord. 2008;11(6):623.

110. Michielsen M, Semeijn E, Comijs HC, Van De Ven P, Beekman ATF, Deeg $\mathrm{DJH}$, et al. Prevalence of attention-deficit hyperactivity disorder in older adults in the Netherlands. Br J Psychiatry. 2012;201(4):298-305.

111. Biederman J, Fried R, Petty CR, Wozniak J, Doyle AE, Henin A, et al. Cognitive development in adults with attention-deficit/hyperactivity disorder: A controlled study in medication-naive adults across the adult life cycle. $J$ Clin Psychiatry. 2011;72(1):11-6.

112. Bramham J, Murphy DGM, Xenitidis K, Asherson P, Hopkin G, Young S. Adults with attention deficit hyperactivity disorder: An investigation of agerelated differences in behavioural symptoms, neuropsychological function and co-morbidity. Psychol Med. 2012;42(10):2225-34. 
113. Michielsen M, Comijs HC, Semeijn EJ, Beekman ATF, Deeg JH, Kooij JJS. The comorbidity of anxiety and depressive symptoms in older adults with attention-deficit/hyperactivity disorder: A longitudinal study. J Affect Disord. 2013;148:220-7.

114. Ivanchak N, Fletcher K, Jicha GA. Attention-deficit/hyperactivity disorder in older adults: Prevalence and possible connections to mild cognitive impairment. Current Psychiatry Rep. 2012;14(5):552-60.

115. Golimstok A, Rojas JI, Romano M, Zurru MC, Doctorovich D, Cristiano E. Previous adult attention-deficit and hyperactivity disorder symptoms and risk of dementia with Lewy bodies: A case-control study. Eur J Neurol. 2011;18(1):78-84.

116. Michielsen M, Comijs HC, Semeijn EJ, Beekman ATF, Deeg DJH, Kooij JJS. Attention deficit hyperactivity disorder and personality characteristics in older adults in the general dutch population. Am $J$ Geriatr Psychiatry. 2014;22(12):1623-32.

117. Michielsen M, Comijs HC, Aartsen MJ, Semeijn EJ, Beekman ATF, Deeg $\mathrm{DJH}$, et al. The relationships between ADHD and social functioning and participation in older adults in a population-based study. J Atten Disord. 2015;19(5):368-79.

118. Michielsen M, de Kruif JTCM, Comijs HC, van Mierlo S, Semeijn EJ, Beekman ATF, et al. The burden of ADHD in older adults: A qualitative study. J Atten Disord. 2018;22(6):591-600.

119. Semeijn EJ, Sandra Kooij JJ, Comijs HC, Michielsen M, Deeg DJH, Beekman ATF. Attention-deficit/hyperactivity disorder, physical health, and lifestyle in older adults. JAGS. 2013;61(6):882-7.

120. Semeijn EJ, Korten NCM, Comijs HC, Michielsen M, Deeg DJH, Beekman 
ATF, et al. No lower cognitive functioning in older adults with attentiondeficit/hyperactivity disorder. Int Psychogeriatrics. 2015;27(9):1467-76.

121. Semeijn EJ, Comijs HC, Kooij JJS, Michielsen M, Beekman ATF, Deeg DJH. The role of adverse life events on depression in older adults with ADHD. $J$ Affect Disord. 2015;174:574-9.

122. Brod M, Schmitt E, Goodwin M, Hodgkins P, Niebler G. ADHD burden of illness in older adults: A life course perspective. Qual Life Res. 2012;21(5):795-9

123. Torgersen T, Gjervan B, Lensing MB, Rasmussen K. Optimal management of ADHD in older adults. Neuropsychiatr Dis Treat. 2016;12:79-87.

124. Altman DG. Some common problems in medical research. In: Practical statistics for medical research. 1 st ed. London: Chapman and Hall/CRC; 1991. p. 455-7.

125. Folstein MF, Folstein SE, Mchugh PR. Mini-mental state: a pratical method for grading the cognitive state of patients for clinician. J Psychiatr Res. 1975;12:189-98.

126. Kessler RC, Adler L, Ames M, Demler O, Faraone S, Hiripi E, et al. The world health organization adult ADHD self-report scale (ASRS): a short screening scale for use in the general population. Psychol Med. 2005;35(2):245-56.

127. Mattos P, Segenreich D, Saboya E, Louzã M, Dias G, Romano M. Adaptação transcultural para o português da escala Adult Self-Report Scale para avaliação do transtorno de déficit de atenção/hiperatividade (TDAH) em adultos. Rev Psiquiatr Clin. 2006;33(4):188-94.

128. Brasil HHA. Development of the brazilian version K-SADS-PL (Schedule for 
affective disorders and schizophrenia for school aged children presente and lifetime version) and study of psychometric properties[Tese Doutorado]. São Paulo: Escola Paulista de Medicina, Universidade Federal de São Paulo; 2003.

129. Cunha JA. Manual da versão em português das Escalas Beck. São Paulo: Casa do Psicólogo; 2001.

130. Almeida OP, Almeida S a. Confiabilidade da versão Brasileira da escala de depressão em geriatria (GDS) versãoo reduzida. Arq Neuropsiquiatr. 1999;57(2-B):421-6.

131. Del-Ben C, Vilela J, Crippa J, Hallak J, Labate C, Zuardi A. Confiabilidade da "Entrevista Clínica Estruturada para o DSM-IV - Versão Clínica" traduzida para o português. Rev Bras Psiquiatr. 2001;23(3):156-9.

132. Sanchez MA dos S, Lourenço RA. Informant questionnaire on cognitive decline in the elderly (IQCODE): adaptação transcultural para uso no Brasil. Cad Saúde Pública. 2009;25(7):1455-65.

133. Mattos P, Lino V, Rizo L, Alfano Â, Araújo C, Raggio R. Memory complaints and test performance in healthy elderly persons. Arq Neuropsiquiatr. 2003;61(4):920-4.

134. Strauss E, Sherman EMS, Spreen OA. Compendium of neuropsychological tests: administration, norms, and commentary - administration, norms, and commentary. 3 rd ed. New York: Oxford University Press; 2006.

135. Lezak MD, Howieson DB, Loring DW. Neuropsychological assessment. 4 th. Oxford: Oxford University Press; 2004.

136. Kalkut EJ. Neuropsychological assessment of executive functioning and its association with depressive symptomology. Loyola University Chicago; 2010. 
137. Lange KW, Hauser J, Lange KM, Makulska-Gertruda E, Takano T, Takeuchi $\mathrm{Y}$, et al. Utility of cognitive neuropsychological assessment in attentiondeficit/hyperactivity disorder. ADHD Atten Def Hyp Disord. 2014;6(4):241-8.

138. Ringe W, Saine KC, Lacritz LH, Hynan LS, Cullum CM. Dyadic short forms of the Wechsler adult intelligence scale-III. Assessment. 2002;9:254-60.

139. Heaton RK. Staff PAR. Wisconsin card sorting test - WCST - 64: CV2. Lutz, FL: Psychological Assesment Resources; 2003.

140. Wechsler D. Wechsler Adult Intelligence Scale. 3 rd. San Antonio: Psychological Corporation; 1997.

141. Wechsler D. Wechsler Memory Scale. 3 rd. San Antonio: Psychological Corporation; 1997.

142. Conners K. Conners' - Continuous performance test II (CPT II V.5). New York: Multi-Health Systems Inc.; 2002.

143. Malloy-Diniz LF, Lasmar VAP, Gazinelli LDSR, Fuentes D, Salgado JV. The Rey auditory-verbal learning test: Applicability for the Brazilian elderly population. Rev Bras Psiquiatr. 2007;29(4):324-9.

144. Benedict RHB. Brief visuospatial memory test-revised (BVMT-R): Professional manual. Lutz: PAR; 1997.

145. Oliveira MS, Rigoni SR. Figuras complexas de Rey: Teste de cópia e de reprodução de memória de figuras geométricas complexas. Padronização brasileira. São Paulo: Casa do Psicólogo®; 2010.

146. Miotto EC, Sato J, Lucia MCS, Camargo CHP, Scaff M. Development of an adapted version of the Boston naming test for Portuguese speakers. Rev Bras Psiquiatr. 2010;32(3):279-82. 
147. Ashburner J, Friston KJ. Unified segmentation. Neuroimage. 2005;26:839-51.

148. Ashburner J, Friston KJ. Voxel-Based Morphometry - The methods. Neuroimage. 2000;11(6):805-21.

149. Smith SM, Jenkinson M, Johansen-Berg H, Rueckert D, Nichols TE, Mackay CE. Tract-based spatial statistics: voxelwise analysis of multi-subject diffusion data. Neuroimage. 2006;31(4):1487-505.

150. Riordan HJ. Constructing Composites to Optimise Cognitive Outcomes. J Clin Stud. 2017;9(2):40-5.

151. Wakana S, Caprihan A, Panzenboeck MM, Fallon JH, Perry M, Gollub RL, et al. Reproducibility of quantitative tractography methods applied to cerebral white matter. Neuroimage. 2007;36:630-44.

152. Hua K, Zhang J, Wakana S, Jiang H, Li X, Daniel S, et al. Tract probability maps in stereotaxic spaces: analyses of white matter anatomy and tractspecific quantification. Neuroimage. 2009;39(1):336-47.

153. Ruigrok AN V, Salimi-Khorshidi G, Lai M-C, Baron-Cohen S, Lombardo M $\mathrm{V}$, Tait RJ, et al. A meta-analysis of sex differences in human brain structure. Neurosci Biobehav Rev. 2014;39:34-50.

154. Brown TE, Reichel PC, Quinlan DM. Executive function impairments in high IQ adults with ADHD. J Atten Disord. 2009;13(2):161-7.

155. Jorm AF. A short form of the informant questionnaire on cognitive decline in the elderly (IQCODE): development and cross-validation. Psychol Med. 1994;24(1):145-53.

156. Eakin L, Minde K, Hechtman L, Ochs E, Krane E, Bouffard R, et al. The marital and family functioning of adults with ADHD and their spouses. J Atten 
Disord. 2004;8(1):1-10.

157. Paulo DLV, Yassuda MS. The relation between memory complaints in the elderly and education, cognitive performance, and symptoms of depression and anxiety. Rev Psiquiatr Clin. 2010;37(1):23-6.

158. Dige N, Maahr E, Backenroth-Ohsako G. Memory tests in subgroups of adult attention deficit hyperactivity disorder reveals simultaneous capacity deficit. Int J Neurosci. 2008;118(4):569-91.

159. Maier S, Perlov E, Graf E, Dieter E, Sobanski E, Rump M, et al. Discrete Global but No Focal Gray Matter Volume Reductions in Unmedicated Adult Patients With Attention-Deficit/Hyperactivity Disorder. Biol Psychiatry. 2016;80:905-15.

160. Dickstein SG, Bannon K, Xavier Castellanos F, Milham MP. The neural correlates of attention deficit hyperactivity disorder: An ALE meta-analysis. $J$ Child Psychol Psychiatry. 2006;47(10):1051-62.

161. Etkin A, Egner T, Kalisch R. Emotional processing in anterior cingulate and medial prefrontal cortex. Trends Cogn Sci. 2011;15(2):85-93.

162. Duan K, Chen J, Calhoun VD, Lin D, Jiang W, Franke B, et al. Neural correlates of cognitive function and symptoms in attentiondeficit/hyperactivity disorder in adults. NeuroImage Clin. 2018;19(May):37483.

163. Perlov E, Philipsen A, van Elst LT, Ebert D, Henning J, Maier S, et al. Hippocampus and amygdala morphology in adults with attention-deficit hyperactivity disorder. J Psychiatry Neurosci. 2008;33(6):509-15.

164. Frodl T, Stauber J, Schaaff N, Koutsouleris N, Scheuerecker J, Ewers M, et al. Amygdala reduction in patients with ADHD compared with major depression 
and healthy volunteers. Acta Psychiatr Scand. 2010;121:111-8.

165. Mulligan RC, Knopik VS, Sweet LH, Fischer M, Seidenberg M, Rao SM. Neural correlates of inhibitory control in adult attention deficit/hyperactivity disorder: evidence from the Milwaukee longitudinal sample. Psychiatry Res. 2011;194(2):119-29.

166. Skirrow C, Asherson P. Emotional lability, comorbidity and impairment in adults with attention-deficit hyperactivity disorder. $J$ Affect Disord. 2013;147(1-3):80-6.

167. Rubia K, Alegría AA, Brinson H. Brain abnormalities in attention-deficit hyperactivity disorder: a review. Rev Neurol. 2014;58(Supl 1):S3-S18. 